Development Center

\title{
Improved Reliability Models for Mechanical and Electrical Components at Navigation Lock and Dam and Flood Risk Management Facilities
}

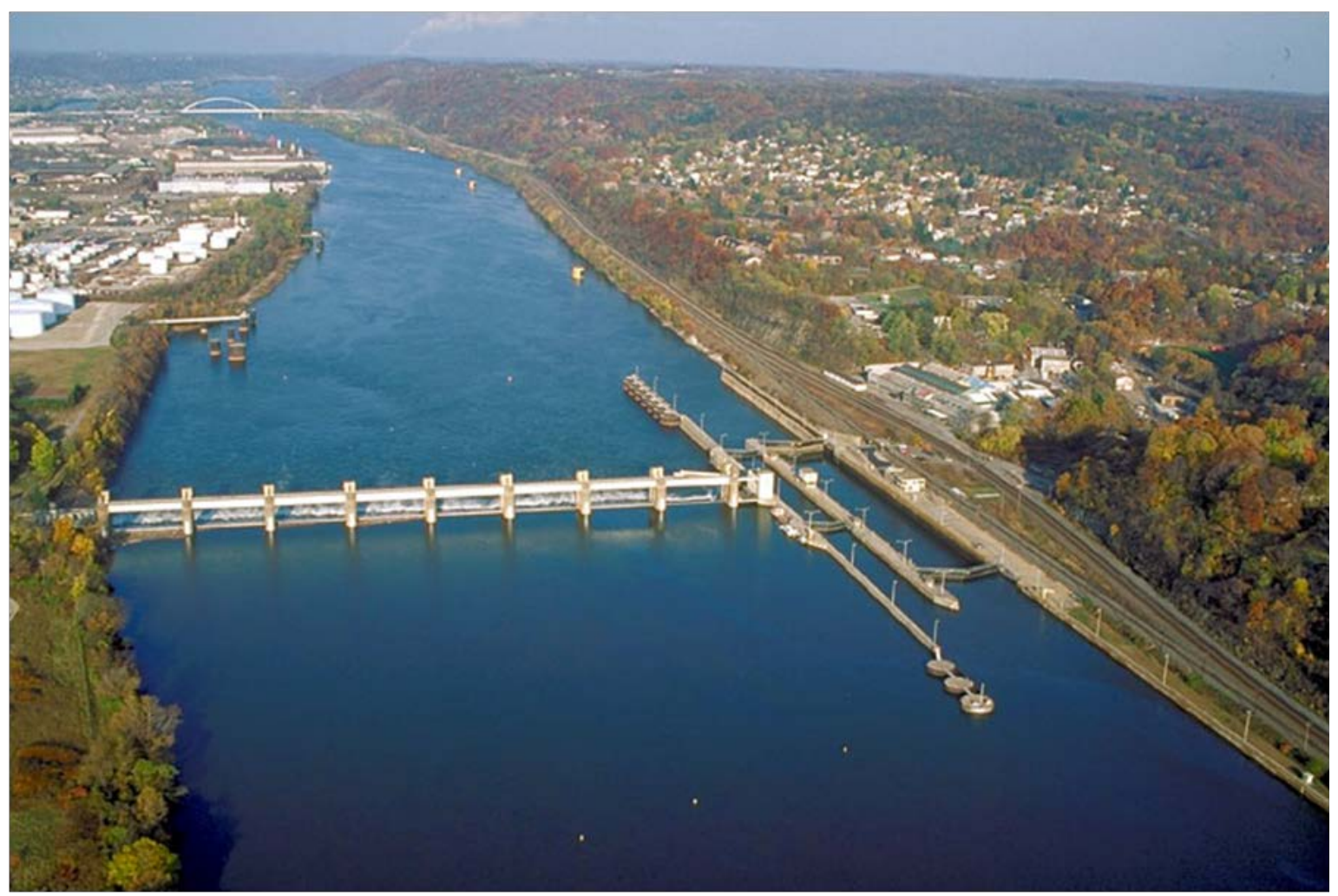


The US Army Engineer Research and Development Center (ERDC) solves the nation's toughest engineering and environmental challenges. ERDC develops innovative solutions in civil and military engineering, geospatial sciences, water resources, and environmental sciences for the Army, the Department of Defense, civilian agencies, and our nation's public good. Find out more at www.erdc.usace.army.mil.

To search for other technical reports published by ERDC, visit the ERDC online library at http://acwc.sdp.sirsi.net/client/default. 


\title{
Improved Reliability Models for Mechanical and Electrical Components at Navigation Lock and Dam and Flood Risk Management Facilities
}

\author{
Robert C. Patev \\ Risk Management Center \\ Institute for Water Resources \\ 696 Virginia Road \\ Concord, MA, 01742 \\ David L. Buccini \\ US Army Corps of Engineers (USACE), Pittsburgh District \\ 1000 Liberty Avenue \\ Pittsburgh, PA 15222 \\ James W. Bartek \\ USACE, Rock Island District \\ Clock Tower Building \\ Rodman Avenue \\ Rock Island, IL 61299 \\ Stuart D. Foltz \\ Construction Engineering Research Laboratory (CERL) \\ US Army Engineer Research and Development Center \\ 2902 Newmark Dr. \\ Champaign, IL 61822-1076
}

Final Report

Approved for public release; distribution is unlimited.

Prepared for Headquarters, US Army Corps of Engineers (HQUSACE)

Washington, DC 20314-1000 


\section{Abstract}

This work developed the use of Expert-Opinion Elicitation (EOE) to help estimate the characteristic life (CL) of mechanical and electrical (ME) components at US Army Corps of Engineers (USACE) navigation projects. This effort developed improved reliability models for the ME components at the USACE navigation facilities. Current USACE ME reliability methods use generic component failure rate data from US Department of Defense (DoD) Military Standard (ML-STD) 756B, in which failure rate data is processed for components that function in operating environments, failure modes, and maintenance practices different from those at USACE navigation and flood risk management projects. The reliability of the ME system from this data set yields very conservative results, very often overestimating the time-dependent reliability of the entire ME system. EOE will be used to define the CL for a list of critical ME components at USACE navigation and flood risk management projects. These elicited values for CL will form the basis for failure rates to be used with the existing methods for ME system reliability calculations. Additional work on fault trees for ME systems is being completed as part of dam safety and levee risk assessment procedures development.

DISCLAIMER: The contents of this report are not to be used for advertising, publication, or promotional purposes. Citation of trade names does not constitute an official endorsement or approval of the use of such commercial products. All product names and trademarks cited are the property of their respective owners. The findings of this report are not to be construed as an official Department of the Army position unless so designated by other authorized documents. 


\section{Contents}

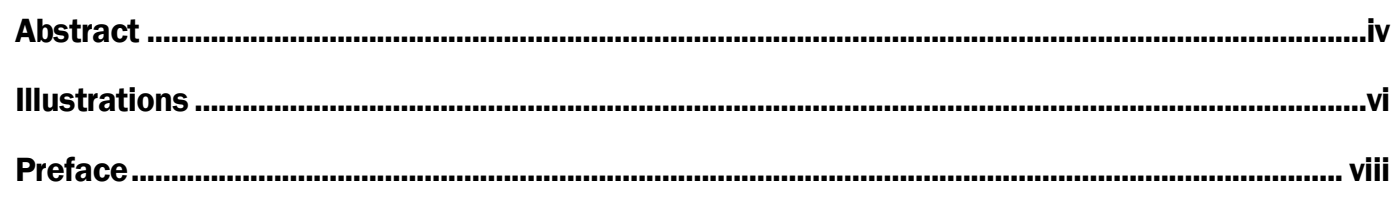

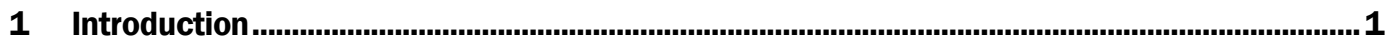

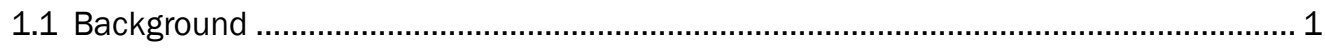

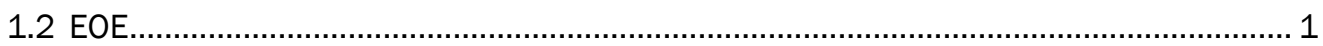

1.3 Recent USACE EOE studies................................................................................. 2

1.4 Characteristic life $(\mathrm{CL})$ of ME components .............................................................. 2

1.5 Objectives and scope of EOE for CL of ME components.......................................... 4

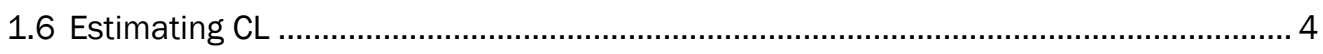

1.7 Selection of critical ME components for navigation projects ................................. 5

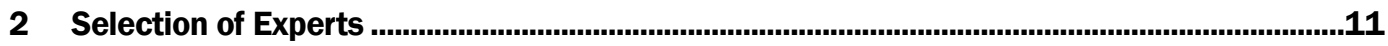

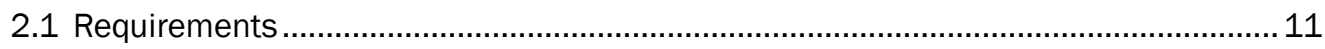

2.2 Lists of experts ...................................................................................................... 12

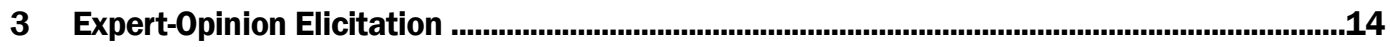



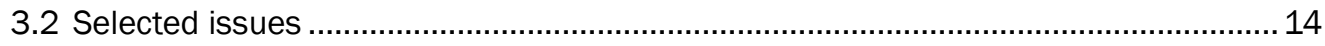

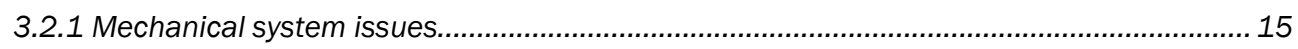

3.2.2 Electrical system issues................................................................................................... 15

3.3 Elicitation and aggregation of expert opinions ...................................................... 16

3.4 Sample questions used for issues ..................................................................... 18

3.5 Example question for mechanical drive system issue - bearings - rolling

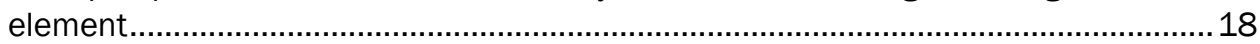

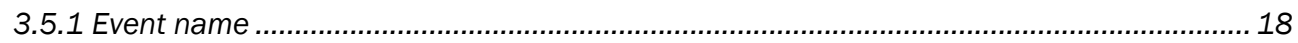

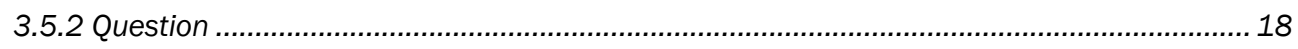

3.6 Summary of results from elicitation ................................................................. 18

3.6.1 Mechanical system - mechanical drive systems................................................................ 19

3.6.2 Mechanical system - hydraulic drive systems .................................................................. 30

3.6.3 Mechanical system - misc. gate/filling and emptying valves and other systems............... 34

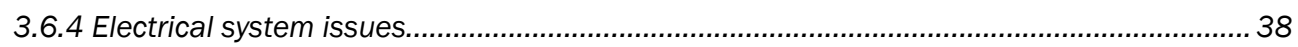

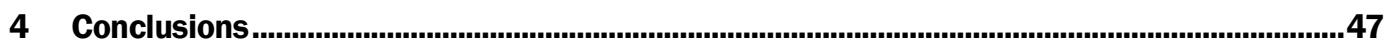

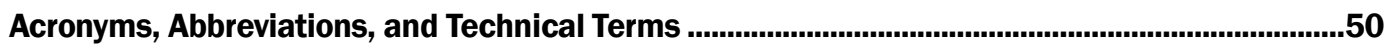

References .......................................................................................................................................53

Appendix A: Expert Elicitation Spreadsheets - Mechanical System Components ....................55

Appendix B: Expert Elicitation Spreadsheets - Electrical System Components .........................85

Appendix C: Results from Flood Risk Management ME Expert-Opinion Elicitation .................103

Report Documentation Page (SF 298) .................................................................................. 


\section{Illustrations}

\section{Figure}

1 Typical Weibull data plot (Abernethy 2009) ……..................................................................

\section{Tables}

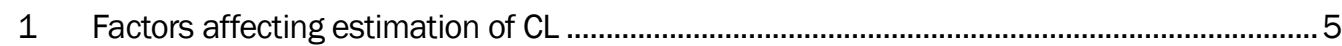

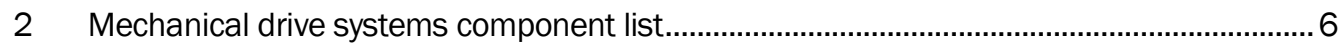

3 Hydraulic drive systems component list........................................................................ 8

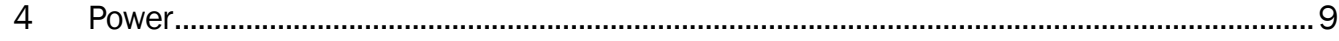

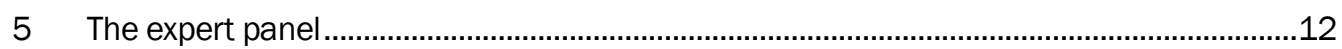



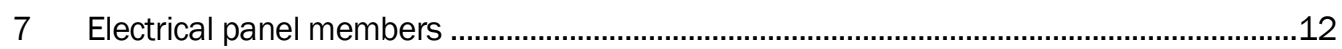



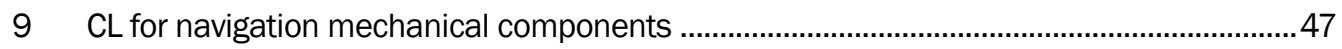

$10 \mathrm{CL}$ for navigation electrical components characteristic power life (in years) .....................49

A1 Mechanical system - bearings............................................................................................56



A3 Mechanical system - pins...........................................................................................59

A4 Mechanical system - gear reducers ............................................................................60

A5 Mechanical system - open gearing ...........................................................................61

A6 Mechanical system - electromechanical brakes, ............................................................62

A7 Mechanical system - slip brakes..................................................................................63

A8 Mechanical system - wire ropes.................................................................................64

A9 Mechanical system - chains ........................................................................................66

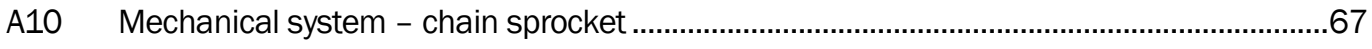

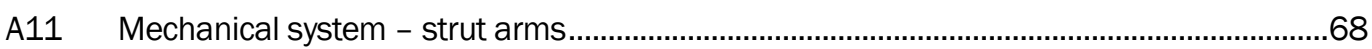

A12 Mechanical system - support roller …………............................................................69

A13 Mechanical system - valves .......................................................................................

A14 Mechanical system - hydraulic cylinder ..........................................................................

A15 Mechanical system - control valves ..................................................................................72

A16 Mechanical system - pumps..................................................................................... 74

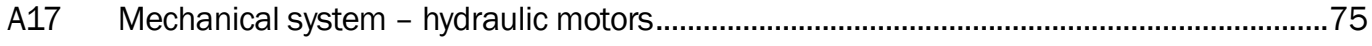

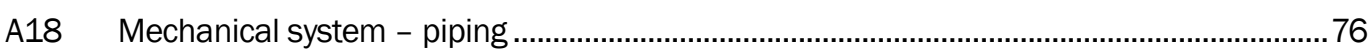

A19 Mechanical system - wheel assembly (rollers)....................................................................

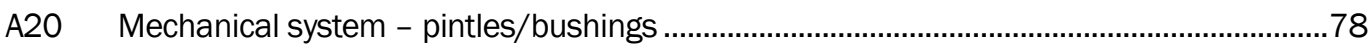

A21 Mechanical system - gudgeon/trunnion............................................................................79 


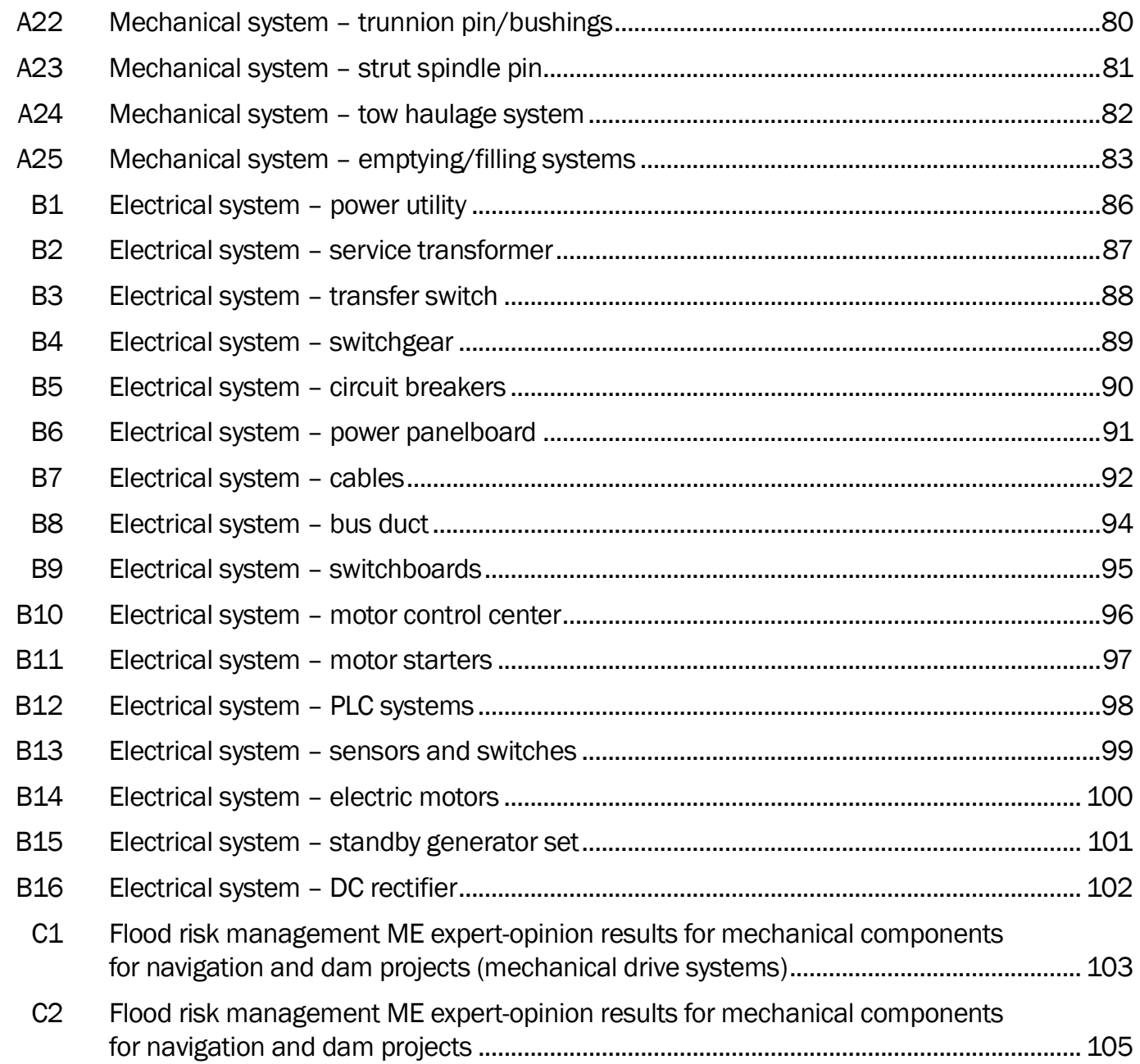




\section{Preface}

This study was conducted for the US Army Corps of Engineers (USACE) Navigation Systems Research Program and the Reliability Models for Major Rehabilitation Program from Fiscal Year 2006 (FY06) through FY08. The technical monitor was Daniel Casapulla, Headquarters, US Army Corps of Engineers (HQUSACE).

The work was performed by the Geotechnical Section of the Geotechnical/ Water Resources Branch of Engineering and Planning, New England District. At the time the work was done, Anthony Firicano was Chief of the Geotechnical Section and Dr. Raimo Liias was Chief of the Geotechnical/Water Resources Branch. At the time of publication, J eff Lillycrop was the Technical Director for Navigation.

At the time of publication, COL Kevin Wilson was the Commander and Executive Director of the Engineer Research and Development Center (ERDC), and Dr. J effery P. Holland was the Director. 


\section{Introduction}

\subsection{Background}

The current USACE mechanical and electrical (ME) reliability methods use generic component failure rate data from US Department of Defense Military Standard 756B (DoD MIL-STD-756B) documents. This failure rate data is typically processed for components that function in a different operating environment, different failure modes, and different maintenance practices than at USACE navigation projects. Therefore, the reliability of the ME system from this data set yields very conservative results and very often overestimates the time-dependent reliability of the entire ME system.

This work was undertaken to develop improved reliability models for the ME) components at the US Army Corps of Engineers (USACE) navigation facilities. While efforts are underway to begin collecting such failure rate data from USACE projects, a functional failure rate data set to use in reliability calculations is at least 10 years away. As part of this research effort to assist with improving the existing reliability models, Expert-Opinion Elicitation (EOE) will be used to define the characteristic life (CL) for a list of critical ME components at USACE navigation projects. These elicited values for CL will be the basis for failure rates to be used with the existing methods for ME system reliability calculations. Additional work on fault trees for ME systems (Patev, Putcha, and Foltz 2005) is being completed as part of dam safety and levee risk assessment procedures development.

\subsection{EOE}

The EOE process is a formal (defined format), heuristic (verbal) process of obtaining information or answers to specific questions. These questions are defined in terms of "issues." These issues can assist in defining such items as cumulative failure rates, event timing, and percentage for event/ fault trees. Ayyub, Blair, and Patev (2000) outline EOE as a process. This process should not really be used in lieu of failure statistics, but should be used where failure statistics are unavailable or too costly to collect. EOE should be performed during a face-to-face meeting of members of an expert panel that is developed specifically for the issues under consideration. The EOE should be conducted after informing the experts of the background infor- 
mation, objectives, list of issues, and anticipated outcome. Ayyub, Blair, and Patev (2000) describe the different components of the EOE process.

\subsection{Recent USACE EOE studies}

EOE is a technique that uses a panel of individuals with various areas of specialized knowledge for estimating parameters or addressing issues of interest based on their expertise. EOE has been recently applied by the Vicksburg District's study of three different construction alternatives for Lindy C. Boggs Lock and Dam (Ayyub, Blair, and Patev 2002) by the Pittsburgh District for concrete deterioration problems at Emsworth Lock and Dam and by Nashville District for Chickamauga Lock and Dam to determine hazard rates for the cost and closure matrices. Other recent uses of EOE by the USACE include those areas of dam safety, flood damages, and navigation system wide studies such as Ohio River Main Stem Study (ORMSS) and the Great Lakes and St. Lawrence Seaway System Study (GLSLS).

\subsection{Characteristic life (CL) of ME components}

Abernethy (2009) defines the CL is defined as the age at which $63.2 \%$ of the units will have failed, sometimes called the B63.2 life. Assuming that this relationship assumes an exponential distribution (Weibull distribution with $\beta=1$ ), the Cumulative Distribution Function (CDF) can be shown mathematically as:

$$
\mathrm{F}(\mathrm{t})=1-\mathrm{e}^{-(\mathrm{t} / \alpha) \beta}=1-(1 / \mathrm{e})=0.632
$$

where $\beta$ is a shape factor and $\alpha$ is the CL.

Figure 1 shows a typical data plot of the slope and Mean Time To Failure (MTTF).

Abernethy (2009) defines the slope of the Weibull plot or beta, $(\beta)$, which determines the member of the family of Weibull failure distributions that best fits or describes the data. The slope, $\beta$, also indicates the class of failure that is present, in which:

$\beta<1.0$ indicates infant mortality

$\beta=1.0$ means random failures (independent of age)

$\beta>1.0$ indicates wear out failures. 


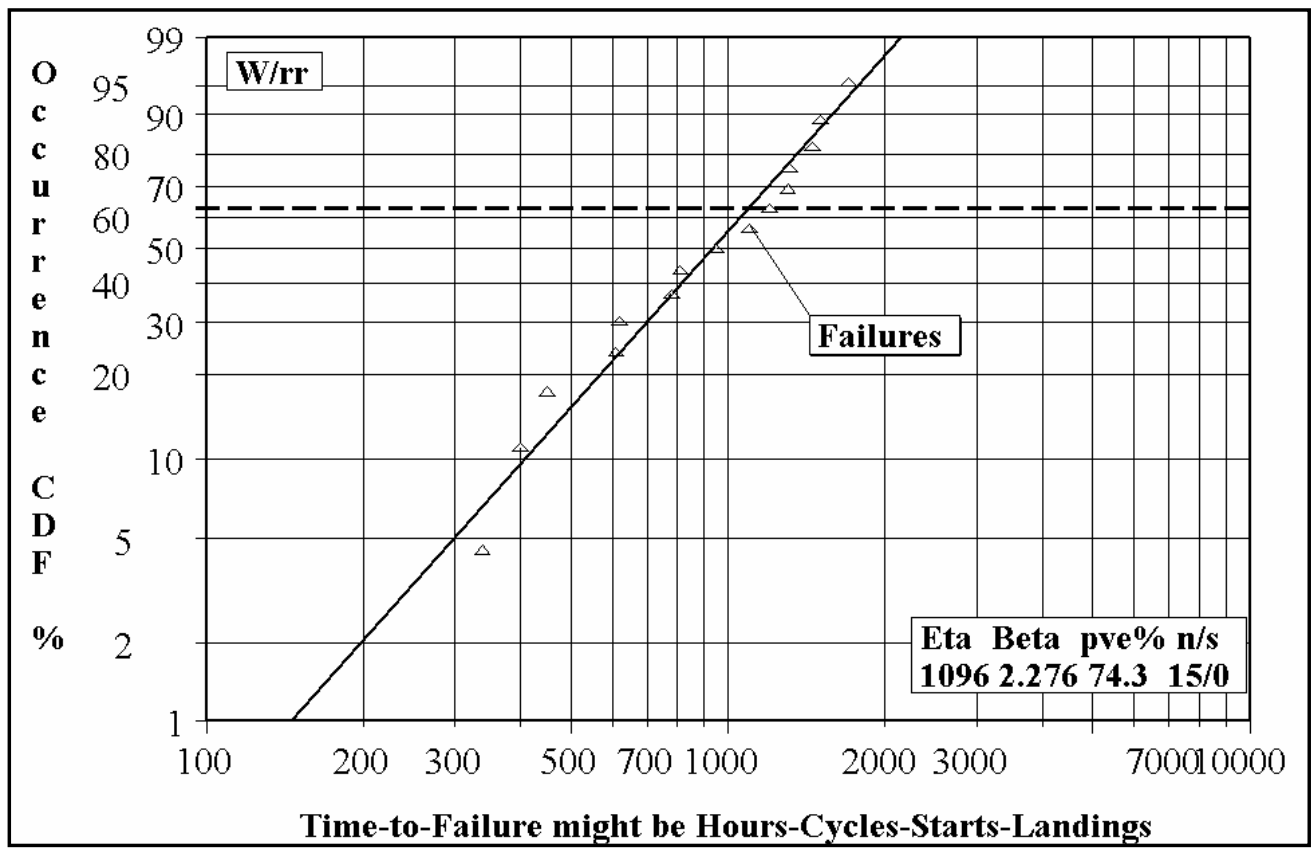

Figure 1. Typical Weibull data plot (Abernethy 2009).

The CL of an ME component is directly related to the MTTF and the failure rate, $\lambda$. This relationship is derived as:

$$
\begin{aligned}
& \mathrm{MTTF}=1 / \lambda \\
& \alpha=\mathrm{MTTF} .
\end{aligned}
$$

Note that the relationship between the CL and MTTF is dependent on $\beta$. The relationship is dependent on the value of $\beta$, in which:

$$
\begin{aligned}
& \beta=1, \mathrm{MTTF}=\alpha \\
& \beta>1, \mathrm{MTF}<\alpha \\
& \beta<1, \mathrm{MTTF}>\alpha \\
& \beta=0.5, \mathrm{MTTF}=2(\alpha) .
\end{aligned}
$$

Typically, CL is based on such assumptions as:

- The components have similar maintenance practices.

- There is no replacement of smaller internal parts.

- Environmental and operating conditions are consistent or protected.

- All components are composed of materials that were properly selected and designed. 
Note that there is uncertainty in defining consistent or proper maintenance and environment. There are no consistent operating conditions within USACE, as loading cycles vary from less than one per year for a dam to more than 10 per day for a lock. This is one of the complications discussed further in Section 1.6.

\subsection{Objectives and scope of EOE for CL of ME components}

This analysis uses EOE to obtain information relating to the CL of critical components at USACE navigation facilities. The information obtained from this EOE is not readily available in the literature. MIL-STDs are based on failure rates and assume a CL based on a defined Weibull distribution. These data standards are not valid for USACE ME equipment since they typically underestimate (i.e., estimate earlier failures) the CL. Also, failure rate data may be available from some ME equipment manufacturers, but this failure rate data is often proprietary and not available to the USACE.

The overall objective and results from this study are to define CL values for use in future ME reliability modeling of USACE navigation projects. A list of critical components will be defined to pinpoint those pieces of ME equipment that create significant economic consequences such as navigation delays, lock shutdowns, and lock closures. These values for CL will be elicited by bringing together a team of USACE ME experts from around the nation. The use of nationwide $\mathrm{ME}$ experts will permit the inclusion of a wide range of experience and operation of these critical components. Chapter 2 discusses the selection of the experts.

\subsection{Estimating CL}

As mentioned previously, the CL is dependent on consistent or proper maintenance, environment, and operating conditions. These factors are not uniform across USACE. Maintenance profiles vary significantly. Environment may include any combination of heat, cold, ice, ultraviolet (UV) light, saltwater, oxygenated water or protection from all such extremes. Operating conditions range from frequent use each day for a navigation lock, to use less than once per year for a flood control dam; the loading during use will also vary. Other non-uniform physical properties include design, water head, and component size. These are only a small portion of the parameters that make it a challenge to estimate an average CL for a particular project. Table 1 lists some factors that may be used to adjust the CL. 
Table 1. Factors affecting estimation of $\mathrm{CL}$.

\begin{tabular}{|c|c|}
\hline Type & Factor \\
\hline \multirow{9}{*}{ 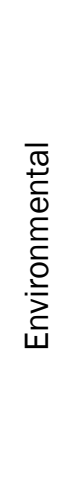 } & Temperature (heat and cold) \\
\hline & Humidity (high or low) \\
\hline & Wind \\
\hline & Frequency of wetting \\
\hline & Ice \\
\hline & UV \\
\hline & Oxygenated water \\
\hline & Protected from environment \\
\hline & Climate controlled environment \\
\hline \multirow{6}{*}{ 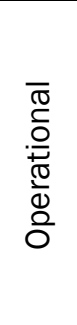 } & Quality of lubrication \\
\hline & Quality of paint protection \\
\hline & Frequency of load cycles \\
\hline & Load history versus design loads \\
\hline & Variation in dominate failure mode across inventory \\
\hline & Era of component manufacture \\
\hline
\end{tabular}

The experts elicited in this study represented a wide range of USACE ME equipment throughout the entire United States. Their consensus was based on their knowledge and experience representing their operating, environment, and maintenance practices. The experts agreed that using the " $\mathrm{k}$ factors" adjustments defined in Engineer Circular (EC) 1110-2-6062 (HQUSACE 2011) and in Military Standards (MIL-STDs) would be sufficient to refine each of the CL for their equipment. This technique has been successfully adopted in the USACE practice and provides reasonable and quantifiable results. Therefore, when experts apply past experience of component maintenance, environment, and operating conditions to estimate CL, they need to consider how each parameter or property varies from normal and how that might have lead to an earlier or later failure than the estimated CL.

\subsection{Selection of critical ME components for navigation projects}

The list of critical component was complied and screened by the facilitator and four ME engineers from Pittsburgh District, Rock Island District, and Headquarters prior to the EOE. One of the primary criteria for screening the ME components was the number of hours of navigation delay it would take to temporarily repair or replace the component. The components 
were screened based on a minimum of 4 hours of navigation delay to repair or replace the component. This value was based on the availability of the failed component (most are not at lock site) and the availability of District staff to inspect and repair the component.

The final list of critical components was sent to the panel of experts as part of the read-ahead package prior to the elicitation. This was to gain their inputs and agreements to the list of components that would be elicited during the EOE. In the read-ahead package sent to the experts, the panel was only informed of the issues and not given any of the questions that would be elicited. The list was reviewed again as the part of startup to the EOE to ensure that no questions or issues lingered with any of the components that were screened.

This list of components was broken into disciplines (i.e., mechanical and electrical [ME]) and by subcategories as well. The list of the mechanical components was broken into the following categories: mechanical drive systems (Table 2), hydraulic drive systems (Table 3), miscellaneous gatevalve systems, and other systems.

The list of electrical components was broken into the following categories: Power (Table 4), Motor Control, Sensors and Switches, and electromechanical (EM) Control.

Table 2. Mechanical drive systems component list.

\begin{tabular}{|l|l|}
\hline Type & Component \\
\hline Bearings & \\
\hline \multirow{2}{*}{ Couplings } & Rolling element \\
\cline { 2 - 2 } & Sleeve (self lubricated) \\
\cline { 2 - 2 } & Bronze sleeve \\
\hline Shafts & \\
\hline Pins & Flexible \\
\hline Gear reducers & Rigid \\
\hline & \\
\hline & \\
\hline & Worm \\
\hline Open gearing & Parallel \\
\hline & Right angle \\
\hline
\end{tabular}




\begin{tabular}{|c|c|}
\hline Type & Component \\
\hline & Spur \\
\hline & Helical \\
\hline & Bevel \\
\hline & Rack \\
\hline Brake & Electromechanical \\
\hline Clutch & Slip \\
\hline \multicolumn{2}{|c|}{ Wire ropes } \\
\hline & Spiral plate \\
\hline & Single/multiple sheave(s) \\
\hline & Single Drum \\
\hline & Round \\
\hline & Flat \\
\hline \multicolumn{2}{|c|}{ Wire rope drums } \\
\hline \multicolumn{2}{|c|}{ Wire rope sheaves } \\
\hline \multirow[t]{2}{*}{ Chains } & Roller \\
\hline & Link \\
\hline \multicolumn{2}{|c|}{ Chain sprocket } \\
\hline \multicolumn{2}{|c|}{ Miter gates } \\
\hline & Sector arms \\
\hline & Strut arms - buffered \\
\hline & Strut arms - rigid \\
\hline & Support roller \\
\hline & Rack support beam \\
\hline \multicolumn{2}{|l|}{ Valves } \\
\hline & Bellcranks \\
\hline & Crosshead/guide \\
\hline & Strut \\
\hline & Butterfly \\
\hline & Ball \\
\hline & Slide \\
\hline & Knife \\
\hline & Jet \\
\hline
\end{tabular}


Table 3. Hydraulic drive systems component list.

\begin{tabular}{|c|c|}
\hline Type & Component \\
\hline \multicolumn{2}{|l|}{ Vertical Lift } \\
\hline \multicolumn{2}{|l|}{ Control Valves } \\
\hline & Check \\
\hline & Relief \\
\hline & Directional \\
\hline & Manual \\
\hline & Solenoid \\
\hline & Proportional/throttle \\
\hline \multicolumn{2}{|l|}{ Pumps } \\
\hline & Fixed \\
\hline & Variable \\
\hline \multicolumn{2}{|l|}{ Hydraulic Motors } \\
\hline & Fixed \\
\hline & Variable \\
\hline \multicolumn{2}{|l|}{ Piping } \\
\hline \multicolumn{2}{|l|}{ Hose } \\
\hline \multicolumn{2}{|c|}{ Misc Gate/Filling Emptying Valves } \\
\hline \multicolumn{2}{|l|}{ Wheel assembly } \\
\hline \multicolumn{2}{|l|}{ Pintles/bushings } \\
\hline \multicolumn{2}{|l|}{ Gudgeon pin/bushings } \\
\hline \multicolumn{2}{|l|}{ Trunnion pin/bushings } \\
\hline \multicolumn{2}{|l|}{ Strut spindle pin } \\
\hline \multicolumn{2}{|c|}{ Other Systems } \\
\hline \multirow[t]{3}{*}{ Tow haulage } & \\
\hline & Hydraulic \\
\hline & Mechanical \\
\hline \multicolumn{2}{|l|}{ Emptying filling } \\
\hline & Butterfly \\
\hline & Vertical lift \\
\hline \multicolumn{2}{|l|}{$\begin{array}{l}\text { Gate connection } \\
\text { (pins, cable, chain) }\end{array}$} \\
\hline \multicolumn{2}{|l|}{ Grease/lube system } \\
\hline $\begin{array}{l}\text { Actuators } \\
\text { (screw type, limit torque) }\end{array}$ & \\
\hline
\end{tabular}


Table 4. Power.

\begin{tabular}{|c|c|}
\hline Type & Component \\
\hline \multicolumn{2}{|c|}{ Power } \\
\hline \multicolumn{2}{|l|}{ Power utility } \\
\hline \multicolumn{2}{|l|}{ Power receptacle } \\
\hline \multicolumn{2}{|l|}{ Service transformer } \\
\hline \multicolumn{2}{|l|}{ Transfer switches } \\
\hline & Automatic \\
\hline & Manual \\
\hline \multicolumn{2}{|l|}{ Switchgear } \\
\hline \multicolumn{2}{|l|}{ Circuit breakers } \\
\hline \multicolumn{2}{|l|}{ Power panelboard } \\
\hline \multicolumn{2}{|l|}{ Cables } \\
\hline & Buried/submerged \\
\hline & Duct/cable tray \\
\hline & Portable/flexible \\
\hline & Twisted \\
\hline & Coax \\
\hline & Fiber optic \\
\hline \multicolumn{2}{|l|}{ Bus duct (electronic } \\
\hline \multicolumn{2}{|l|}{ Switchboards } \\
\hline \multicolumn{2}{|l|}{ Motor control centers } \\
\hline \multicolumn{2}{|c|}{ Motor Control } \\
\hline \multicolumn{2}{|l|}{ Motor starters } \\
\hline & Full voltage \\
\hline & Reduced/variable \\
\hline & Variable Frequency Drive (VFD) \\
\hline \multicolumn{2}{|c|}{ Programmable Logic Controller (PLC) systems } \\
\hline \multicolumn{2}{|c|}{ Sensors and Switches } \\
\hline \multicolumn{2}{|l|}{ Selsyn motor } \\
\hline \multicolumn{2}{|l|}{ Traveling nut limit switch } \\
\hline \multicolumn{2}{|l|}{ Rotating cam } \\
\hline \multicolumn{2}{|l|}{ Encoder resolver } \\
\hline \multicolumn{2}{|l|}{ Hydraulic cylinder position sensor } \\
\hline \multicolumn{2}{|l|}{ Rotating limit switches } \\
\hline \multicolumn{2}{|l|}{ Proximity switch (mag/photo) } \\
\hline \multicolumn{2}{|l|}{ Mechanical proximity plunger switch } \\
\hline \multicolumn{2}{|l|}{ Linear displacement transducer } \\
\hline Pressure switch (hydraulic systems) & \\
\hline
\end{tabular}




\begin{tabular}{|l|l|}
\hline Type & Component \\
\hline Water level transducer (all types) & \\
\hline Inclinometer & \\
\hline Relay-based control panel & \\
\hline Supervisory Control And Data Acquisition (SCADA) & \\
\hline \multicolumn{1}{|c|}{ Electromechanical Drives } \\
\hline Electric motors (new and rebuilt) & \\
\hline Standby generator sets & \\
\hline DC rectifier (brakes) & \\
\hline
\end{tabular}




\section{Selection of Experts}

\subsection{Requirements}

The size of the expert panel should be large enough to achieve a needed diversity of opinion and credibility that will lead to resultant CL with minimal bias and robustness. Depending on the topics of interest, it is recommended to have five to seven paneled experts for this type of study and analysis. This EOE will have six experts for each discipline, mechanical and electrical. A nomination process was first used to establish a list of candidates who could contribute best to the elicitation. From this list, formal nominations and a selection process was established to define the candidates with the best background that closely fit the topics at hand. The panel members were defined based on a comprehensive combined knowledge of:

- design of ME system for navigation structures

- construction of ME systems for navigation structures

- operating and maintenance of ME systems navigation structures

- knowledge of state-of-the-art mechanical/ electrical equipment used at USACE and external navigation projects

- knowledge and experience with reliability calculations.

Observers also need to be invited to participate in the elicitation process. The observers can contribute to the discussion, but not to the expert judgment and results. The observers can include:

- One or two observers from the USACE offices with detailed experience and knowledge of ME systems for navigation projects including planned construction, and operations and maintenance.

- One or two people with expertise in probabilistic analysis, probabilistic computations, consequence computations and assessment, and expert elicitation. This observer can be the technical facilitator or the technical integrator and facilitator. 


\subsection{Lists of experts}

Tables 5- 8 list and give brief biographical statements for all identified experts.

Table 5. The expert panel.

\begin{tabular}{|l|l|}
\hline Name & Affiliation \\
\hline Jim Hay, P.E. & Operations Division, McNairy Lock and Dam, Walla Walla District USACE \\
\hline Ross Woodbury, P.E. & Operations Division, Louisville District, USACE \\
\hline David Buccini & $\begin{array}{l}\text { Mechanical Engineer, Mechanical/Electrical Section, Pittsburgh District, } \\
\text { USACE }\end{array}$ \\
\hline Bryan Radkte, P.E. & $\begin{array}{l}\text { Electrical Engineer, Mechanical/Electrical Section, Rock Island District, } \\
\text { USACE }\end{array}$ \\
\hline John Nites, P.E. & $\begin{array}{l}\text { Electrical Engineer, Mechanical/Electrical Section, Pittsburgh District, } \\
\text { USACE }\end{array}$ \\
\hline Todd Jennings, P.E. & Civil Engineer, General Engineering Section, Huntington District, USACE \\
\hline Chuck Palmer & Operations Division, Walla Walls District, USACE \\
\hline Tim Paulus & Mechanical Engineer, St. Paul District, USACE \\
\hline Russ Whitten & Chief Electrical/Mechanical Division, Huntington District (Ret.) \\
\hline
\end{tabular}

Table 6. Mechanical panel members.

\begin{tabular}{|l|l|}
\hline Name & Affiliation \\
\hline Jim Hay, P.E. & Operations Division, Walla Walla District USACE \\
\hline Chuck Palmer, P.E. & $\begin{array}{l}\text { Mechanical Engineer, Mechanical/Electrical Section, Walla Walls District, } \\
\text { USACE }\end{array}$ \\
\hline Tim Paulus, P.E. & $\begin{array}{l}\text { Mechanical Engineer, Mechanical/Electrical Section, St. Paul District, } \\
\text { USACE }\end{array}$ \\
\hline Ross Woodbury, P.E. & Operations Division, Louisville District, USACE \\
\hline Todd Jennings, P.E. & Civil Engineer, General Engineering Section, Huntington District, USACE \\
\hline Russ Whitten, P.E. & Chief, Mechanical/Electrical Section, Huntington District, USACE \\
\hline
\end{tabular}

Table 7. Electrical panel members.

\begin{tabular}{|l|l|}
\hline Name & Affiliation \\
\hline Jim Hay, P.E. & Operations Division, McNairy Lock and Dam, Walla Walla District USACE \\
\hline Ross Woodbury, P.E. & Operations Division, Louisville District, USACE \\
\hline David Buccini & $\begin{array}{l}\text { Mechanical Engineer, Mechanical/Electrical Section, Pittsburgh District, } \\
\text { USACE }\end{array}$ \\
\hline Bryan Radkte, P.E. & $\begin{array}{l}\text { Electrical Engineer, Mechanical/Electrical Section, Rock Island District, } \\
\text { USACE }\end{array}$ \\
\hline John Nites, P.E. & $\begin{array}{l}\text { Electrical Engineer, Mechanical/Electrical Section, Pittsburgh District, } \\
\text { USACE }\end{array}$ \\
\hline Todd Jennings, P.E. & Civil Engineer, General Engineering Section, Huntington District, USACE \\
\hline
\end{tabular}


Table 8. Observers.

\begin{tabular}{|l|l|}
\hline Name & Affiliation \\
\hline James Bartek, P.E. & $\begin{array}{l}\text { Chief of the Mechanical/Electrical Section in Engineering Division, } \\
\text { Rock Island District, USACE }\end{array}$ \\
\hline David Buccini & $\begin{array}{l}\text { Regional Technical Specialist - Mechanical Engineering for the Great } \\
\text { Lakes and Ohio River Division (LRD), USACE }\end{array}$ \\
\hline Dan Casapulla, P.E. & Lead Mechanical Engineer at HQUSACE \\
\hline Stuart D. Foltz & $\begin{array}{l}\text { Research civil engineer at the Engineer Research and Development } \\
\text { Center, Construction Engineering Research Laboratory (ERDC-CERL) }\end{array}$ \\
\hline Brendan McKinley & $\begin{array}{l}\text { Regional Technical Specialist - Mechanical Engineering for Lakes and } \\
\text { Rivers Division (LRD), USACE }\end{array}$ \\
\hline $\begin{array}{l}\text { Richard W. Schultz, } \\
\text { P.E. }\end{array}$ & $\begin{array}{l}\text { Chief of the Mechanical/Electrical Section in Engineering Division, } \\
\text { Louisville District, USACE }\end{array}$ \\
\hline
\end{tabular}

The technical integrator and facilitator was Robert C. Patev, the USACE North Atlantic Division Regional Technical Specialist for Navigation Design and a structural/geotechnical engineer with the US Army Corps of Engineer, New England District in Concord, MA. Mr. Patev was more recently a research civil engineer at the Engineer Research and Development Center, Information Technology Laboratory (ERDC-ITL). For the past 15 years, Mr. Patev has focused his work in the areas of risk assessment and engineering reliability. He has worked in directing the risk and reliability research arena for the Corps and has worked with Corps Districts on the application of time-dependent reliability procedures to many navigation projects. Mr. Patev's background is diverse; he has bachelor's and master's degrees in geology, geotechnical engineering, and structural engineering. He has published a variety of journal and conference papers on risk assessment and engineering reliability and has contributed technical chapters to a variety of textbooks. 


\section{Expert-Opinion Elicitation}

\subsection{Background}

The elicitation process of opinions is a formal process that is performed systematically for each issue according to the following steps:

- Issue familiarization of experts and review of critical component list.

- Train experts in elicitation process using two examples.

- Experts discuss and come to agreement on assumptions for each issue.

- Facilitate the first elicitation and collection of opinions.

- Collect and present results to experts.

- The group discusses its first response.

- Facilitate the second elicitation and collection of opinions.

- Make the final presentation of experts' opinions.

- Solicit the experts' confidence of final response.

- Return to Step 3 and repeat for all components.

The issues consist of groups of similar questions concerning the CL of critical ME components at navigation projects. The issues also include the experts' confidence level in the final value that was obtained after the second elicitation. Assumptions made and defined by the experts with each issue will be documented with the final results. These final tabulated responses define a CL for the components that will be used in the system reliability analysis of ME equipment at USACE navigation projects.

\subsection{Selected issues}

The issues for the experts were developed from the critical ME list that theexperts reviewed in their read-ahead package. The issues were only focused on the normal deterioration and wear on the ME systems at navigation projects. Since the goal of the elicitation was to only estimate CL, the issues to address in this EOE are less difficult than typical EOE for navigation reliability. 


\subsubsection{Mechanical system issues}

\subsubsection{Description of problem}

The mechanical system consists of four major categories: (1) mechanical drive systems, (2) hydraulic drive systems, (3) misc. gate/ filling/ emptying valves, and (4) other systems. The components in each of these categories are subjected to deterioration due to wear, corrosion, overstress, and fatigue from normal operational and environmental conditions at lock and dam facilities.

\subsubsection{Potential failure mode(s)}

The failure modes for these components were limited to any potential internal failure mechanism that could occur during normal operation of the lock and dam system. Individual failure modes were not identified for each component since it would be difficult to identify and elicit CL estimates for each failure mode with a high level of confidence.

\subsubsection{Potential consequences/repair scenarios}

The CL for the mechanical components was defined as the time until the component caused a navigation delay or closure greater than 4 hours. Partial or temporary repair scenarios were not considered for the mechanical system other than a replacement or rehabilitation of the entire system at a particular life cycle.

\subsubsection{Issue definition for questions}

Questions were defined for each critical mechanical component to determine the CL of that component and their confidence in that final elicited value. No assumptions were given to the experts as to the life of a navigation project.

\subsubsection{Electrical system issues}

\subsubsection{Description of problem}

The electrical system consists of four major categories: (1) power, (2) motor control, (3) motor and switches, and (4) electromechanical drives. The components in each of these categories are subjected to deterioration due to 
wear and fatigue from normal operational and environmental conditions at lock and dam facilities.

\subsubsection{Potential failure mode(s)}

The failure modes for these components were limited to any potential internal failure mechanism that could occur during normal operation of the lock and dam system. Individual failure modes were not identified for each component since it would be difficult to identify and elicit CL estimates for each failure mode with a high level of confidence.

\subsubsection{Potential consequences/repair scenarios}

The CL for the mechanical components was defined as the time until the component caused a navigation delay or closure greater than 4 hours. Partial or temporary repair scenarios were not considered for the mechanical system other than a replacement or rehabilitation of the entire system at a particular life cycle.

\subsubsection{Event definition for questions}

Questions were defined for each critical electrical component to determine the CL of that component and their confidence in that final elicited value. No assumptions were given to the experts as to the life of a navigation project.

\subsection{Elicitation and aggregation of expert opinions}

The panel of experts, observers and the facilitator convened at the Louisville District offices in Louisville, $\mathrm{KY}$ for the period of 2 days to discuss and address the issues shown above. The following protocol was followed in the deliberation of the issues:

- Training of the experts on probabilities and the elicitation process was conducted using two different elicitation examples. This training was conducted to familiarize the experts with the type of questions that were forthcoming, and to focus the experts on how to discuss and answer the issues that were forthcoming. The experts felt this training was very helpful in understanding and making them more comfortable with their elicitation and gained their confidence for discussion with other panel members. 
- After presenting an issue and question, discussion of the issue was encouraged to ensure that all experts clearly understood the questions and event before answering. The participants also listed and agreed to the assumptions. For each issue, experts were given a general form to record their evaluation or input. The experts' judgment along with their supportive reasoning was recorded for the issues. The experts were also advised that the CL can only be answered in a whole number.

- The collected assessments from the experts were analyzed and aggregated quickly to obtain the first response from the experts about the issue. The medians and percentiles for the issue were computed in real time, and were discussed as they were being shown on a computer projection unit. Discussions then ensued among the experts to develop a consensus and agreement among the experts toward their first responses. The experts were given the opportunity to revise their assessments of the individual issues at the end of discussion. Also, the experts were asked to state the rationale for their statements and revisions. The revised assessments of the experts were collected for aggregation and analysis. Any additional assumptions made by the experts were documented as well.

- The experts were then asked for their second responses after discussion was formally closed. The collected assessments from the experts were analyzed and aggregated quickly for review by the experts. This last assessment was shown to the experts, but no changes were made to these results. The median of the final expert estimates was used as the final value. The experts were also asked to give a qualitative response to their confidence in the final medians for the CL estimate from the second response. This response was requested as high ( \pm 5 years), medium ( \pm 10 years), or low ( \pm 15 years). These medians are documented in this report for initial and final responses.

- In addition, a comprehensive documentation of this process is essential to ensure acceptance and credibility of the elicitation results. This document includes complete descriptions of both the first and second responses and the confidence of the experts in the final median response. The summarized results for each issue are provided in Section 3.6. Appendix A includes the actual elicited results in Microsoft Excel spreadsheets form. 


\subsection{Sample questions used for issues}

The elicitation questions defined for each issue were developed based on defining the CL for the ME components. The following section gives an example elicitation question for "Mechanical Drive System - Bearings Roller" issue. For each question, Appendix A includes the Excel spreadsheet used to record the results and the expert panel responses for each issue.

\subsection{Example question for mechanical drive system issue - bearings - rolling element}

\subsubsection{Event name}

Bearing (rolling element) fail in the mechanical drive system during normal operation.

\subsubsection{Question}

What is the CL (in years) for a rolling element type bearing?

\subsection{Summary of results from elicitation}

This section discusses an aggregated summary of the results from the elicitation. The results in this section are shown as the median of each (first and second) response. The minimums and maximums are included to show the variation in the expert's responses. Also included with these results are the assumptions made and agreed to by the experts as shown for each response and the confidence each expert had in each of the final median response to the question. The confidence levels were solicited only in three categories: high ( \pm 5 years), medium ( \pm 10 years), or low ( \pm 15 years). Appendix A contains more detailed results from the elicitation, including the non-aggregated results, which contain the minimum, maximum, and various percentiles for each question. The non-aggregated results also show individual responses for each expert.

Note that, in all cases, experts' confidence was established using "low," "medium," and "high" categories. The confidence results are expressed for each question based on the median for the second response. 


\subsubsection{Mechanical system - mechanical drive systems}

\subsubsection{Assumptions made by experts for mechanical drive systems}

The experts made and agreed to the following assumptions:

- CL is the expected life until failure.

- Normal maintenance is done; there is no replacement.

- Operations are assumed to be "normal," i.e., there is no increase in future traffic.

- CL is expressed in years (no fractions).

- The general purpose environment is "good."

- The typical lock and dam does not go underwater.

- All materials are properly selected and designed. 


\subsubsection{Bearings-rolling element}

What is the estimated CL (in years) for a rolling element type bearing?

\begin{tabular}{|l|c|c|}
\hline & 1st $^{\text {sesponse }}$ & 2 $^{\text {nd }}$ response \\
\hline Minimum & 40 & 40 \\
\hline Median & 40 & 40 \\
\hline Maximum & 45 & 40 \\
\hline
\end{tabular}

\begin{tabular}{|l|c|c|c|c|}
\hline & Median & Low & Med & High \\
\hline Final value(s) & 40 & 0 & 1 & 5 \\
\hline
\end{tabular}

3.6.1.3 Bearing sleeve (self lubricated)

What is the estimated CL (in years) for a sleeve (self lubricated) bearing?

\begin{tabular}{|l|c|c|}
\hline & 1 $^{\text {st }}$ response & 2 $^{\text {nd }}$ response \\
\hline Minimum & 20 & 20 \\
\hline Median & 28 & $\mathbf{2 5}$ \\
\hline Maximum & 40 & 35 \\
\hline
\end{tabular}

\begin{tabular}{|l|c|c|c|c|}
\hline & Median & Low & Med & High \\
\hline Final value(s) & 25 & 1 & 4 & 1 \\
\hline
\end{tabular}

\subsubsection{Bearing - bronze sleeve}

What is the estimated CL (in years) for a bronze sleeve bearing?

\begin{tabular}{|l|c|c|}
\hline & 1 $^{\text {st }}$ response & 2 $^{\text {nd }}$ response \\
\hline Minimum & 30 & 20 \\
\hline Median & 40 & 25 \\
\hline Maximum & 45 & 35 \\
\hline
\end{tabular}

\begin{tabular}{|l|c|c|c|c|}
\hline & Median & Low & Med & High \\
\hline Final value(s) & 25 & 1 & 4 & 1 \\
\hline
\end{tabular}




\subsubsection{Couplings-flexible}

What is the estimated CL (in years) for flexible couplings?

\begin{tabular}{|l|c|c|}
\hline & 1 $^{\text {st }}$ response & 2 $^{\text {nd }}$ response \\
\hline Minimum & 30 & 20 \\
\hline Median & 40 & $\mathbf{2 5}$ \\
\hline Maximum & 45 & 35 \\
\hline
\end{tabular}

\begin{tabular}{|l|c|c|c|c|}
\hline & Median & Low & Med & High \\
\hline Final value(s) & 25 & 1 & 4 & 1 \\
\hline
\end{tabular}

\subsubsection{Couplings-rigid}

What is the estimated CL (in years) for flexible couplings?

\begin{tabular}{|l|c|c|}
\hline & 1 $^{\text {st }}$ response & 2 $^{\text {nd }}$ response \\
\hline Minimum & 40 & 45 \\
\hline Median & 50 & 50 \\
\hline Maximum & 80 & 70 \\
\hline
\end{tabular}

\begin{tabular}{|l|c|c|c|c|}
\hline & Median & Low & Med & High \\
\hline Final value(s) & 50 & 0 & 0 & 6 \\
\hline
\end{tabular}

\subsubsection{Shafts}

What is the estimated CL (in years) for shafts?

\begin{tabular}{|l|c|c|c|c|}
\hline & \multicolumn{2}{|c|}{ 1 $^{\text {st }}$ response } & \multicolumn{2}{c|}{ 2 $^{\text {nd }}$ response } \\
\hline Minimum & \multicolumn{2}{|c|}{50} & \multicolumn{2}{c|}{50} \\
\hline Median & \multicolumn{2}{|c|}{50} & \multicolumn{2}{c|}{50} \\
\hline Maximum & \multicolumn{2}{|c|}{80} & Mow & High \\
\hline & Median & 0 & 0 & 6 \\
\hline Final value(s) & 50 & &
\end{tabular}




\subsubsection{Pins}

What is the estimated CL (in years) for pins?

\begin{tabular}{|l|c|c|}
\hline & 1 $^{\text {st }}$ response & 2 $^{\text {nd }}$ response \\
\hline Minimum & 25 & 30 \\
\hline Median & 33 & 35 \\
\hline Maximum & 40 & 35 \\
\hline
\end{tabular}

\begin{tabular}{|l|c|c|c|c|}
\hline & Median & Low & Med & High \\
\hline Final value(s) & 35 & 0 & 1 & 5 \\
\hline
\end{tabular}

\subsubsection{Gear reducers - worm}

What is the estimated CL (in years) for worm gear reducers?

\begin{tabular}{|l|c|c|}
\hline & 1 $^{\text {st }}$ response & 2 $^{\text {nd }}$ response \\
\hline Minimum & 25 & 25 \\
\hline Median & 28 & 25 \\
\hline Maximum & 40 & 30 \\
\hline
\end{tabular}

\begin{tabular}{|l|c|c|c|c|}
\hline & Median & Low & Med & High \\
\hline Median Final value(s) & 25 & 0 & 3 & 3 \\
\hline
\end{tabular}

\subsubsection{Gear reducers - parallel}

What is the estimated CL (in years) for parallel gear reducers?

\begin{tabular}{|l|c|c|}
\hline & 1 $^{\text {st }}$ response & 2 $^{\text {nd }}$ response \\
\hline Minimum & 30 & 40 \\
\hline Median & 40 & 40 \\
\hline Maximum & 50 & 45 \\
\hline
\end{tabular}

\begin{tabular}{|l|c|c|c|c|}
\hline & Median & Low & Med & High \\
\hline Final value(s) & 40 & 0 & 1 & 5 \\
\hline
\end{tabular}


3.6.1.11 Gear reducers - right angle

What is the estimated CL (in years) for right angle gear reducers?

\begin{tabular}{|l|c|c|}
\hline & 1 $^{\text {st }}$ response & 2 $^{\text {nd }}$ response \\
\hline Minimum & 30 & 35 \\
\hline Median & 40 & $\mathbf{3 8}$ \\
\hline Maximum & 45 & 45 \\
\hline
\end{tabular}

\begin{tabular}{|l|c|c|c|c|}
\hline & Median & Low & Med & High \\
\hline Final value(s) & 38 & 0 & 4 & 2 \\
\hline
\end{tabular}

\subsubsection{Open gearing -spur}

What is the estimated CL (in years) for spur open gearing?

\begin{tabular}{|c|c|c|c|c|}
\hline & \multicolumn{2}{|c|}{$1^{\text {st }}$ response } & \multicolumn{2}{|c|}{$2^{\text {nd }}$ response } \\
\hline Minimum & \multicolumn{2}{|c|}{35} & \multicolumn{2}{|c|}{45} \\
\hline Median & \multicolumn{2}{|c|}{48} & \multicolumn{2}{|c|}{50} \\
\hline Maximum & \multicolumn{2}{|c|}{60} & \multicolumn{2}{|c|}{60} \\
\hline & Median & Low & Med & High \\
\hline Final value(s) & 50 & 0 & 1 & 5 \\
\hline
\end{tabular}

\subsubsection{Open gearing -helical}

What is the estimated CL (in years) for helical open gearing?

\begin{tabular}{|l|c|c|}
\hline & 1 $^{\text {st }}$ response & 2 $^{\text {nd }}$ response \\
\hline Minimum & 30 & 35 \\
\hline Median & 38 & 38 \\
\hline Maximum & 50 & 40 \\
\hline
\end{tabular}

\begin{tabular}{|l|c|c|c|c|}
\hline & Median & Low & Med & High \\
\hline Final value(s) & 38 & 0 & 6 & 0 \\
\hline
\end{tabular}


3.6.1.14 Open gearing-bevel

What is the estimated CL (in years) for bevel open gearing?

\begin{tabular}{|l|c|c|c|c|}
\hline & \multicolumn{2}{|c|}{ 1 $^{\text {st }}$ response } & \multicolumn{2}{c|}{ 2 $^{\text {nd }}$ response } \\
\hline Minimum & \multicolumn{2}{|c|}{30} & \multicolumn{2}{c|}{35} \\
\hline Median & \multicolumn{2}{|c|}{38} & \multicolumn{2}{c|}{40} \\
\hline Maximum & \multicolumn{2}{|c|}{40} & \multicolumn{2}{|c|}{40} \\
\hline & Median & 0 & 6 & Hed \\
\hline Final value(s) & 40 & \multicolumn{2}{|c|}{0} \\
\hline
\end{tabular}

\subsubsection{Open gearing -rack}

What is the estimated CL (in years) for rack open gearing?

\begin{tabular}{|c|c|c|c|c|}
\hline & \multicolumn{2}{|c|}{$1^{\text {st }}$ response } & \multicolumn{2}{|c|}{$2^{\text {nd }}$ response } \\
\hline Minimum & \multicolumn{2}{|c|}{35} & \multicolumn{2}{|c|}{40} \\
\hline Median & \multicolumn{2}{|c|}{45} & \multicolumn{2}{|c|}{50} \\
\hline Maximum & \multicolumn{2}{|c|}{60} & \multicolumn{2}{|c|}{60} \\
\hline & Median & Low & Med & High \\
\hline Final value(s) & 50 & 0 & 4 & 2 \\
\hline
\end{tabular}

\subsubsection{Brake - electromechanical}

What is the estimated CL (in years) for electromechanical brake?

\begin{tabular}{|l|c|c|}
\hline & 1 $^{\text {st }}$ response & 2 $^{\text {nd }}$ response \\
\hline Minimum & 35 & 40 \\
\hline Median & 43 & 45 \\
\hline Maximum & 45 & 45 \\
\hline
\end{tabular}

\begin{tabular}{|l|c|c|c|c|}
\hline & Median & Low & Med & High \\
\hline Final value(s) & 45 & 0 & 0 & 6 \\
\hline
\end{tabular}




\subsubsection{Clutch}

What is the estimated CL (in years) for the clutch?

\begin{tabular}{|l|c|c|}
\hline & 1 $^{\text {st }}$ response & 2 $^{\text {nd }}$ response \\
\hline Minimum & 20 & 20 \\
\hline Median & 30 & 30 \\
\hline Maximum & 35 & 35 \\
\hline
\end{tabular}

\begin{tabular}{|l|c|c|c|c|}
\hline & Median & Low & Med & High \\
\hline Final value(s) & 30 & 2 & 4 & 0 \\
\hline
\end{tabular}

\subsubsection{Wire ropes-spiral}

What is the estimated $\mathrm{CL}$ (in years) for spiral wire ropes?

\begin{tabular}{|c|c|c|c|c|}
\hline & \multicolumn{2}{|c|}{$1^{\text {st }}$ response } & \multicolumn{2}{|c|}{$2^{\text {nd }}$ response } \\
\hline Minimum & \multicolumn{2}{|c|}{3} & \multicolumn{2}{|c|}{3} \\
\hline Median & \multicolumn{2}{|c|}{5} & \multicolumn{2}{|c|}{5} \\
\hline Maximum & \multicolumn{2}{|c|}{40} & \multicolumn{2}{|c|}{20} \\
\hline & Median & Low & Med & High \\
\hline Final value(s) & 5 & 2 & 0 & 4 \\
\hline
\end{tabular}

\subsubsection{Wire ropes-single sheave}

What is the estimated $\mathrm{CL}$ (in years) for single sheave wire ropes?

\begin{tabular}{|c|c|c|c|c|}
\hline & \multicolumn{2}{|c|}{$1^{\text {st }}$ response } & \multicolumn{2}{|c|}{$2^{\text {nd }}$ response } \\
\hline Minimum & \multicolumn{2}{|c|}{12} & \multicolumn{2}{|c|}{15} \\
\hline Median & \multicolumn{2}{|c|}{20} & \multicolumn{2}{|c|}{20} \\
\hline Maximum & \multicolumn{2}{|c|}{40} & \multicolumn{2}{|c|}{25} \\
\hline & Median & Low & Med & High \\
\hline Final value(s) & 20 & 0 & 4 & 2 \\
\hline
\end{tabular}


3.6.1.20 Wire ropes-single drum

What is the estimated CL (in years) for single drum wire ropes?

\begin{tabular}{|l|c|c|}
\hline & 1 $^{\text {st }}$ response & 2 $^{\text {nd }}$ response \\
\hline Minimum & 10 & 25 \\
\hline Median & 25 & $\mathbf{2 8}$ \\
\hline Maximum & 30 & 30 \\
\hline
\end{tabular}

\begin{tabular}{|l|c|c|c|c|}
\hline & Median & Low & Med & High \\
\hline Final value(s) & 28 & 0 & 3 & 3 \\
\hline
\end{tabular}

\subsubsection{Wire ropes drums}

What is the estimated CL (in years) for wire ropes drums?

\begin{tabular}{|l|c|c|}
\hline & 1 $^{\text {st }}$ response & 2 $^{\text {nd }}$ response \\
\hline Minimum & 40 & 50 \\
\hline Median & 50 & 50 \\
\hline Maximum & 60 & 60 \\
\hline
\end{tabular}

\begin{tabular}{|l|c|c|c|c|}
\hline & Median & Low & Med & High \\
\hline Final value(s) & 50 & 0 & 0 & 6 \\
\hline
\end{tabular}

\subsubsection{Wire ropes sheaves}

What is the estimated $\mathrm{CL}$ (in years) for wire ropes sheaves?

\begin{tabular}{|l|c|c|}
\hline & $1^{\text {st }}$ response & 2 $^{\text {nd }}$ response \\
\hline Minimum & 20 & 25 \\
\hline Median & 30 & 33 \\
\hline Maximum & 40 & 40 \\
\hline
\end{tabular}

\begin{tabular}{|l|c|c|c|c|}
\hline & Median & Low & Med & High \\
\hline Final value(s) & 33 & 0 & 4 & 2 \\
\hline
\end{tabular}




\subsubsection{Chains}

What is the estimated CL (in years) for chains?

\begin{tabular}{|l|c|c|}
\hline & 1st $^{\text {sesponse }}$ & 2 $^{\text {nd }}$ response \\
\hline Minimum & 20 & 25 \\
\hline Median & 28 & 40 \\
\hline Maximum & 60 & 45 \\
\hline
\end{tabular}

\begin{tabular}{|l|c|c|c|c|}
\hline & Median & Low & Med & High \\
\hline Final value(s) & 40 & 2 & 3 & 1 \\
\hline
\end{tabular}

\subsubsection{Chain sprockets}

What is the estimated CL (in years) for chain sprockets?

\begin{tabular}{|c|c|c|c|c|}
\hline & \multicolumn{2}{|c|}{$1^{\text {st }}$ response } & \multicolumn{2}{|c|}{$2^{\text {nd }}$ response } \\
\hline Minimum & \multicolumn{2}{|l|}{40} & \multicolumn{2}{|c|}{50} \\
\hline Median & \multicolumn{2}{|l|}{48} & \multicolumn{2}{|c|}{60} \\
\hline Maximum & \multicolumn{2}{|l|}{60} & \multicolumn{2}{|c|}{60} \\
\hline & Median & Low & Med & High \\
\hline Final value(s) & 40 & 2 & 3 & 1 \\
\hline
\end{tabular}

\subsubsection{Miter gate sector arms}

What is the estimated CL (in years) miter gate sector arms?

\begin{tabular}{|c|c|c|c|c|}
\hline & \multicolumn{2}{|c|}{$1^{\text {st }}$ response } & \multicolumn{2}{|c|}{$2^{\text {nd }}$ response } \\
\hline Minimum & \multicolumn{2}{|l|}{50} & \multicolumn{2}{|c|}{50} \\
\hline Median & \multicolumn{2}{|l|}{68} & \multicolumn{2}{|c|}{73} \\
\hline \multirow[t]{2}{*}{ Maximum } & \multicolumn{2}{|l|}{120} & \multicolumn{2}{|c|}{75} \\
\hline & Median & Low & Med & High \\
\hline Final value(s) & 73 & 1 & 1 & 4 \\
\hline
\end{tabular}


3.6.1.26 Miter gate strut arms (buffered)

What is the estimated CL (in years) miter gate strut (buffered) arms?

\begin{tabular}{|l|c|c|}
\hline & 1 $^{\text {st }}$ response & 2 $^{\text {nd }}$ response \\
\hline Minimum & 30 & 30 \\
\hline Median & 40 & 35 \\
\hline Maximum & 75 & 40 \\
\hline
\end{tabular}

\begin{tabular}{|l|c|c|c|c|}
\hline & Median & Low & Med & High \\
\hline Final value(s) & 35 & 0 & 3 & 3 \\
\hline
\end{tabular}

\subsubsection{Miter gate arms - strut (rigid)}

What is the estimated CL (in years) miter gate strut (rigid) arms?

\begin{tabular}{|c|c|c|c|c|}
\hline & \multicolumn{2}{|c|}{$1^{\text {st }}$ response } & \multicolumn{2}{|c|}{$2^{\text {nd }}$ response } \\
\hline Minimum & \multicolumn{2}{|c|}{20} & \multicolumn{2}{|c|}{30} \\
\hline Median & \multicolumn{2}{|c|}{43} & \multicolumn{2}{|c|}{40} \\
\hline Maximum & \multicolumn{2}{|c|}{120} & \multicolumn{2}{|c|}{75} \\
\hline & Median & Low & Med & High \\
\hline Final value(s) & 40 & 0 & 6 & 0 \\
\hline
\end{tabular}

\subsubsection{Miter gate support roller}

What is the estimated CL (in years) miter gate support roller?

\begin{tabular}{|l|c|c|}
\hline & 1st response $^{\text {2nd }}$ & 2esponse $^{30}$ \\
\hline Minimum & 30 & $\mathbf{4 3}$ \\
\hline Median & 43 & 50 \\
\hline Maximum & 50 & 50 \\
\hline
\end{tabular}

\begin{tabular}{|l|c|c|c|c|}
\hline & Median & Low & Med & High \\
\hline Final value(s) & 43 & 0 & 5 & 1 \\
\hline
\end{tabular}


3.6.1.29 Miter gate rack support beam

What is the estimated CL (in years) miter gate rack support beam?

\begin{tabular}{|l|c|c|}
\hline & 1 $^{\text {st }}$ response & 2 $^{\text {nd }}$ response \\
\hline Minimum & 50 & 50 \\
\hline Median & 60 & 60 \\
\hline Maximum & 80 & 80 \\
\hline
\end{tabular}

\begin{tabular}{|l|c|c|c|c|}
\hline & Median & Low & Med & High \\
\hline Final value(s) & 60 & 0 & 5 & 1 \\
\hline
\end{tabular}

3.6.1.30 Valves - bellcranks

What is the estimated CL (in years) for the valve bellcranks?

\begin{tabular}{|c|c|c|c|c|}
\hline & \multicolumn{2}{|c|}{$1^{\text {st }}$ response } & \multicolumn{2}{|c|}{$2^{\text {nd }}$ response } \\
\hline Minimum & \multicolumn{2}{|c|}{50} & \multicolumn{2}{|c|}{70} \\
\hline Median & \multicolumn{2}{|c|}{75} & \multicolumn{2}{|c|}{78} \\
\hline Maximum & \multicolumn{2}{|c|}{100} & \multicolumn{2}{|c|}{100} \\
\hline & Median & Low & Med & High \\
\hline Final value(s) & 78 & 0 & 3 & 3 \\
\hline
\end{tabular}

\subsubsection{Valves - crossheads/guides}

What is the estimated CL (in years) for valve crossheads/guides?

\begin{tabular}{|l|c|c|}
\hline & $1^{\text {st }}$ response & 2 $^{\text {nd }}$ response \\
\hline Minimum & 45 & 55 \\
\hline Median & 63 & 73 \\
\hline Maximum & 80 & 80 \\
\hline
\end{tabular}

\begin{tabular}{|l|c|c|c|c|}
\hline & Median & Low & Med & High \\
\hline Final value(s) & 73 & 0 & 4 & 2 \\
\hline
\end{tabular}




\subsubsection{Valves -struts}

What is the estimated CL (in years) for the valve struts?

\begin{tabular}{|l|c|c|}
\hline & 1 $^{\text {st }}$ response & 2 $^{\text {nd }}$ response \\
\hline Minimum & 35 & 35 \\
\hline Median & 45 & $\mathbf{4 3}$ \\
\hline Maximum & 60 & 60 \\
\hline
\end{tabular}

\begin{tabular}{|l|c|c|c|c|}
\hline & Median & Low & Med & High \\
\hline Final value(s) & 43 & 0 & 2 & 4 \\
\hline
\end{tabular}

\subsubsection{Mechanical system - hydraulic drive systems}

\subsubsection{Assumptions made by experts for hydraulic drive systems}

The experts made and agreed to the following assumptions:

- $\quad$ CL is the expected life until failure.

- Normal maintenance is done; there is no replacement.

- Operations are assumed to be "normal," i.e., there is no increase in future traffic.

- CL is expressed in years (no fractions).

- The general purpose environment is "good."

- The typical lock and dam does not go underwater.

- All materials are properly selected and designed.

- All materials are properly selected and designed. 


\subsubsection{Hydraulic cylinders}

What is the estimated CL (in years) for the hydraulic cylinders?

\begin{tabular}{|l|c|c|}
\hline & 1 $^{\text {st }}$ response & 2 $^{\text {nd }}$ response \\
\hline Minimum & 50 & 55 \\
\hline Median & 60 & 60 \\
\hline Maximum & 70 & 70 \\
\hline
\end{tabular}

\begin{tabular}{|l|c|c|c|c|}
\hline & Median & Low & Med & High \\
\hline Final value(s) & 60 & 0 & 0 & 6 \\
\hline
\end{tabular}

\subsubsection{Control valves -check}

What is the estimated CL (in years) for check valves?

\begin{tabular}{|c|c|c|c|c|}
\hline & \multicolumn{2}{|c|}{$1^{\text {st }}$ response } & \multicolumn{2}{|c|}{$2^{\text {nd }}$ response } \\
\hline Minimum & \multicolumn{2}{|c|}{30} & \multicolumn{2}{|c|}{40} \\
\hline Median & \multicolumn{2}{|c|}{50} & \multicolumn{2}{|c|}{45} \\
\hline Maximum & \multicolumn{2}{|c|}{60} & \multicolumn{2}{|c|}{50} \\
\hline & Median & Low & Med & High \\
\hline Final value(s) & 45 & 0 & 2 & 4 \\
\hline
\end{tabular}

\subsubsection{Control valves -relief}

What is the estimated CL (in years) for relief valves?

\begin{tabular}{|l|c|c|}
\hline & 1 $^{\text {st }}$ response & 2 $^{\text {nd }}$ response \\
\hline Minimum & 30 & 30 \\
\hline Median & 45 & 40 \\
\hline Maximum & 60 & 50 \\
\hline
\end{tabular}

\begin{tabular}{|l|c|c|c|c|}
\hline & Median & Low & Med & High \\
\hline Final value(s) & 40 & 0 & 2 & 4 \\
\hline
\end{tabular}


3.6.2.5 Control valves - manual

What is the estimated CL (in years) for manual valves?

\begin{tabular}{|l|c|c|}
\hline & 1st $^{\text {sesponse }}$ & 2 $^{\text {nd }}$ response \\
\hline Minimum & 50 & 60 \\
\hline Median & 60 & 60 \\
\hline Maximum & 70 & 70 \\
\hline
\end{tabular}

\begin{tabular}{|l|c|c|c|c|}
\hline & Median & Low & Med & High \\
\hline Final value(s) & 60 & 0 & 1 & 5 \\
\hline
\end{tabular}

\subsubsection{Control valves -solenoid}

What is the estimated CL (in years) for solenoid valves?

\begin{tabular}{|l|c|c|}
\hline & 1 $^{\text {st }}$ response & 2 $^{\text {nd }}$ response \\
\hline Minimum & 30 & 30 \\
\hline Median & 45 & $\mathbf{4 0}$ \\
\hline Maximum & 60 & 50 \\
\hline
\end{tabular}

\begin{tabular}{|l|c|c|c|c|}
\hline & Median & Low & Med & High \\
\hline Final value(s) & 40 & 0 & 5 & 1 \\
\hline
\end{tabular}

\subsubsection{Control valves - proportional/throttle}

What is the estimated CL (in years) for proportional/throttle valves?

\begin{tabular}{|c|c|c|c|c|}
\hline & \multicolumn{2}{|c|}{$1^{\text {st }}$ response } & \multicolumn{2}{|c|}{$2^{\text {nd }}$ response } \\
\hline Minimum & \multicolumn{2}{|c|}{30} & \multicolumn{2}{|c|}{30} \\
\hline Median & \multicolumn{2}{|c|}{40} & \multicolumn{2}{|c|}{40} \\
\hline \multirow[t]{2}{*}{ Maximum } & \multicolumn{2}{|c|}{50} & \multicolumn{2}{|c|}{50} \\
\hline & Median & Low & Med & High \\
\hline Final value(s) & 40 & 0 & 5 & 1 \\
\hline
\end{tabular}


3.6.2.8 Pumps -fixed

What is the estimated CL (in years) for fixed drive pumps?

\begin{tabular}{|l|c|c|c|c|}
\hline & \multicolumn{2}{|c|}{ 1 $^{\text {st }}$ response } & \multicolumn{2}{c|}{ 2 $^{\text {nd }}$ response } \\
\hline Minimum & \multicolumn{2}{|c|}{45} & \multicolumn{2}{c|}{50} \\
\hline Median & \multicolumn{2}{|c|}{50} & \multicolumn{2}{c|}{50} \\
\hline Maximum & \multicolumn{2}{|c|}{80} & \multicolumn{2}{|c|}{60} \\
\hline & Median & Low & Med & High \\
\hline Final value(s) & 50 & 0 & 0 & 6 \\
\hline
\end{tabular}

\subsubsection{Pumps -variable}

What is the estimated CL (in years) for variable drive pumps?

\begin{tabular}{|l|c|c|}
\hline & 1st $^{\text {sesponse }}$ & 2 $^{\text {nd }}$ response \\
\hline Minimum & 25 & 25 \\
\hline Median & 45 & $\mathbf{3 0}$ \\
\hline Maximum & 60 & 45 \\
\hline
\end{tabular}

\begin{tabular}{|l|c|c|c|c|}
\hline & Median & Low & Med & High \\
\hline Final value(s) & 30 & 0 & 1 & 5 \\
\hline
\end{tabular}

\subsubsection{Piping}

What is the estimated CL (in years) for variable drive pumps?

\begin{tabular}{|c|c|c|c|c|}
\hline & \multicolumn{2}{|c|}{$1^{\text {st }}$ response } & \multicolumn{2}{|c|}{$2^{\text {nd }}$ response } \\
\hline Minimum & \multicolumn{2}{|c|}{40} & \multicolumn{2}{|c|}{40} \\
\hline Median & \multicolumn{2}{|c|}{40} & \multicolumn{2}{|c|}{40} \\
\hline Maximum & \multicolumn{2}{|c|}{50} & \multicolumn{2}{|c|}{50} \\
\hline & Median & Low & Med & High \\
\hline Final value(s) & 60 & 0 & 3 & 3 \\
\hline
\end{tabular}


3.6.3 Mechanical system - misc. gate/filling and emptying valves and other systems

3.6.3.1 Assumptions made by experts for misc. gate/filling and emptying valves

The experts made and agreed to the following assumptions:

- CL is the expected life until failure.

- Normal maintenance is done; there is no replacement.

- Operations are assumed to be "normal," i.e., there is no increase in future traffic.

- CL is expressed in years (no fractions).

- The general purpose environment is "good."

- The typical lock and dam does not go underwater.

- All materials are properly selected and designed. 
3.6.3.2 Wheel assembly (rollers)

What is the estimated CL (in years) for the wheel assembly (rollers)?

\begin{tabular}{|c|c|c|c|c|}
\hline & \multicolumn{2}{|c|}{$1^{\text {st }}$ response } & \multicolumn{2}{|c|}{$2^{\text {nd }}$ response } \\
\hline Minimum & \multicolumn{2}{|c|}{10} & \multicolumn{2}{|c|}{40} \\
\hline Median & \multicolumn{2}{|c|}{40} & \multicolumn{2}{|c|}{40} \\
\hline Maximum & \multicolumn{2}{|c|}{50} & \multicolumn{2}{|c|}{40} \\
\hline & Median & Low & Med & High \\
\hline Final value(s) & 40 & 0 & 3 & 3 \\
\hline
\end{tabular}

\subsubsection{Pintles/bushings}

What is the estimated CL (in years) for the pintle/bushings?

\begin{tabular}{|l|c|c|c|c|}
\hline & \multicolumn{2}{|c|}{ 1 $^{\text {st }}$ response } & \multicolumn{2}{c|}{ 2 $^{\text {nd }}$ response } \\
\hline Minimum & \multicolumn{2}{|c|}{25} & \multicolumn{2}{c|}{30} \\
\hline Median & \multicolumn{2}{|c|}{30} & \multicolumn{2}{|c|}{30} \\
\hline Maximum & \multicolumn{2}{|c|}{75} & \multicolumn{2}{c|}{60} \\
\hline & Median & Low & Med & High \\
\hline Final value(s) & 30 & 0 & 2 & 4 \\
\hline
\end{tabular}

\subsubsection{Gudgeon pin/bushings}

What is the estimated CL (in years) for the gudgeon pin/bushings?

\begin{tabular}{|l|c|c|}
\hline & 1 $^{\text {st }}$ response & 2 $^{\text {nd }}$ response \\
\hline Minimum & 30 & 35 \\
\hline Median & 48 & $\mathbf{4 3}$ \\
\hline Maximum & 50 & 50 \\
\hline
\end{tabular}

\begin{tabular}{|l|c|c|c|c|}
\hline & Median & Low & Med & High \\
\hline Final value(s) & 43 & 0 & 4 & 2 \\
\hline
\end{tabular}


3.6.3.5 Trunnion pin/bushings

What is the estimated CL (in years) for the trunnion pin/bushings?

\begin{tabular}{|l|c|c|}
\hline & 1 $^{\text {st }}$ response & 2 $^{\text {nd }}$ response \\
\hline Minimum & 15 & 25 \\
\hline Median & 35 & 38 \\
\hline Maximum & 45 & 40 \\
\hline
\end{tabular}

\begin{tabular}{|l|c|c|c|c|}
\hline & Median & Low & Med & High \\
\hline Final value(s) & 38 & 0 & 1 & 5 \\
\hline
\end{tabular}

\subsubsection{Trunnion pin/bushings}

What is the estimated CL (in years) for the trunnion pin/bushings?

\begin{tabular}{|l|c|c|}
\hline & 1st $^{\text {response }}$ & 2 $^{\text {nd }}$ response \\
\hline Minimum & 15 & 25 \\
\hline Median & 35 & $\mathbf{3 8}$ \\
\hline Maximum & 45 & 40 \\
\hline
\end{tabular}

\begin{tabular}{|l|c|c|c|c|}
\hline & Median & Low & Med & High \\
\hline Final value(s) & 38 & 0 & 1 & 5 \\
\hline
\end{tabular}

\subsubsection{Strut spindle pin}

What is the estimated CL (in years) for the strut spindle pin?

\begin{tabular}{|l|c|c|}
\hline & 1 $^{\text {st }}$ response & 2 $^{\text {nd }}$ response \\
\hline Minimum & 20 & 20 \\
\hline Median & 25 & 25 \\
\hline Maximum & 40 & 25 \\
\hline
\end{tabular}

\begin{tabular}{|l|c|c|c|c|}
\hline & Median & Low & Med & High \\
\hline Final value(s) & 25 & 0 & 0 & 6 \\
\hline
\end{tabular}


3.6.3.8 Tow haulage -hydraulic

What is the estimated CL (in years) for a hydraulic tow haulage unit?

\begin{tabular}{|l|c|c|c|c|}
\hline & \multicolumn{2}{|c|}{ 1 $^{\text {st }}$ response } & \multicolumn{2}{c|}{ 2 $^{\text {nd }}$ response } \\
\hline Minimum & \multicolumn{2}{|c|}{20} & \multicolumn{2}{c|}{25} \\
\hline Median & \multicolumn{2}{|c|}{35} & \multicolumn{2}{c|}{30} \\
\hline Maximum & \multicolumn{2}{|c|}{50} & \multicolumn{2}{|c|}{35} \\
\hline & Median & 0 & 6 & Hed \\
\hline Final value(s) & 30 & \multicolumn{2}{|c|}{0} \\
\hline
\end{tabular}

\subsubsection{Tow haulage - mechanical}

What is the estimated CL (in years) for a hydraulic tow haulage unit?

\begin{tabular}{|l|c|c|}
\hline & 1 $^{\text {st }}$ response & 2 $^{\text {nd }}$ response \\
\hline Minimum & 20 & 30 \\
\hline Median & 43 & $\mathbf{4 8}$ \\
\hline Maximum & 60 & 60 \\
\hline
\end{tabular}

\begin{tabular}{|l|c|c|c|c|}
\hline & Median & Low & Med & High \\
\hline Final value(s) & 48 & 1 & 3 & 2 \\
\hline
\end{tabular}

\subsubsection{Butterfly valves}

What is the estimated CL (in years) for butterfly valves?

\begin{tabular}{|l|c|c|}
\hline & 1 & 2 $^{\text {st }}$ response \\
\hline Minimum & 40 & 40 \\
\hline Median & 45 & 50 \\
\hline Maximum & 60 & 60 \\
\hline
\end{tabular}

\begin{tabular}{|l|c|c|c|c|}
\hline & Median & Low & Med & High \\
\hline Final value(s) & 50 & 0 & 6 & 0 \\
\hline
\end{tabular}




\subsubsection{Vertical lift valves}

What is the estimated CL (in years) for vertical lift valves?

\begin{tabular}{|l|c|c|}
\hline & 1 $^{\text {st }}$ response & 2 $^{\text {nd }}$ response \\
\hline Minimum & 30 & 40 \\
\hline Median & 45 & 50 \\
\hline Maximum & 50 & 50 \\
\hline
\end{tabular}

\begin{tabular}{|l|c|c|c|c|}
\hline & Median & Low & Med & High \\
\hline Final value(s) & 50 & 0 & 4 & 2 \\
\hline
\end{tabular}

\subsubsection{Electrical system issues}

The experts for electrical system issues made the following assumptions:

- CL is the expected life until failure.

- Normal maintenance is done; there is no replacement.

- Operations are assumed to be "normal," i.e., there is no increase in future traffic.

- CL is expressed in years (no fractions).

- The general purpose environment is "good."

- The typical lock and dam does not go underwater.

- The equipment has been in service for 50-60 years.

- All materials are properly selected and designed.

- A power outage of 4 hours or more is assumed.

- Environmental factors could be used for site specific conditions. 


\subsubsection{Power utility}

What is the estimated CL (in years) for power utility (commercial) power?

\begin{tabular}{|l|c|c|}
\hline & 1 $^{\text {st }}$ response & 2 $^{\text {nd }}$ response \\
\hline Minimum & 1 & 1 \\
\hline Median & 5 & 4 \\
\hline Maximum & 10 & 10 \\
\hline
\end{tabular}

\begin{tabular}{|l|c|c|c|c|}
\hline & Median & Low & Med & High \\
\hline Final value(s) & 50 & 4 & 0 & 3 \\
\hline
\end{tabular}

3.6.4.2 Service transformer

What are estimated CL (in years) the service transformer?

\begin{tabular}{|l|c|c|c|c|}
\hline & \multicolumn{2}{|c|}{ 1st response $^{2}$ 2 $^{\text {nd }}$ response } \\
\hline Minimum & \multicolumn{2}{|c|}{30} & \multicolumn{2}{c|}{40} \\
\hline Median & \multicolumn{2}{|c|}{45} & \multicolumn{2}{c|}{55} \\
\hline Maximum & \multicolumn{2}{|c|}{60} & \multicolumn{2}{c|}{60} \\
\hline & Median & 0 & 3 & Low \\
\hline Final value(s) & 55 & \multicolumn{2}{|c|}{ Med } & High \\
\hline
\end{tabular}

3.6.4.3 Transfer switches -automatic

What are estimated CL (in years) automatic transfer switches?

\begin{tabular}{|c|c|c|c|c|}
\hline & \multicolumn{2}{|c|}{$1^{\text {st }}$ response } & \multicolumn{2}{|c|}{$2^{\text {nd }}$ response } \\
\hline Minimum & \multicolumn{2}{|c|}{15} & \multicolumn{2}{|c|}{20} \\
\hline Median & \multicolumn{2}{|c|}{30} & \multicolumn{2}{|c|}{30} \\
\hline Maximum & \multicolumn{2}{|c|}{40} & \multicolumn{2}{|c|}{40} \\
\hline & Median & Low & Med & High \\
\hline Final value(s) & 30 & 0 & 0 & 6 \\
\hline
\end{tabular}


3.6.4.4 Transfer switches - manual

What are estimated CL (in years) for manual transfer switches?

\begin{tabular}{|c|c|c|c|c|}
\hline & \multicolumn{2}{|c|}{$1^{\text {st }}$ response } & \multicolumn{2}{|c|}{$2^{\text {nd }}$ response } \\
\hline Minimum & \multicolumn{2}{|c|}{40} & \multicolumn{2}{|c|}{60} \\
\hline Median & \multicolumn{2}{|c|}{60} & \multicolumn{2}{|c|}{65} \\
\hline Maximum & \multicolumn{2}{|c|}{80} & \multicolumn{2}{|c|}{80} \\
\hline & Median & Low & Med & High \\
\hline Final value(s) & 65 & 0 & 1 & 5 \\
\hline
\end{tabular}

\subsubsection{Switchgear}

What is the estimated CL (in years) for the switchgear?

\begin{tabular}{|l|c|c|}
\hline & 1st response & 2 $^{\text {nd }}$ response \\
\hline Minimum & 40 & 70 \\
\hline Median & 55 & 78 \\
\hline Maximum & 90 & 90 \\
\hline
\end{tabular}

\begin{tabular}{|l|c|c|c|c|}
\hline & Median & Low & Med & High \\
\hline Final value(s) & 78 & 0 & 4 & 2 \\
\hline
\end{tabular}

\subsubsection{Circuit breakers}

What is estimated CL (in years) for circuit breakers?

\begin{tabular}{|l|c|c|c|c|}
\hline & \multicolumn{2}{|c|}{ 1st response $^{2}$ 2 $^{\text {nd }}$ response } \\
\hline Minimum & \multicolumn{2}{|c|}{30} & \multicolumn{2}{c|}{40} \\
\hline Median & \multicolumn{2}{|c|}{45} & \multicolumn{2}{c|}{63} \\
\hline Maximum & \multicolumn{2}{|c|}{70} & Med & High \\
\hline & Median & 0 & 2 & 4 \\
\hline Final value(s) & 63 & \multicolumn{2}{|c|}{ Low } & Med \\
\hline
\end{tabular}




\subsubsection{Power panelboard}

What is the estimated CL (in years) for power panelboard?

\begin{tabular}{|l|c|c|c|c|}
\hline & \multicolumn{2}{|c|}{ 1 $^{\text {st }}$ response } & \multicolumn{2}{c|}{ 2 $^{\text {nd }}$ response } \\
\hline Minimum & \multicolumn{2}{|c|}{25} & \multicolumn{2}{c|}{60} \\
\hline Median & \multicolumn{2}{|c|}{65} & \multicolumn{2}{c|}{78} \\
\hline Maximum & \multicolumn{2}{|c|}{90} & \multicolumn{2}{c|}{90} \\
\hline & Median & Low & Med & High \\
\hline Final value(s) & 20.0 & 0 & 4 & 2 \\
\hline
\end{tabular}

\subsubsection{Cables-buried/submerged}

What is the estimated CL (in years) for buried/submerged cables?

\begin{tabular}{|l|c|c|c|c|}
\hline & \multicolumn{2}{|c|}{ 1 $^{\text {st }}$ response } & \multicolumn{2}{c|}{ 2 $^{\text {nd }}$ response } \\
\hline Minimum & \multicolumn{2}{|c|}{30} & \multicolumn{2}{c|}{50} \\
\hline Median & \multicolumn{2}{|c|}{55} & \multicolumn{2}{c|}{75} \\
\hline Maximum & \multicolumn{2}{|c|}{75} & Med & High \\
\hline & Median & 0 & 4 & 2 \\
\hline Final value(s) & 60 & &
\end{tabular}

\subsubsection{Cables-duct/cable tray}

What is the estimated CL (in years) for buried/submerged cables?

\begin{tabular}{|l|c|c|}
\hline & 1st $^{\text {st }}$ & 2 $^{\text {nd }}$ response \\
\hline Minimum & 75 & 75 \\
\hline Median & 80 & 80 \\
\hline Maximum & 100 & 100 \\
\hline
\end{tabular}

\begin{tabular}{|l|c|c|c|c|}
\hline & Median & Low & Med & High \\
\hline Final value(s) & 80 & 0 & 4 & 2 \\
\hline
\end{tabular}




\subsubsection{Cables-portable/flexible}

What is the estimated CL (in years) for portable/flexible cables?

\begin{tabular}{|c|c|c|c|c|}
\hline & \multicolumn{2}{|c|}{$1^{\text {st }}$ response } & \multicolumn{2}{|c|}{$2^{\text {nd }}$ response } \\
\hline Minimum & \multicolumn{2}{|c|}{20} & \multicolumn{2}{|c|}{20} \\
\hline Median & \multicolumn{2}{|c|}{28} & \multicolumn{2}{|c|}{38} \\
\hline Maximum & \multicolumn{2}{|c|}{35} & \multicolumn{2}{|c|}{35} \\
\hline & Median & Low & Med & High \\
\hline Final value(s) & 38 & 1 & 3 & 2 \\
\hline
\end{tabular}

3.6.4.11 Bus duct (electronic)

What is the estimated CL (in years) for portable/flexible cables?

\begin{tabular}{|c|c|c|c|c|}
\hline & \multicolumn{2}{|c|}{$1^{\text {st }}$ response } & \multicolumn{2}{|c|}{$2^{\text {nd }}$ response } \\
\hline Minimum & \multicolumn{2}{|c|}{75} & \multicolumn{2}{|c|}{80} \\
\hline Median & \multicolumn{2}{|c|}{95} & \multicolumn{2}{|c|}{95} \\
\hline Maximum & \multicolumn{2}{|c|}{150} & \multicolumn{2}{|c|}{120} \\
\hline & Median & Low & Med & High \\
\hline Final value(s) & 95 & 2 & 1 & 3 \\
\hline
\end{tabular}

\subsubsection{Switchboards}

What is the $\mathrm{CL}$ (in years) for switchboards?

\begin{tabular}{|c|c|c|c|c|}
\hline & \multicolumn{2}{|c|}{$1^{\text {st }}$ response } & \multicolumn{2}{|c|}{$2^{\text {nd }}$ response } \\
\hline Minimum & \multicolumn{2}{|c|}{50} & \multicolumn{2}{|c|}{75} \\
\hline Median & \multicolumn{2}{|c|}{75} & \multicolumn{2}{|c|}{83} \\
\hline Maximum & \multicolumn{2}{|c|}{90} & \multicolumn{2}{|c|}{90} \\
\hline & Median & Low & Med & High \\
\hline Final value(s) & 83 & 0 & 6 & 0 \\
\hline
\end{tabular}




\subsubsection{Motor control centers}

What is the CL (in years) for motor control centers?

\begin{tabular}{|l|c|c|c|c|}
\hline & \multicolumn{2}{|c|}{ 1st response $^{2}$ 2 $^{\text {nd }}$ response } \\
\hline Minimum & \multicolumn{2}{|c|}{50} & \multicolumn{2}{c|}{75} \\
\hline Median & \multicolumn{2}{|c|}{75} & \multicolumn{2}{c|}{83} \\
\hline Maximum & \multicolumn{2}{|c|}{90} & \multicolumn{2}{c|}{90} \\
\hline & Median & Low & Med & High \\
\hline Final value(s) & 83 & 0 & 6 & 0 \\
\hline
\end{tabular}

\subsubsection{Motor starters - full voltage}

What is the $\mathrm{CL}$ (in years) for full voltage motor starters?

\begin{tabular}{|l|c|c|}
\hline & 1 $^{\text {st }}$ response & 2 $^{\text {nd }}$ response \\
\hline Minimum & 30 & 60 \\
\hline Median & 60 & 63 \\
\hline Maximum & 80 & 80 \\
\hline
\end{tabular}

\begin{tabular}{|l|c|c|c|c|}
\hline & Median & Low & Med & High \\
\hline Final value(s) & 63 & 0 & 1 & 5 \\
\hline
\end{tabular}

\subsubsection{Motor starters - reduced/variable}

What is the CL (in years) for reduced/variable motor starters?

\begin{tabular}{|l|c|c|}
\hline & 1 $^{\text {st }}$ response & 2 $^{\text {nd }}$ response \\
\hline Minimum & 15 & 50 \\
\hline Median & 50 & 50 \\
\hline Maximum & 60 & 60 \\
\hline
\end{tabular}

\begin{tabular}{|l|c|c|c|c|}
\hline & Median & Low & Med & High \\
\hline Final value(s) & 50 & 0 & 5 & 1 \\
\hline
\end{tabular}




\subsubsection{Motor starters - VFD}

What is the CL (in years) for VFD motor starters?

\begin{tabular}{|c|c|c|c|c|}
\hline & \multicolumn{2}{|c|}{$1^{\text {st }}$ response } & \multicolumn{2}{|c|}{$2^{\text {nd }}$ response } \\
\hline Minimum & \multicolumn{2}{|c|}{15} & \multicolumn{2}{|c|}{25} \\
\hline Median & \multicolumn{2}{|c|}{25} & \multicolumn{2}{|c|}{35} \\
\hline Maximum & \multicolumn{2}{|c|}{40} & \multicolumn{2}{|c|}{40} \\
\hline & Median & Low & Med & High \\
\hline Final value(s) & 35 & 4 & 2 & 0 \\
\hline
\end{tabular}

\subsubsection{PLC systems}

What is the CL (in years) for PLC systems?

\begin{tabular}{|l|c|c|}
\hline & 1 & 2 $^{\text {nd }}$ response \\
\hline Minimum & 20 & 25 \\
\hline Median & 25 & 25 \\
\hline Maximum & 40 & 40 \\
\hline
\end{tabular}

\begin{tabular}{|l|c|c|c|c|}
\hline & Median & Low & Med & High \\
\hline Final value(s) & 25 & 0 & 3 & 3 \\
\hline
\end{tabular}

\subsubsection{Selsyn motor}

What is the $\mathrm{CL}$ (in years) for a Selsyn motor?

\begin{tabular}{|l|c|c|}
\hline & 1 $^{\text {st }}$ response & 2 $^{\text {nd }}$ response \\
\hline Minimum & 30 & 30 \\
\hline Median & 55 & $\mathbf{4 3}$ \\
\hline Maximum & 100 & 80 \\
\hline
\end{tabular}

\begin{tabular}{|l|c|c|c|c|}
\hline & Median & Low & Med & High \\
\hline Final value(s) & 43 & 0 & 6 & 0 \\
\hline
\end{tabular}


3.6.4.19 Traveling nut limit switch

What is the CL (in years) for a traveling nut limit switch?

\begin{tabular}{|c|c|c|c|c|}
\hline & \multicolumn{2}{|c|}{$1^{\text {st }}$ response } & \multicolumn{2}{|c|}{$2^{\text {nd }}$ response } \\
\hline Minimum & \multicolumn{2}{|c|}{30} & \multicolumn{2}{|c|}{50} \\
\hline Median & \multicolumn{2}{|c|}{73} & \multicolumn{2}{|c|}{65} \\
\hline Maximum & \multicolumn{2}{|c|}{105} & \multicolumn{2}{|c|}{100} \\
\hline & Median & Low & Med & High \\
\hline Final value(s) & 65 & 0 & 6 & 0 \\
\hline
\end{tabular}

3.6.4.20 Electric motors (new and rebuilt)

What is the CL (in years) for new or rebuilt electric motors?

\begin{tabular}{|c|c|c|c|c|}
\hline & \multicolumn{2}{|c|}{$1^{\text {st }}$ response } & \multicolumn{2}{|c|}{$2^{\text {nd }}$ response } \\
\hline Minimum & \multicolumn{2}{|c|}{50} & \multicolumn{2}{|c|}{60} \\
\hline Median & \multicolumn{2}{|c|}{65} & \multicolumn{2}{|c|}{68} \\
\hline Maximum & \multicolumn{2}{|c|}{85} & \multicolumn{2}{|c|}{80} \\
\hline & Median & Low & Med & High \\
\hline Final value(s) & 68 & 0 & 6 & 0 \\
\hline
\end{tabular}

3.6.4.21 Standby generator set

What is the CL (in years) for a standby generator set?

\begin{tabular}{|c|c|c|}
\hline & $1^{\text {st }}$ response & $2^{\text {nd }}$ response \\
\hline Minimum & 25 & 40 \\
\hline Median & 50 & 50 \\
\hline Maximum & 75 & 70 \\
\hline
\end{tabular}

\begin{tabular}{|l|c|c|c|c|}
\hline & Median & Low & Med & High \\
\hline Final value(s) & 50 & 0 & 2 & 4 \\
\hline
\end{tabular}


3.6.4.22 Direct current (DC) rectifier (brakes)

What is the $\mathrm{CL}$ (in years) for a standby generator set?

\begin{tabular}{|l|l|l|l|l|}
\hline & \multicolumn{2}{|c|}{ 1 $^{\text {st }}$ response } & \multicolumn{2}{c|}{ 2 $^{\text {nd }}$ response } \\
\hline Minimum & \multicolumn{2}{|c|}{10} & \multicolumn{2}{c|}{25} \\
\hline Median & \multicolumn{2}{|c|}{35} & \multicolumn{2}{|c|}{35} \\
\hline Maximum & \multicolumn{2}{|c|}{50} & Med & High \\
\hline & Median & Low & 1 & 4 \\
\hline Final value(s) & 35 & 1 & & \multicolumn{2}{|c|}{45} \\
\hline
\end{tabular}




\section{Conclusions}

The CL data collected as part of this study will be useful in evaluation of the reliability of ME systems at USACE navigation projects. The results documented in this report are estimates of the characteristic lives of the typical navigation project across the country. The results for the CL presented here may be modified if more detailed information on performance is known for a site specific project. This data collected from this elicitation can be used in Weibull models to predict the reliability of ME components. Weibull models are recommended for use with fault tree methods for analysis of ME system reliability (Patev, Putcha, and Foltz 2005).

Tables 9 and 10 summarize all the median elicitation values for the mechanical system and electrical system at navigation projects. Reference is made to Appendices A and B for the actual response values, and the elicitation and confidence results for each component.

Table 9. CL for navigation mechanical components.

\begin{tabular}{|l|l|c|}
\hline \multicolumn{2}{|l|}{ Component } & Life (in years) \\
\hline Characteristic shafts pins gear reducers \\
\hline Bearings & Rolling element & 40 \\
\cline { 2 - 3 } & Sleeve (self lubricated) & 25 \\
\cline { 2 - 3 } Couplings & Bronze sleeve & 40 \\
\hline \multirow{5}{*}{} & Flexible & 35 \\
\cline { 2 - 3 } & Rigid & 50 \\
\cline { 2 - 3 } & & 35 \\
\cline { 2 - 3 } & Worm & 25 \\
\cline { 2 - 3 } & Parallel & 40 \\
\cline { 2 - 3 } & Right angle & 38 \\
\cline { 2 - 3 } & Spur & 50 \\
\cline { 2 - 3 } & Helical & 38 \\
\hline \multirow{5}{*}{ Open Gearing } & Bevel & 40 \\
\cline { 2 - 3 } & Rack & 50 \\
\cline { 2 - 3 } & Electromechanical & 45 \\
\cline { 2 - 3 } & Slip & 30 \\
\cline { 2 - 3 } & Spiral Plate & 5 \\
\cline { 2 - 3 } & Single Sheave(s) & \\
\hline
\end{tabular}




\begin{tabular}{|c|c|c|}
\hline \multicolumn{2}{|l|}{ Component } & \multirow{2}{*}{\begin{tabular}{|c|} 
Life (in years) \\
28
\end{tabular}} \\
\hline Brake Clutch Wire & Single Drum & \\
\hline & & 50 \\
\hline & & 33 \\
\hline \multirow{8}{*}{$\begin{array}{l}\text { Wire rope drums } \\
\text { Wire rope }\end{array}$} & Roller & 40 \\
\hline & & 60 \\
\hline & Sector arms & 73 \\
\hline & Strut arms - buffered & 35 \\
\hline & Strut arms - rigid & 40 \\
\hline & Support roller & 43 \\
\hline & Rack support beam & 60 \\
\hline & Bellcranks & 78 \\
\hline \multirow[t]{5}{*}{ Valves } & Crosshead/Guide & 73 \\
\hline & Strut & 43 \\
\hline & Worm & 25 \\
\hline & Parallel & 40 \\
\hline & Right angle & 38 \\
\hline \multicolumn{3}{|c|}{ Hydraulic Drive Systems } \\
\hline Hydraulic cylinder & & 60 \\
\hline \multicolumn{3}{|l|}{ Control Valves } \\
\hline Check & & 45 \\
\hline Relief & & 40 \\
\hline \multicolumn{3}{|l|}{ Directional } \\
\hline Manual & & 60 \\
\hline Solenoid & & 40 \\
\hline $\begin{array}{l}\text { Proportional/Throttl } \\
\text { e }\end{array}$ & & 40 \\
\hline \multicolumn{3}{|l|}{ Pumps } \\
\hline Fixed & & 50 \\
\hline Variable & & 30 \\
\hline \multirow[t]{2}{*}{ Hydraulic Motors } & Fixed & 50 \\
\hline & Variable & 30 \\
\hline Piping & & 40 \\
\hline Selsyn motor & & 43 \\
\hline $\begin{array}{l}\text { Traveling nut limit } \\
\text { switch }\end{array}$ & & 65 \\
\hline \multicolumn{3}{|c|}{ ElectroMechanical Drives } \\
\hline $\begin{array}{l}\text { Electric Motors (new } \\
\text { and rebuilt) }\end{array}$ & & 68 \\
\hline $\begin{array}{l}\text { Standby generator } \\
\text { sets }\end{array}$ & & 50 \\
\hline DC Rectifier (brakes) & & 35 \\
\hline Tow Haulage & Hydraulic & 30 \\
\hline
\end{tabular}




\begin{tabular}{|l|l|c|}
\hline \multicolumn{2}{|l|}{ Component } & Life (in years) \\
\hline & Mechanical & 48 \\
\cline { 2 - 3 } & & \\
\hline \multirow{2}{*}{ Emptying Filling } & Mutterfly & 50 \\
\cline { 2 - 3 } & Vertical Lift & 50 \\
\hline \multicolumn{2}{|c|}{ Gate/Filling Emptying Valves } \\
\hline Wheel assembly & & 40 \\
\hline Pintles/Bushings & & 30 \\
\hline $\begin{array}{l}\text { Gudgeon } \\
\text { pin/bushings }\end{array}$ & & 43 \\
\hline $\begin{array}{l}\text { Trunnion } \\
\text { pin/bushings }\end{array}$ & & 38 \\
\hline Strut spindle pin & & 25 \\
\hline
\end{tabular}

Table 10. CL for navigation electrical components characteristic power life (in years).

\begin{tabular}{|l|l|c|}
\hline Component & Life (in years) \\
\hline Service transformer & & 4 \\
\hline Transfer switches & & 55 \\
\hline & Automatic & \\
\hline & Manual & 30 \\
\hline Switchgear & & 65 \\
\hline Circuit breakers & & 78 \\
\hline Power Panelboard & & 63 \\
\hline Cables & & 78 \\
\hline & Buried Submerged & \\
\hline & Duct/Cable Tray & 60 \\
\hline & Portable/Flexible & 80 \\
\hline Bus duct & & 28 \\
\hline Switchboards & & 95 \\
\hline Motor control & & 83 \\
\hline centers & & 83 \\
\hline Motor control & & \\
\hline Motor Starters & & 63 \\
\hline & Full Voltage & 50 \\
\hline & Reduced/Variable & 25 \\
\hline & VFD & \\
\hline PLC systems & & \\
\hline Service transformer & & \\
\hline & & \\
\hline
\end{tabular}




\section{Acronyms, Abbreviations, and Technical Terms}

\section{Acronyms and Abbreviations}

$\begin{array}{ll}\text { Term } & \text { Definition } \\ \text { CDF } & \text { Cumulative Distribution Function } \\ \text { CERL } & \text { Construction Engineering Research Laboratory } \\ \text { CL } & \text { Characteristic Life } \\ \text { DC } & \text { Direct Current } \\ \text { DoD } & \text { US Department of Defense } \\ \text { EC } & \text { Engineer Circular } \\ \text { EM } & \text { ElectroMechanical } \\ \text { EOE } & \text { Expert-Opinion Elicitation (EOE) } \\ \text { ERDC } & \text { Engineer Research and Development Center } \\ \text { GLSLS } & \text { Great Lakes and St. Lawrence Seaway System Study } \\ \text { HQUSACE } & \text { Headquarters, US Army Corps of Engineers } \\ \text { ITL } & \text { Information Technology Laboratory } \\ \text { LRD } & \text { Great Lakes and Ohio River Division } \\ \text { ME } & \text { Mechanical and Electrical } \\ \text { MTTF } & \text { Mean Time To Failure } \\ \text { OMB } & \text { Office of Management and Budget } \\ \text { ORMSS } & \text { Ohio River Main Stem Study } \\ \text { PLC } & \text { Programmable Logic Controller } \\ \text { TF } & \text { Technical Facilitator } \\ \text { TI } & \text { Technical Integrator } \\ \text { TIF } & \text { Technical Integrator and Facilitator } \\ \text { TR } & \text { Technical Report } \\ \text { US } & \text { United States } \\ \text { USACE } & \text { US Army Corps of Engineers } \\ \text { UV } & \text { Ultraviolet } \\ \text { VFD } & \text { Variable Frequency Drive } \\ & \end{array}$




\section{Technical Terms}

\author{
Term \\ Average \\ Evaluators \\ Expert \\ Expert elicitation \\ Expert-Opinion \\ Elicitation (EOE) \\ process \\ Leader of EOE process \\ Mean \\ Median value \\ Observers \\ Peer reviewers \\ p-percentile value \\ Probability \\ Proponents \\ Resource experts \\ Technical Facilitator \\ (TF) \\ Technical integrator \\ (TI)

\section{Definition} \\ A central tendency measure that is computed as the sum of values \\ divided by their count. \\ Evaluators consider available data, become familiar with the views of \\ proponents and other evaluators, question the technical bases of \\ data, and challenge the views of proponents. \\ A person with related or unique experience to an issue or question of \\ interest for the process. \\ A formal process of obtaining information or answers to specific \\ questions about certain issues. \\ A formal, heuristic process of gathering informing and data or \\ answering questions on issues or problems of concern. \\ An entity having managerial and technical responsibility for organizing \\ and executing the project, overseeing all participants, and \\ intellectually owning the results. \\ Refer to average. \\ The point that divides the data into two equal parts, i.e., $50 \%$ of the \\ data are above it and 50\% are below it. \\ Observers can contribute to the discussion, but cannot provide expert \\ opinion that enters in the aggregated opinion of the experts. \\ Experts that can provide an unbiased assessment and critical review \\ of an Expert-Opinion Elicitation process, its technical issues, and \\ results. \\ The value of the parameter such that $\mathrm{p} \%$ of the data is less or equal \\ to this value. \\ Measured by dividing the number of occurrences by the total number \\ of repetitions. \\ Proponents are experts who advocate a particular hypothesis or \\ technical position. In science, a proponent evaluates experimental \\ data and professionally offers a hypothesis that would be challenges \\ by the proponent's peers until proven correct or wrong. \\ Resource experts are technical experts with detailed and deep \\ knowledge of particular data, issue aspects, particular \\ methodologies, or use of evaluators. \\ An entity responsible for structuring and facilitating the discussions \\ and interactions of experts in the EOE process; staging effective \\ interactions among experts; ensuring equity in presented views; \\ eliciting formal evaluations from each expert; and creating conditions \\ for direct, non-controversial integration of expert opinions. \\ An entity responsible for developing the composite representation of \\ issues based on informed members and/or sources of related \\ technical communities and experts; explaining and defending \\ composite results to experts and outside experts, peer reviewers, \\ regulators, and policy makers; and obtaining feedback and revising \\ composite results.
}


Term

Technical Integrator and Facilitator (TIF)

Uncertainty

Failure event

Failure rate

Variance

\section{Definition}

An entity responsible for both functions of TI and TF.

The doubt (or the lack of sureness) about the outcomes (in number or magnitude) of a system.

Any event that will have an adverse impact on lock performance is defined a failure event.

The probability of failure per unit time or a unit of operation, such as cycle, revolution, rotation, startup, etc.

Measure of dispersion. 


\section{References}

Abernethy, R. B. 2009. The New Weibull Handbook. North Palm Beach, FL: Robert B. Abernethy (Publisher and Distributor).

Ayyub, B. M., A. N. Blair, and R. C. Patev. December 2002. Expert-opinion elicitation for the risk analysis of design-improvement alternatives to the Lindy C. Boggs Lock and Dam. ERDC/ ITL TR-02-2. Vicksburg, MS: Engineering Research and Development Center, Information Technology Laboratory (ERDC-ITL).

Headquarters, US Army Corps of Engineers (HQUSACE). 1 February 2011. Risk and reliability for major rehabilitation studies. Engineer Circular (EC) 1110-2-6062. Washington, DC: HQUSACE, http://publications.usace.army.mil/publications/eng-circulars/EC_1110-2-6062.pdf

Patev, R. C., C. S. Putcha, and S. D. Foltz. May 2005. Methodology for risk analysis of dam gates and associated operating equipment using fault tree analysis. ERDC/ITL TR-05-3. Vicksburg, MS: ERDC-ITL.

US Department of Defense (DoD), 18 November 1981. Reliability Modeling and Prediction. Mil-Std-756B. Washington, DC: DoD, http://www.responseboatproject.net/rbmcontract/sections/Section_J/References/MIL-STD756B.pdf 


\section{Appendix A: Expert Elicitation Spreadsheets - Mechanical System Components}


Table A1. Mechanical system - bearings.

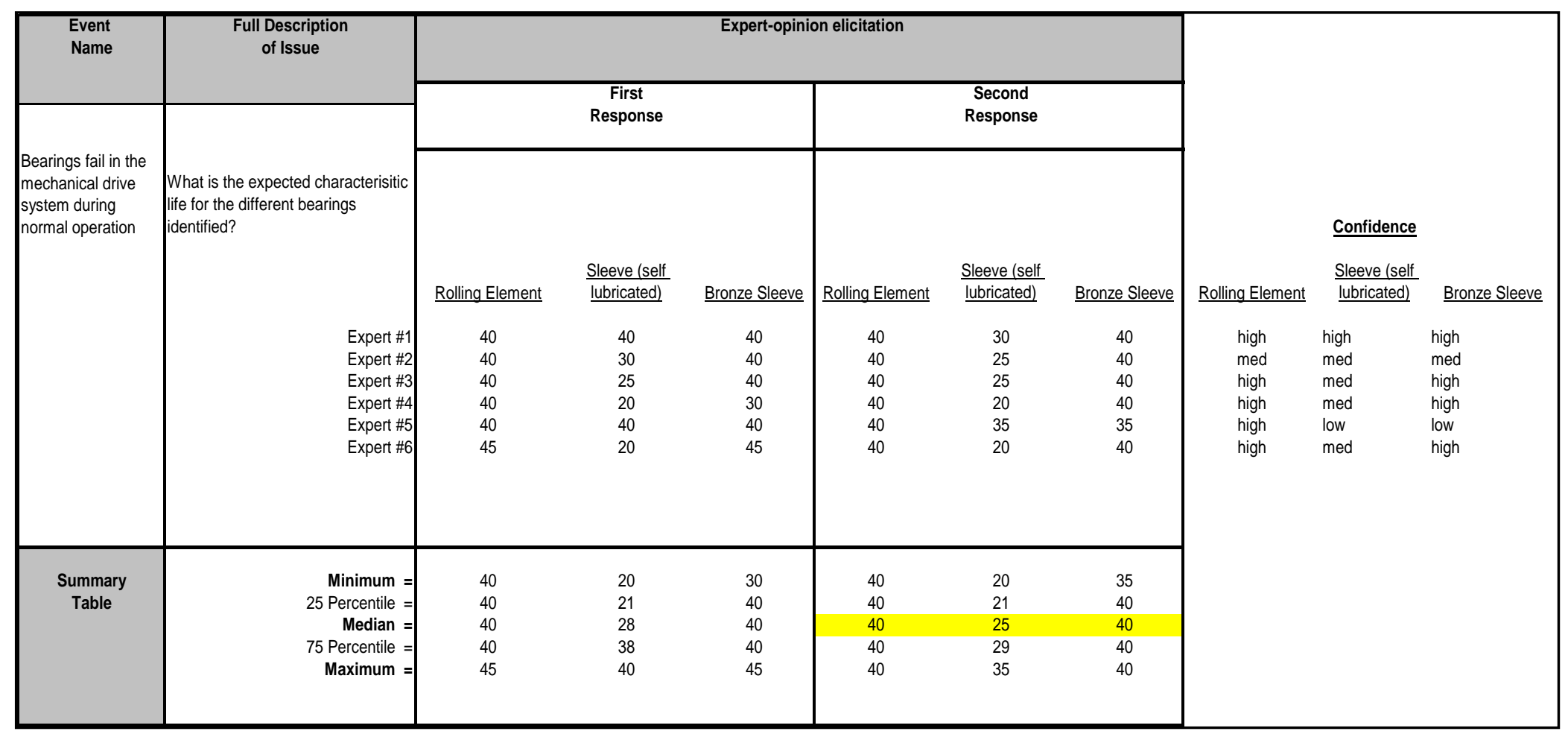


Table A1. (Cont'd).

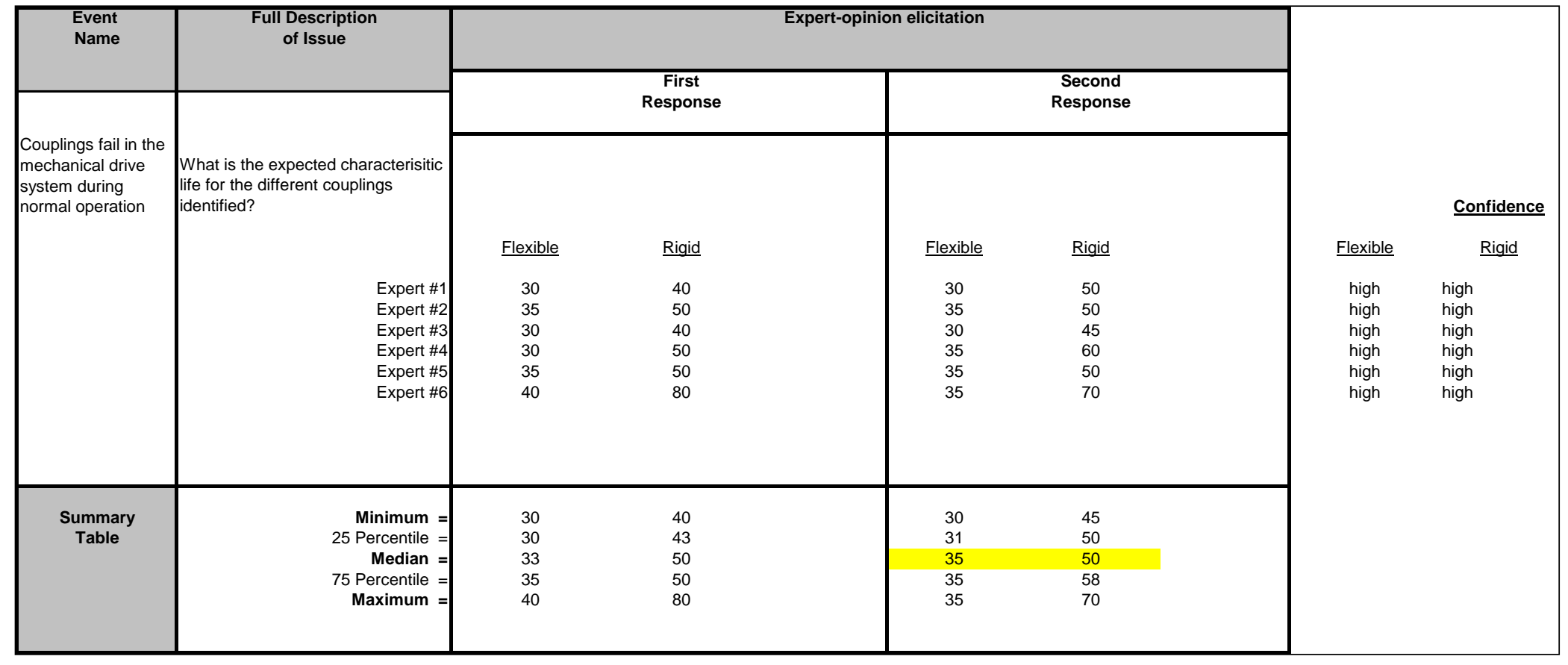


Table A2. Mechanical system - shafts

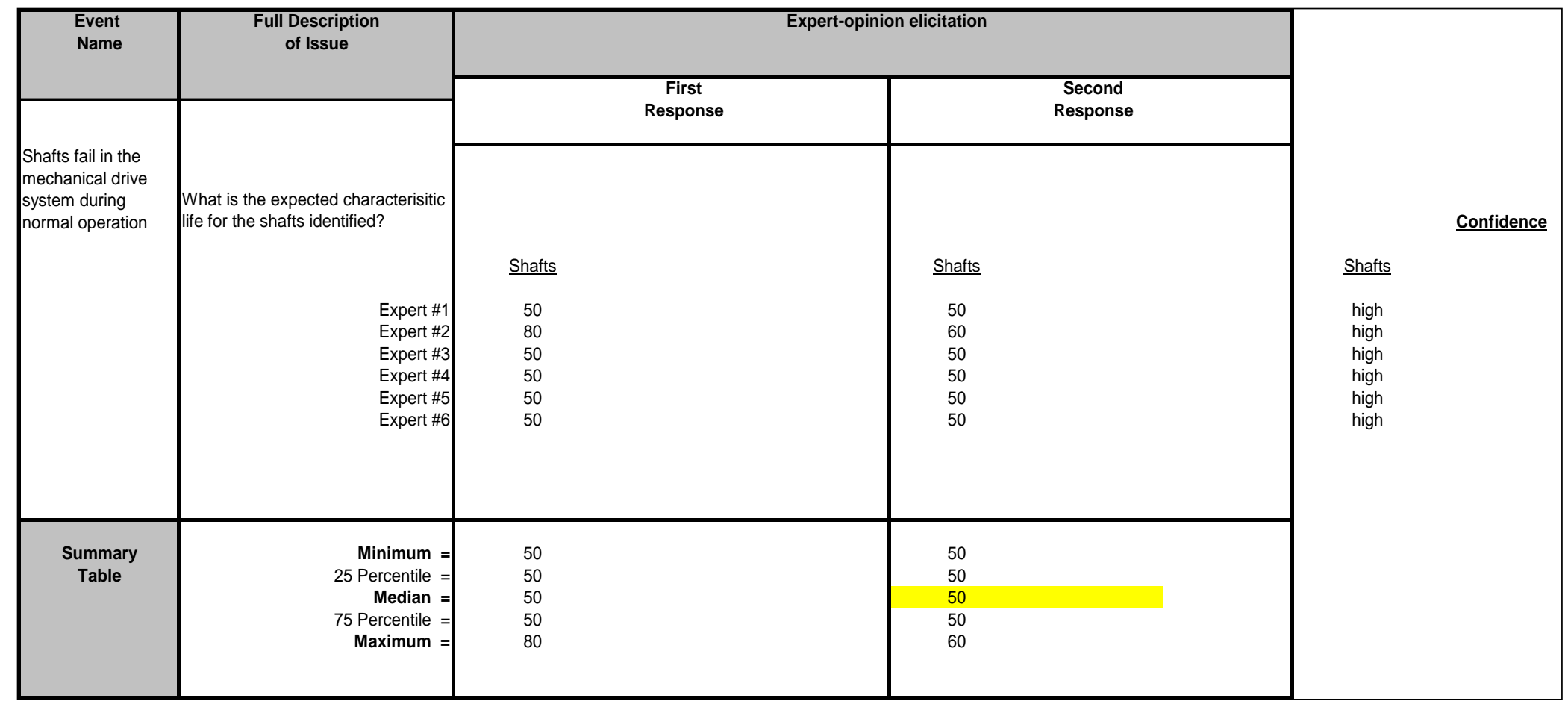


Table A3. Mechanical system - pins.

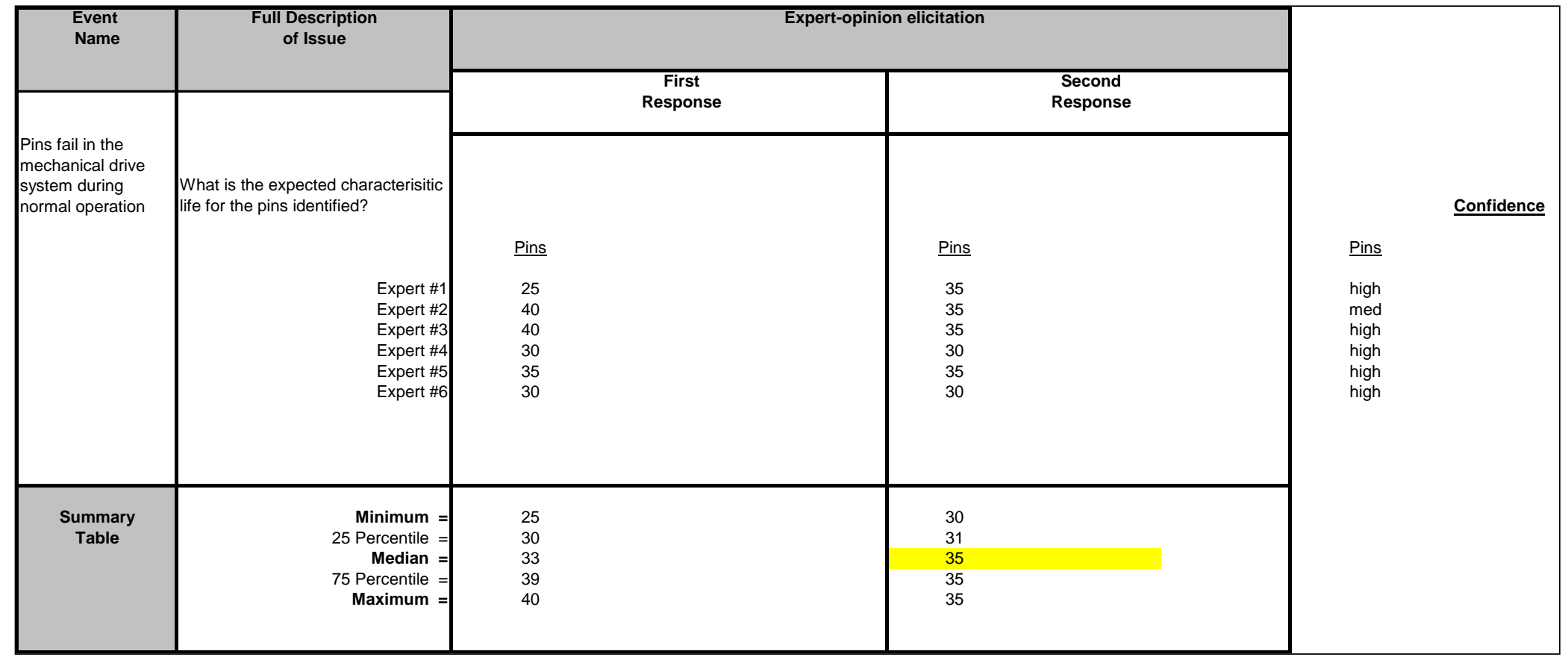


Table A4. Mechanical system - gear reducers.

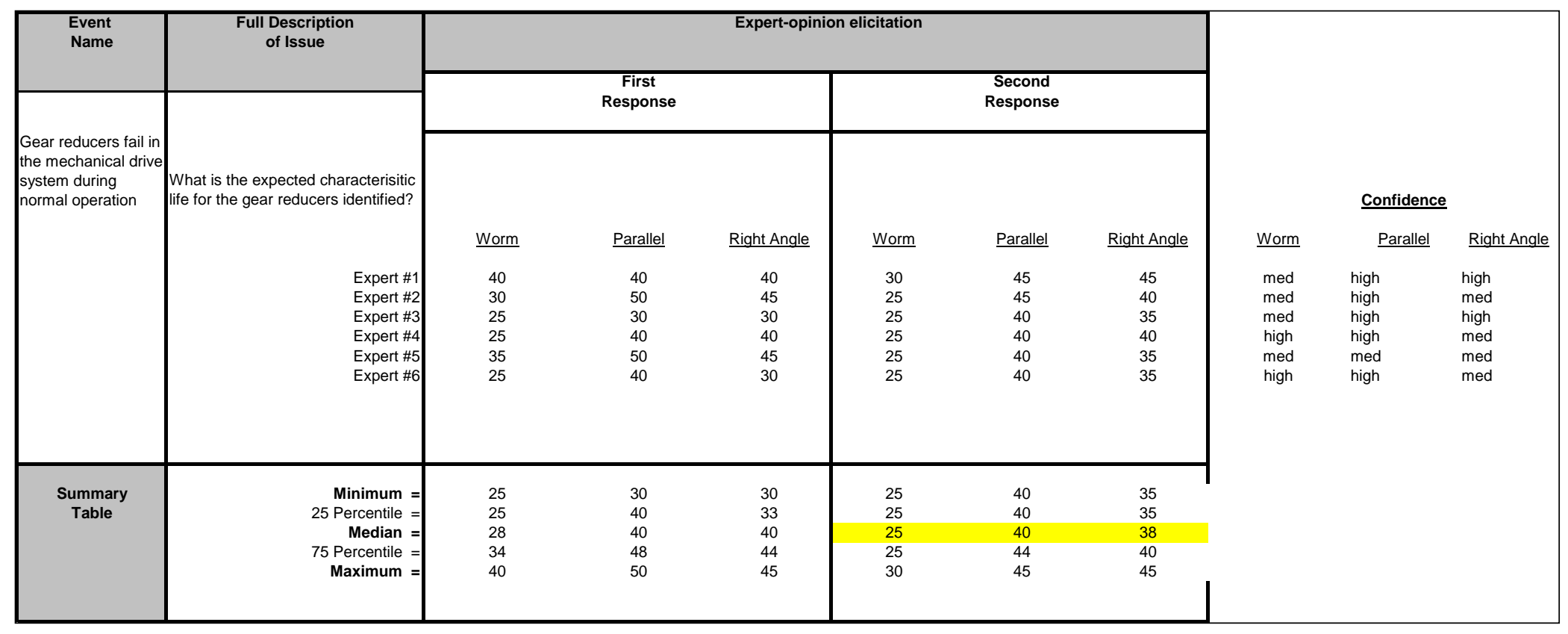


Table A5. Mechanical system - open gearing.

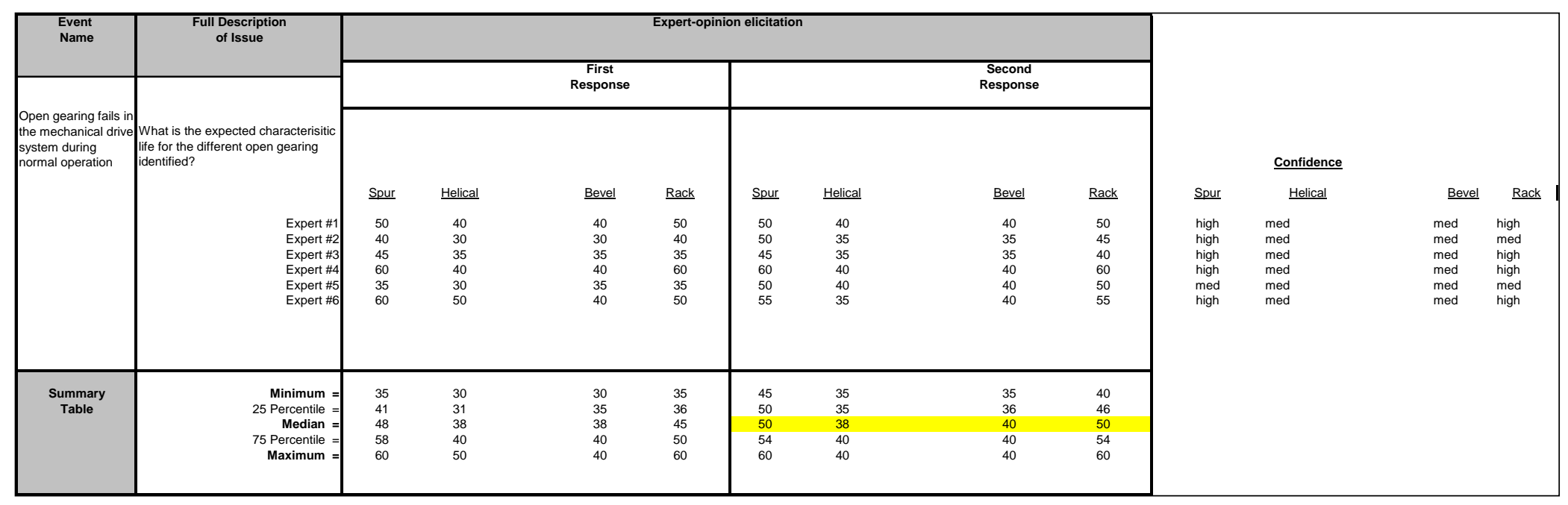


Table A6. Mechanical system - electromechanical brakes,

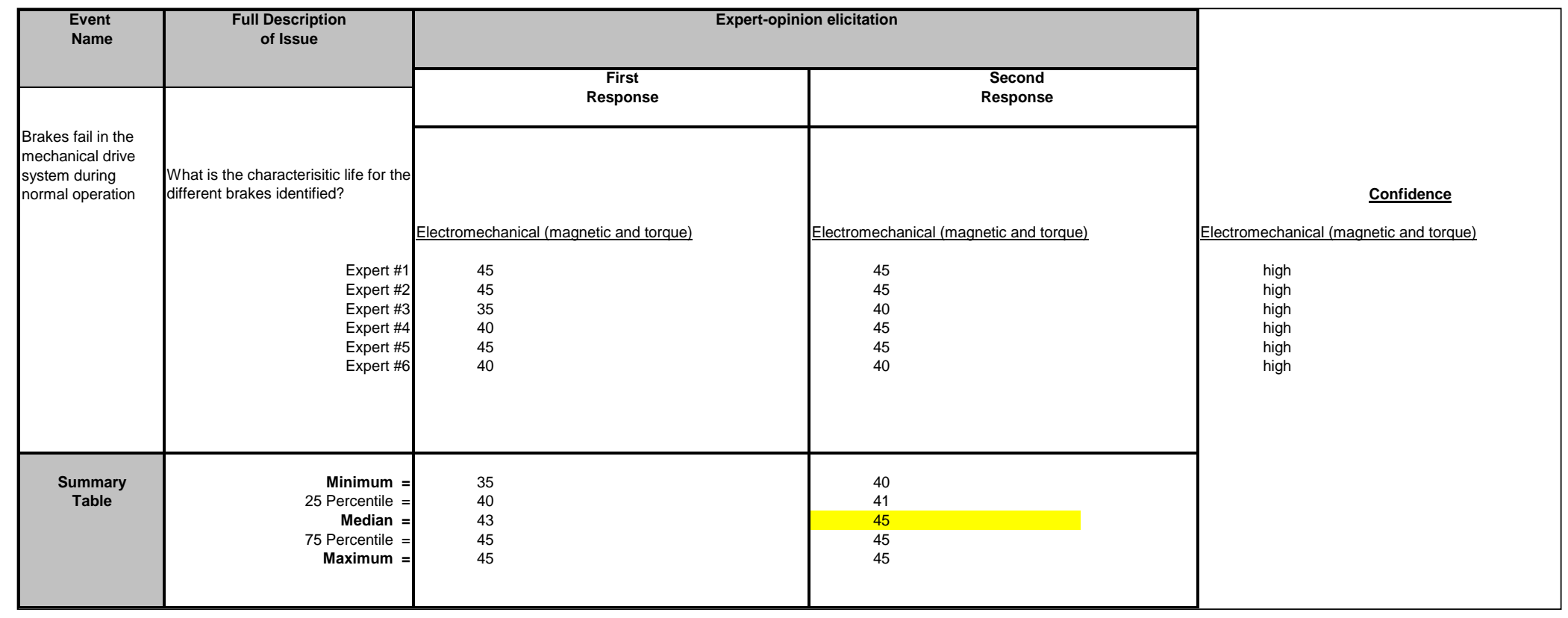


Table A7. Mechanical system - slip brakes.

\begin{tabular}{|c|c|c|c|c|c|}
\hline $\begin{array}{l}\text { Event } \\
\text { Name }\end{array}$ & Full Description & & citation & \multirow{5}{*}{$\begin{array}{l}\text { Slip } \\
\text { med } \\
\text { med } \\
\text { med } \\
\text { med } \\
\text { low } \\
\text { low }\end{array}$} & \multirow{5}{*}{ Confidence } \\
\hline \multirow{3}{*}{$\begin{array}{l}\text { Brakes fail in the } \\
\text { mechanical drive } \\
\text { system during } \\
\text { normal operation }\end{array}$} & \multirow{3}{*}{$\begin{array}{l}\text { What is the characterisitic life for the } \\
\text { different brakes identified? }\end{array}$} & $\begin{array}{cc}\text { First } \\
\text { Response }\end{array}$ & $\begin{array}{l}\text { Second } \\
\text { Response }\end{array}$ & & \\
\hline & & & & & \\
\hline & & $\begin{array}{l}\text { Slip } \\
30 \\
30 \\
35 \\
30 \\
35 \\
20\end{array}$ & $\begin{array}{l}\text { Slip } \\
30 \\
30 \\
35 \\
30 \\
35 \\
20\end{array}$ & & \\
\hline $\begin{array}{l}\text { Summary } \\
\text { Table }\end{array}$ & $\begin{array}{r}\text { Minimum }= \\
25 \text { Percentile }= \\
\text { Median }= \\
75 \text { Percentile }= \\
\text { Maximum }=\end{array}$ & $\begin{array}{l}20 \\
30 \\
30 \\
34 \\
35\end{array}$ & $\begin{array}{l}20 \\
30 \\
30 \\
34 \\
35\end{array}$ & & \\
\hline
\end{tabular}


Table A8. Mechanical system - wire ropes.

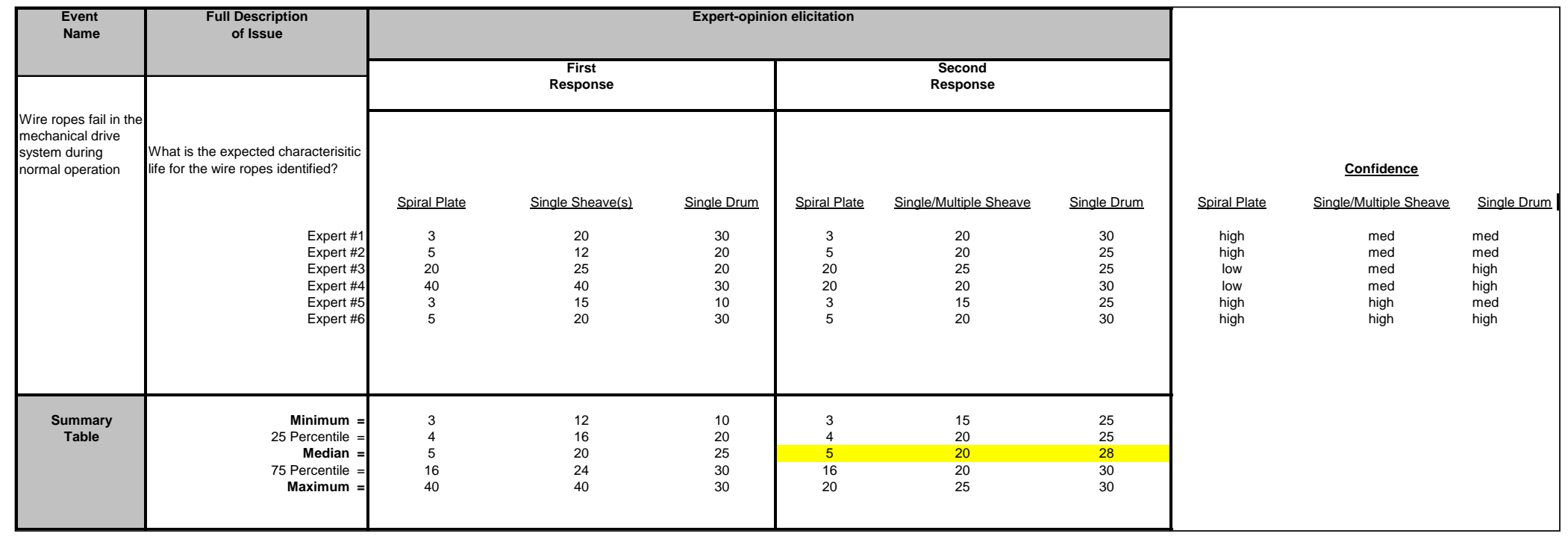


Table A8. (Cont'd).

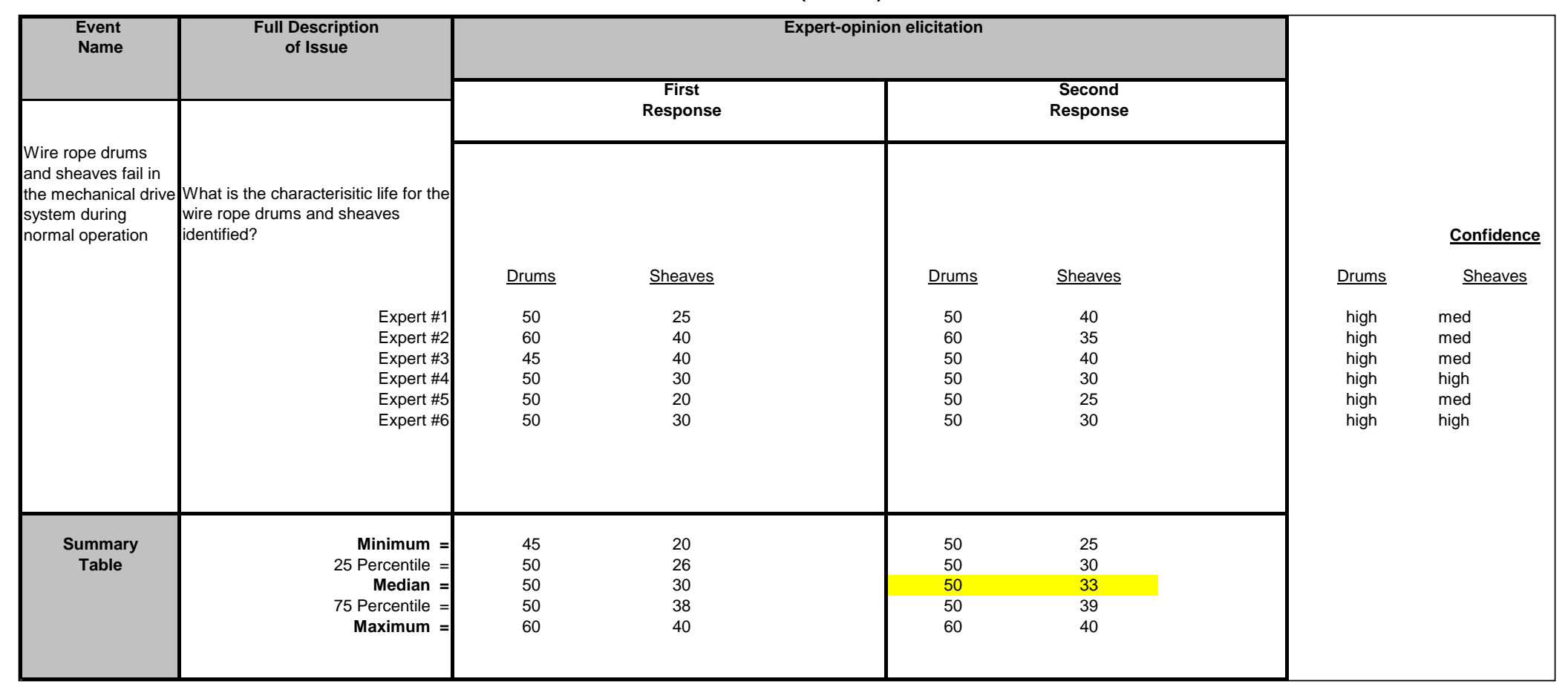


Table A9. Mechanical system - chains.

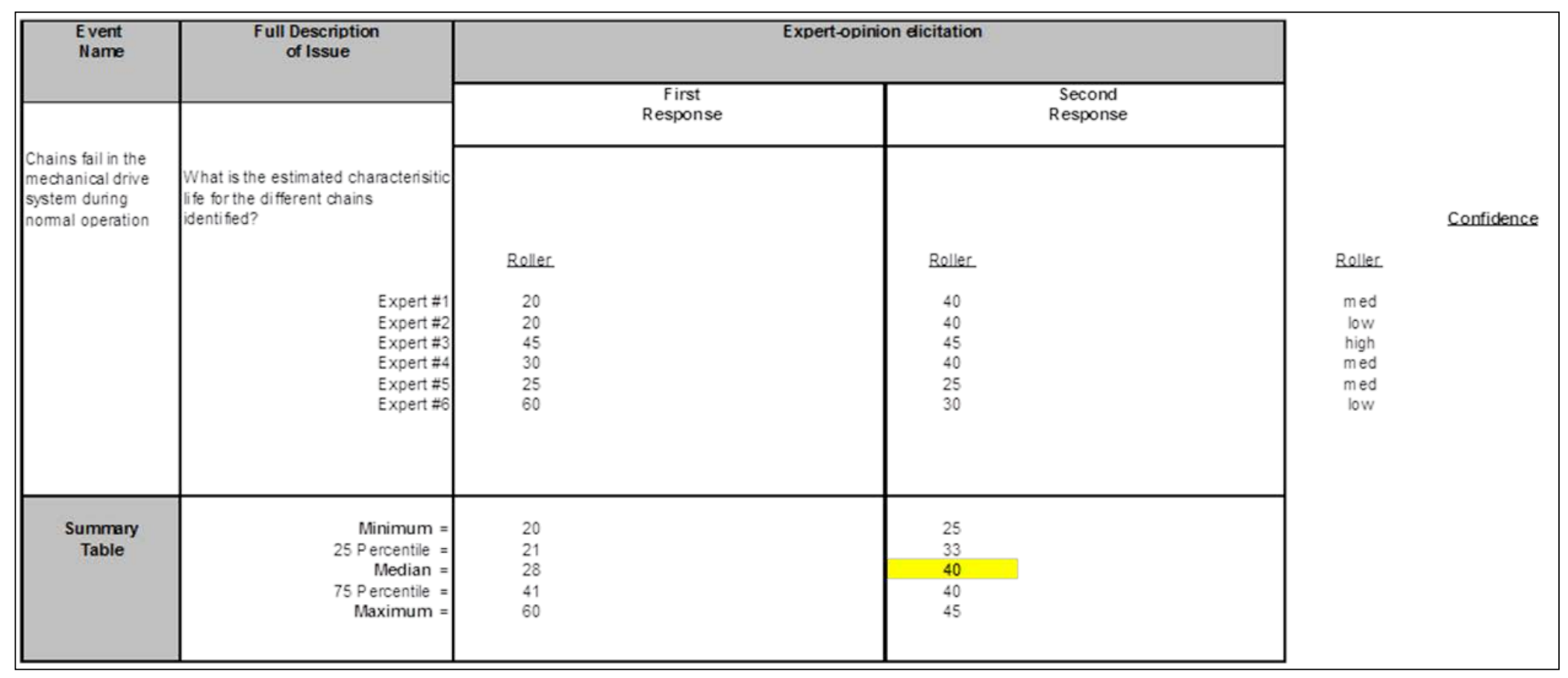


Table A10. Mechanical system - chain sprocket.

\begin{tabular}{|c|c|c|c|c|}
\hline \multirow{3}{*}{$\begin{array}{l}\text { Chain sprocket fails } \\
\text { in the mechanical } \\
\text { drive system during } \\
\text { nomal operation }\end{array}$} & \multirow{2}{*}{$\begin{array}{l}\text { Full Description } \\
\text { of Issue }\end{array}$} & \multicolumn{2}{|c|}{ Expert-opinion elicitation } & \multirow{4}{*}{$\begin{array}{c}\text { Chain Sprodet } \\
\text { med } \\
\text { med } \\
\text { high } \\
\text { med } \\
\text { low } \\
\text { low }\end{array}$} \\
\hline & & $\begin{array}{c}\text { First } \\
\text { Response }\end{array}$ & $\begin{array}{c}\text { Second } \\
\text { Response }\end{array}$ & \\
\hline & $\begin{array}{l}\text { What is the estimated characterisitic } \\
\text { life for the different chain sprodket } \\
\text { identifed? } \\
\qquad \begin{array}{l}\text { Expert \#1 } \\
\text { Expert \#2 } \\
\text { Expert \#3 } \\
\text { Expert \#4 } \\
\text { Expert \#5 } \\
\text { Expert \#6 }\end{array}\end{array}$ & $\begin{array}{c}\text { Chain Sprocket } \\
\text { 40 } \\
45 \\
60 \\
40 \\
50 \\
60\end{array}$ & $\begin{array}{c}\text { Chain Sprodet } \\
50 \\
60 \\
60 \\
60 \\
50 \\
60\end{array}$ & \\
\hline $\begin{array}{l}\text { Summary } \\
\text { Table }\end{array}$ & $\begin{aligned} \text { Minimum } & = \\
25 \text { Percentile } & = \\
\text { Median } & = \\
75 \text { Percentile } & = \\
\text { Maximum } & =\end{aligned}$ & $\begin{array}{l}40 \\
41 \\
48 \\
58 \\
60\end{array}$ & $\begin{array}{l}50 \\
53 \\
60 \\
60 \\
60\end{array}$ & \\
\hline
\end{tabular}


Table A11. Mechanical system - strut arms.




Table A12. Mechanical system - support roller.

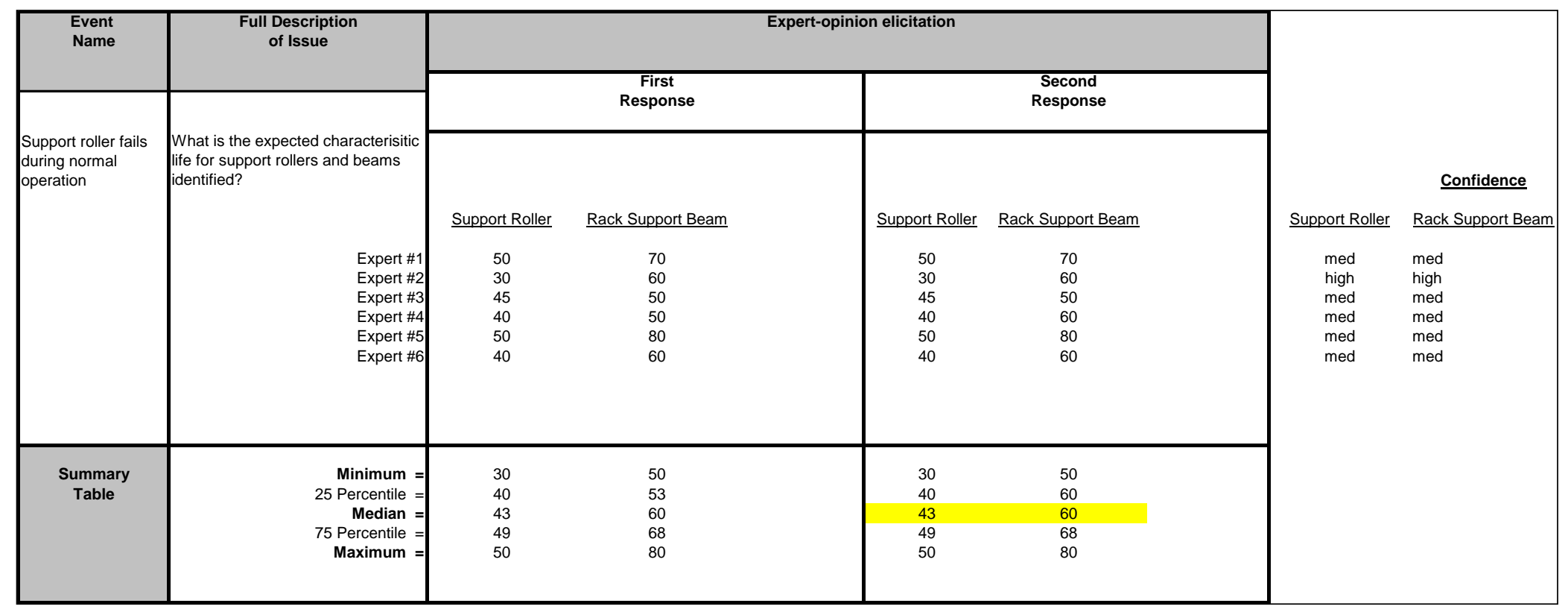


Table A13. Mechanical system - valves.

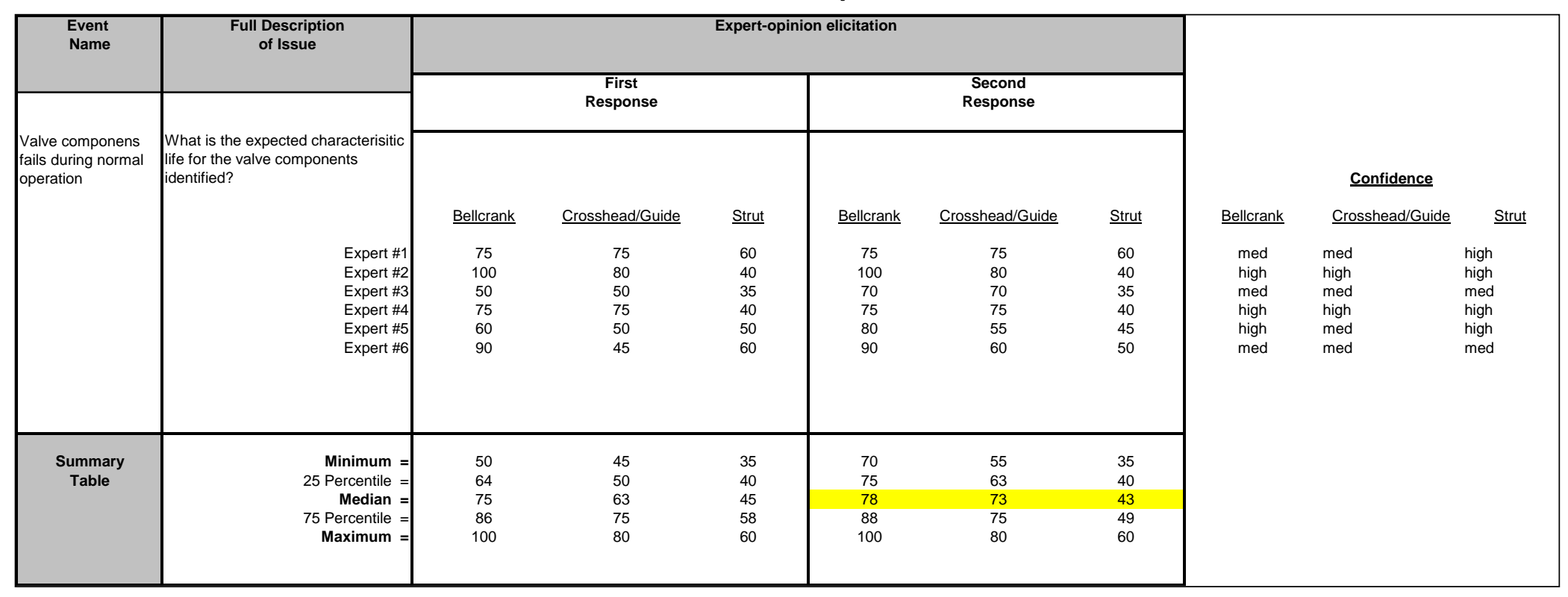


Table A14. Mechanical system - hydraulic cylinder.




Table A15. Mechanical system - control valves.

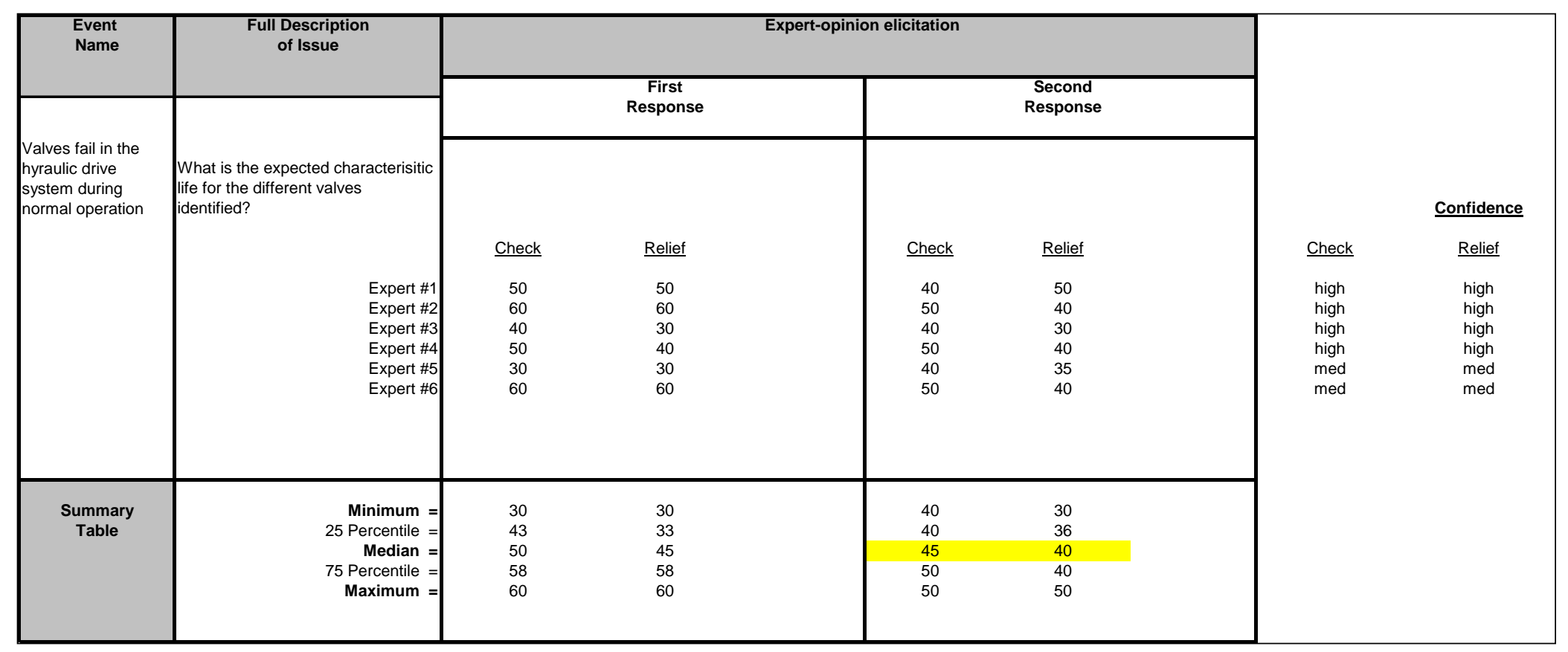


Table A16. Mechanical system - pumps.

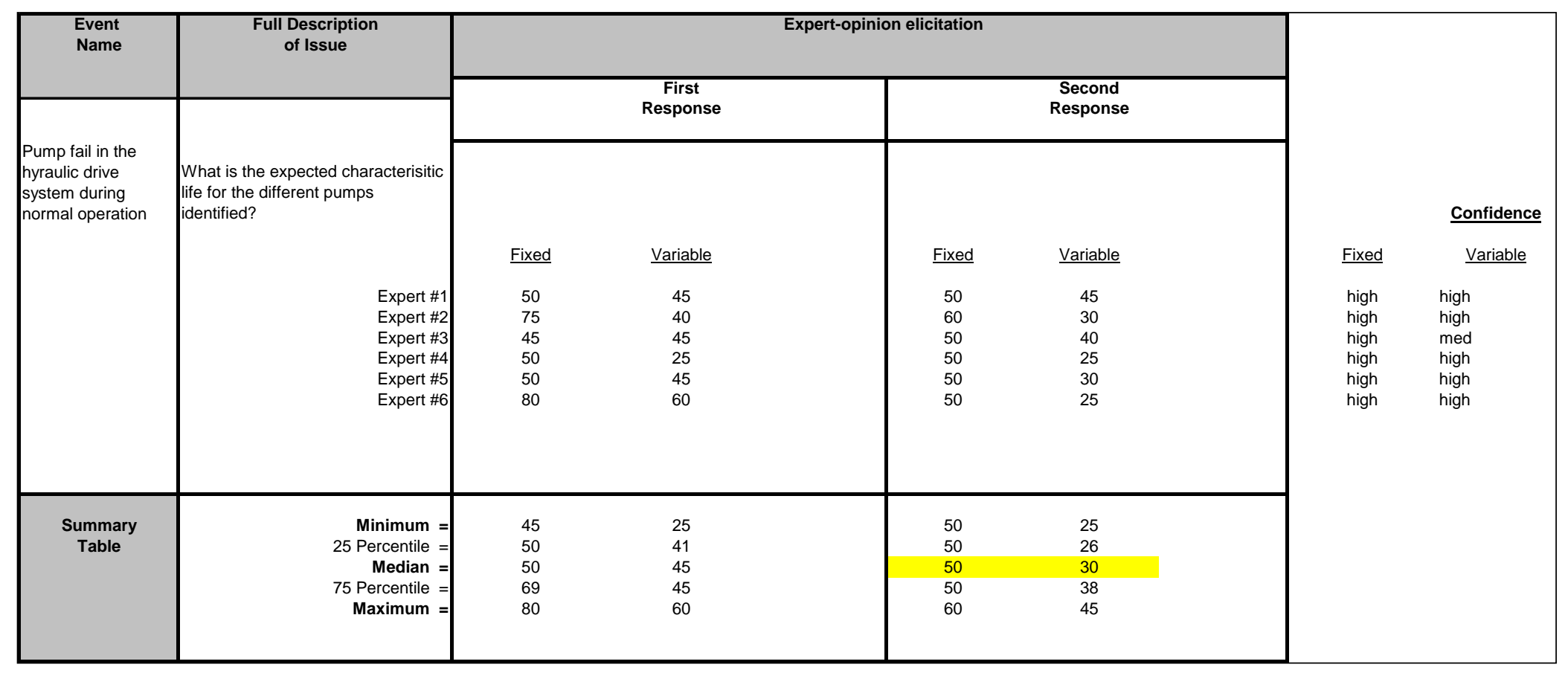


Table A17. Mechanical system - hydraulic motors.

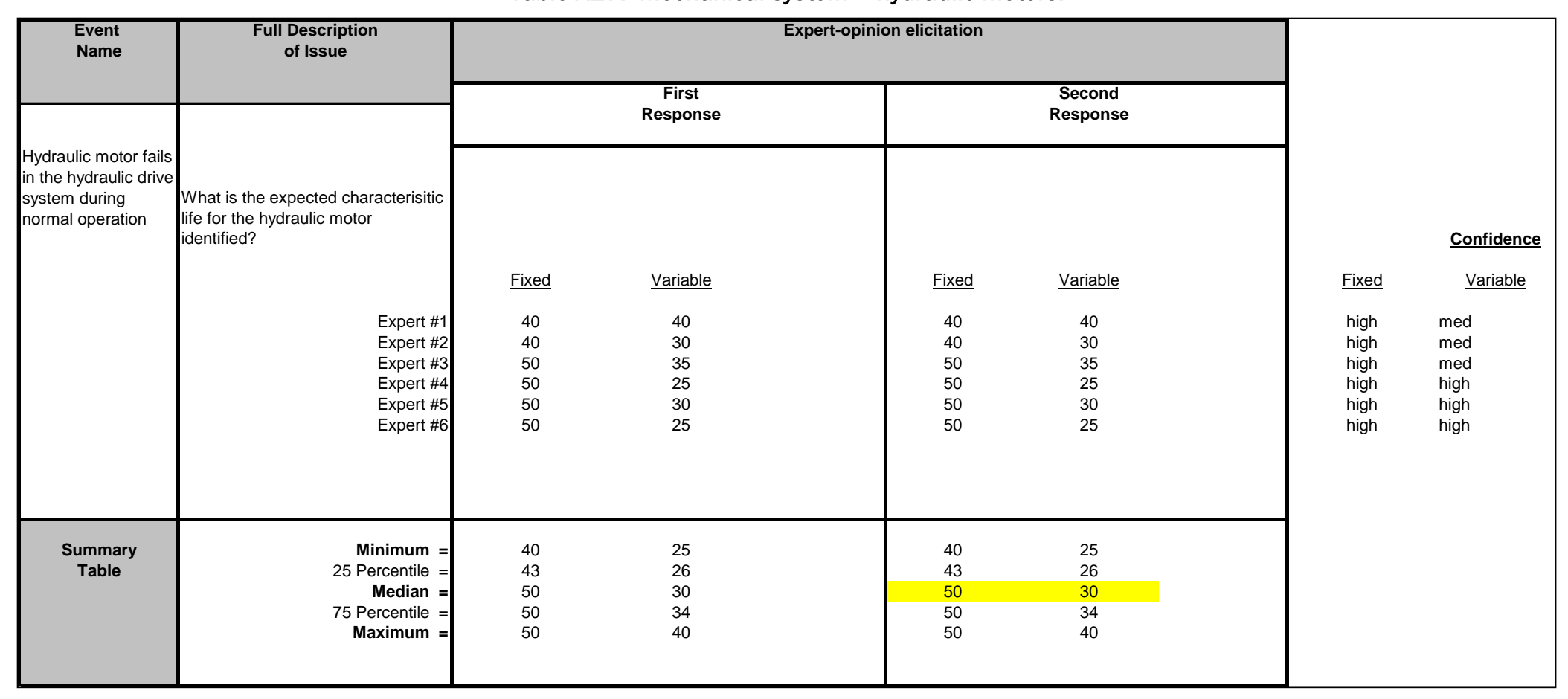


Table A18. Mechanical system - piping.

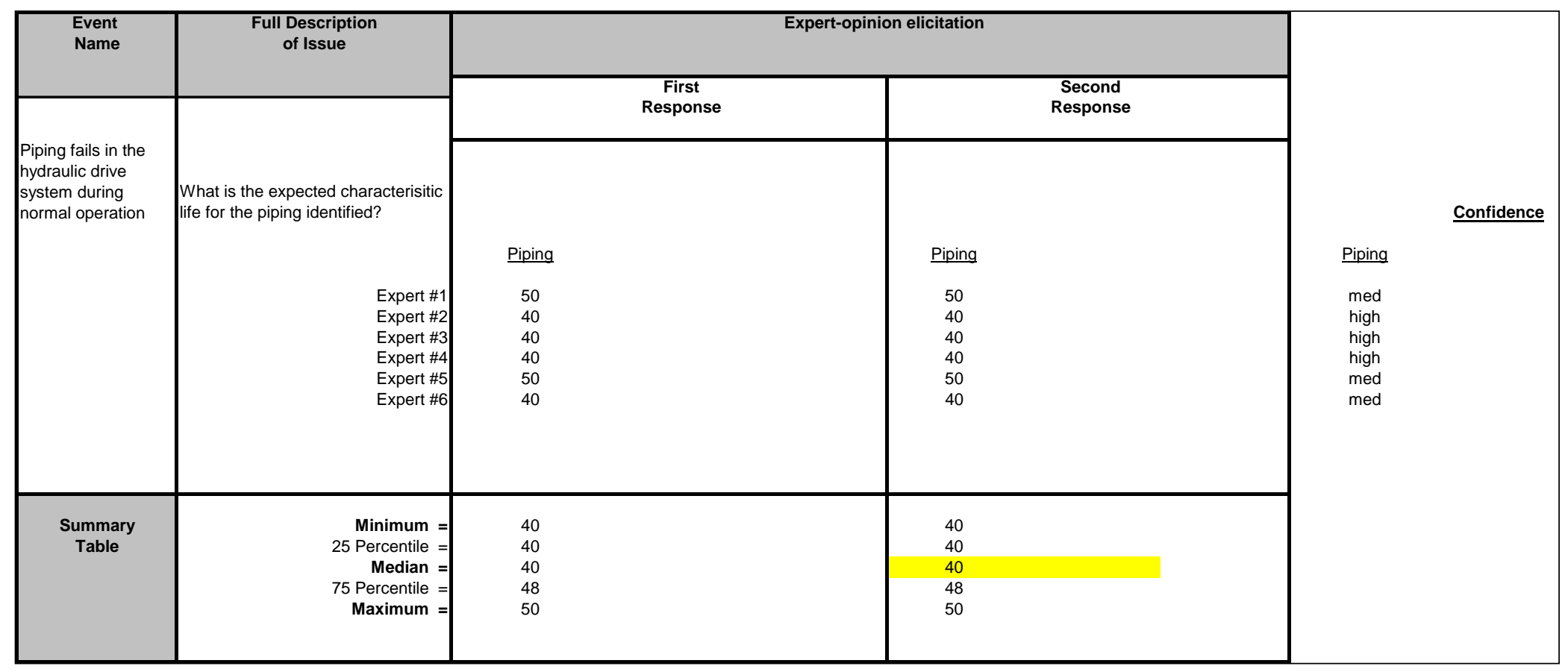


Table A19. Mechanical system - wheel assembly (rollers).




Table A20. Mechanical system - pintles/bushings.

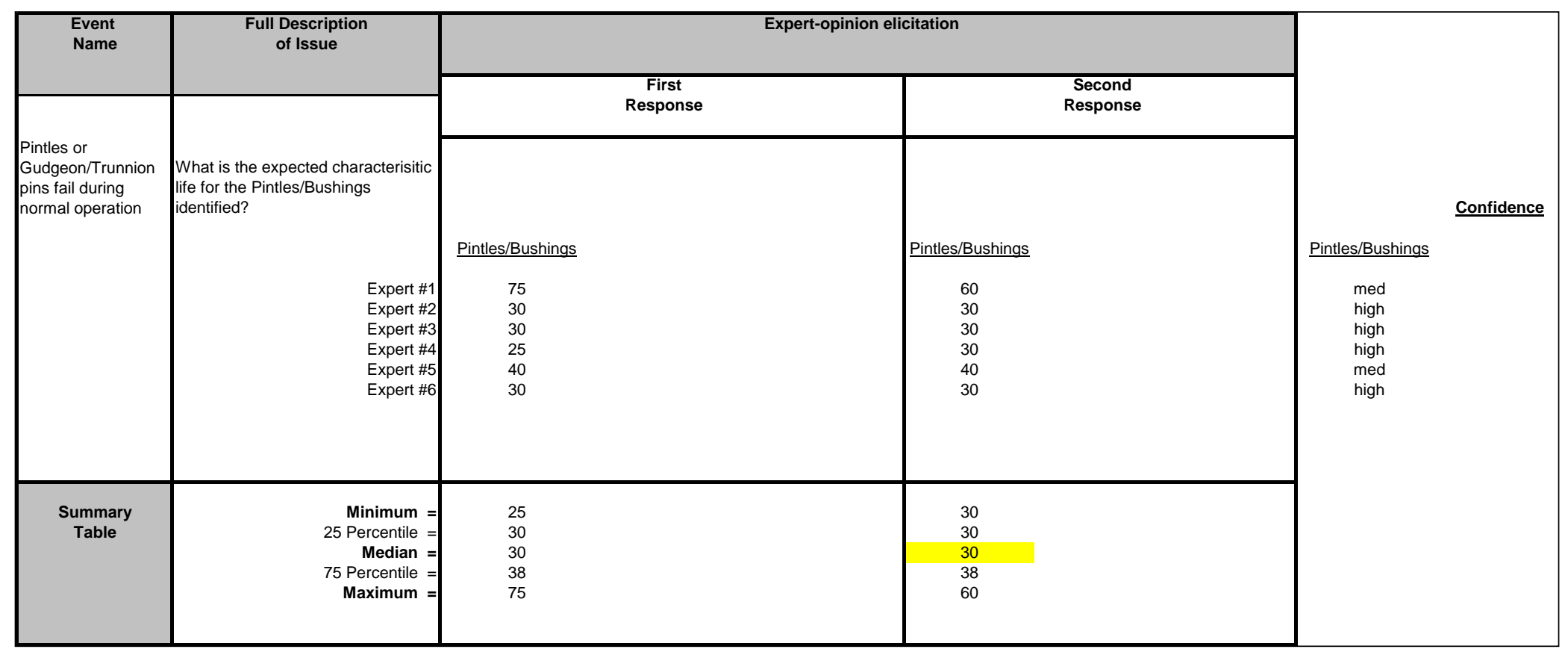


Table A21. Mechanical system - gudgeon/trunnion.

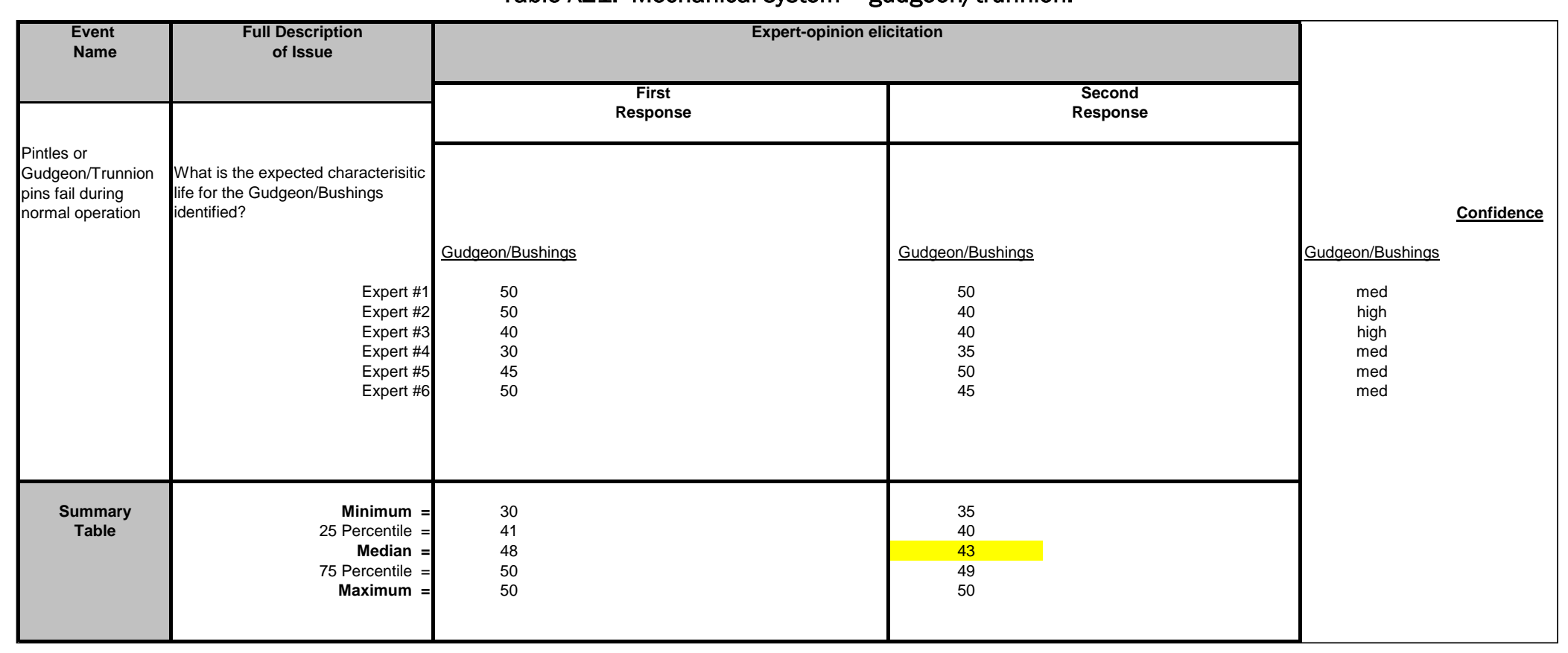


Table A22. Mechanical system - trunnion pin/bushings.

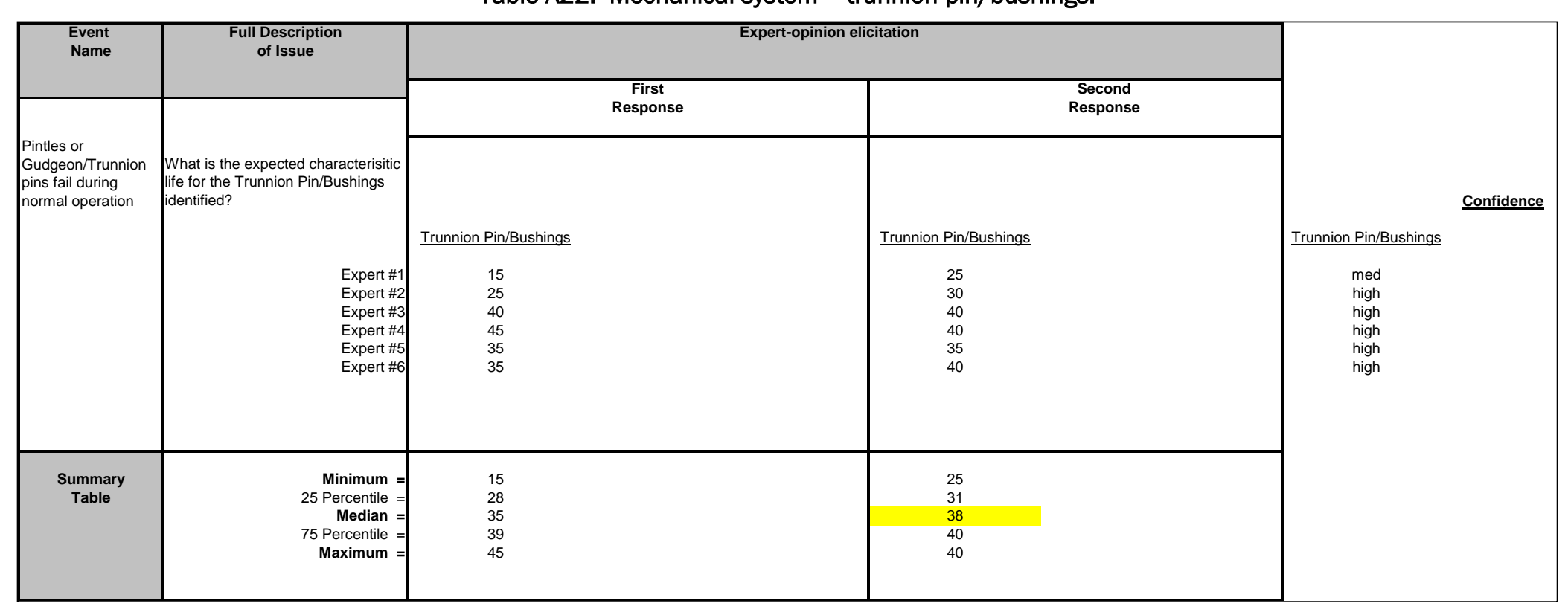


Table A23. Mechanical system - strut spindle pin.

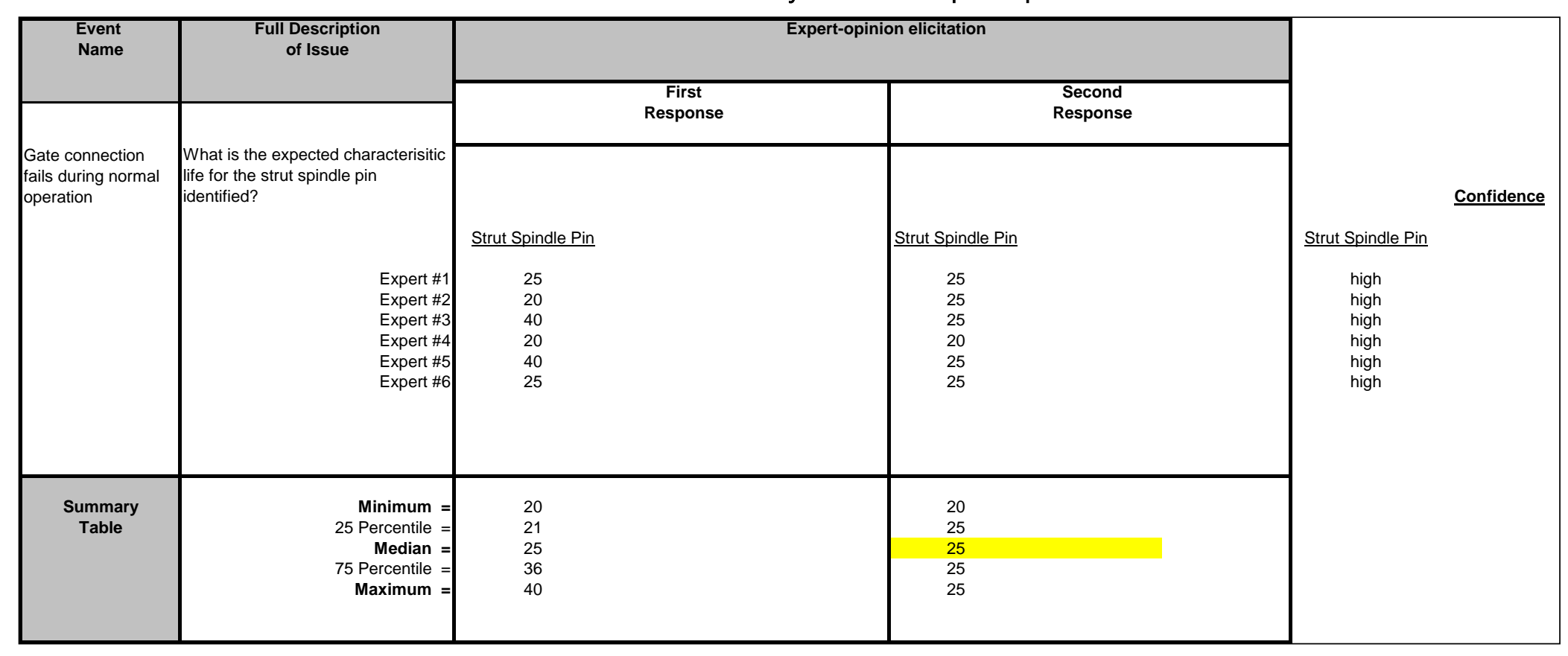


Table A24. Mechanical system - tow haulage system.

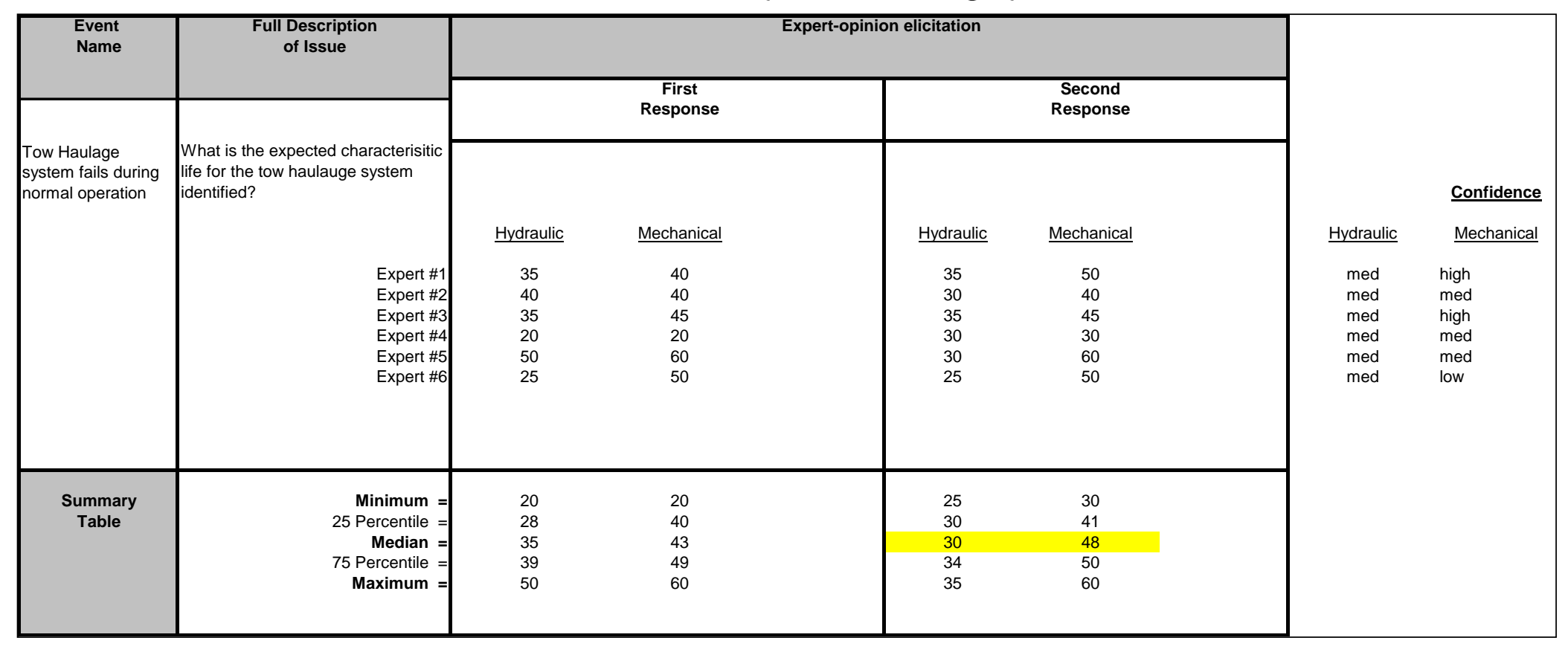


Table A25. Mechanical system - emptying/filling systems.

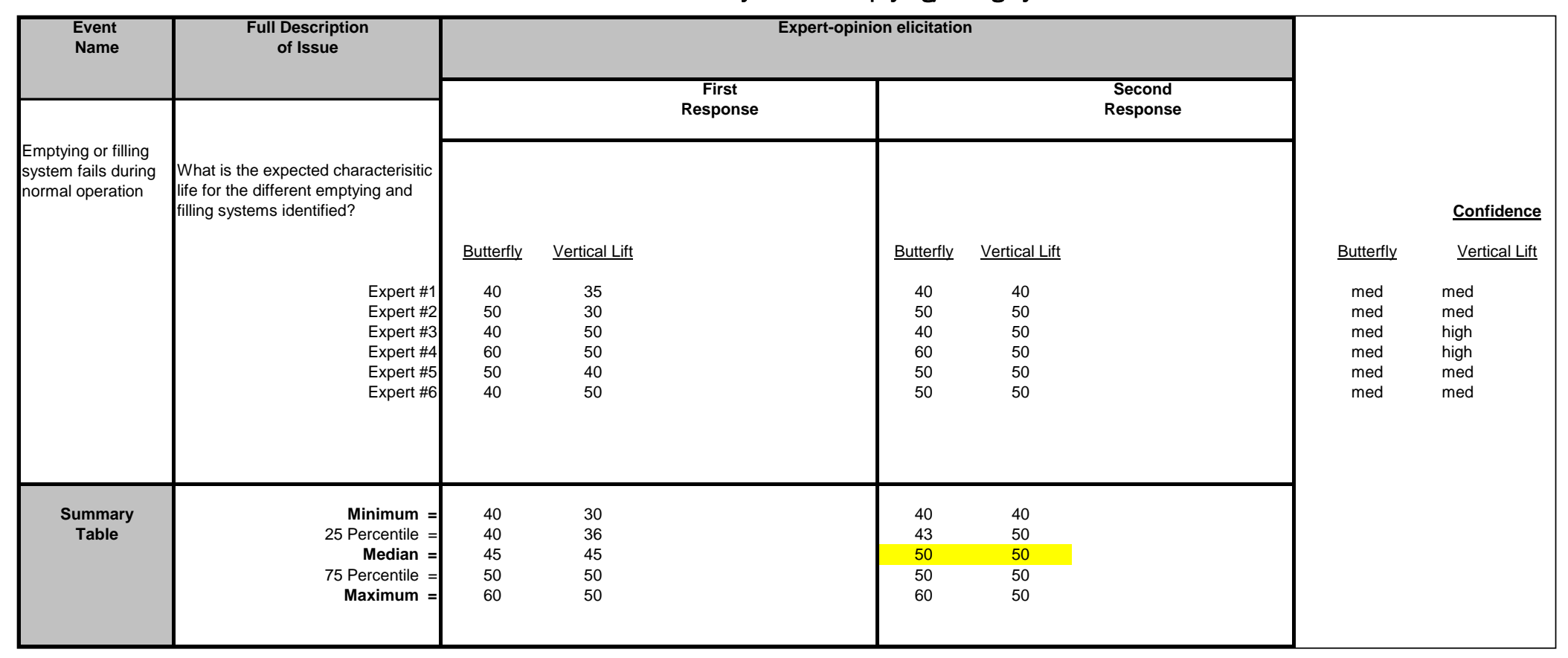




\section{Appendix B: Expert Elicitation Spreadsheets - Electrical System Components}


Table B1. Electrical system - power utility.

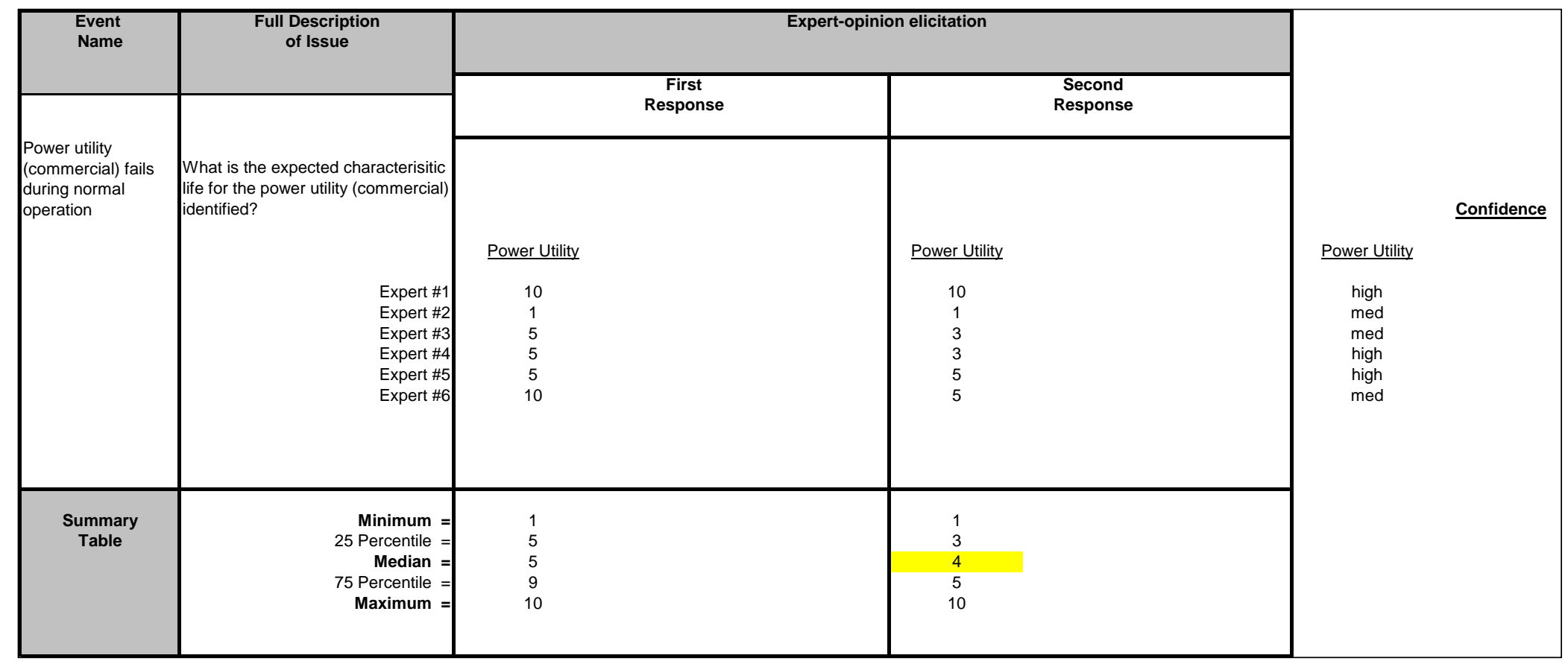


Table B2. Electrical system - service transformer.

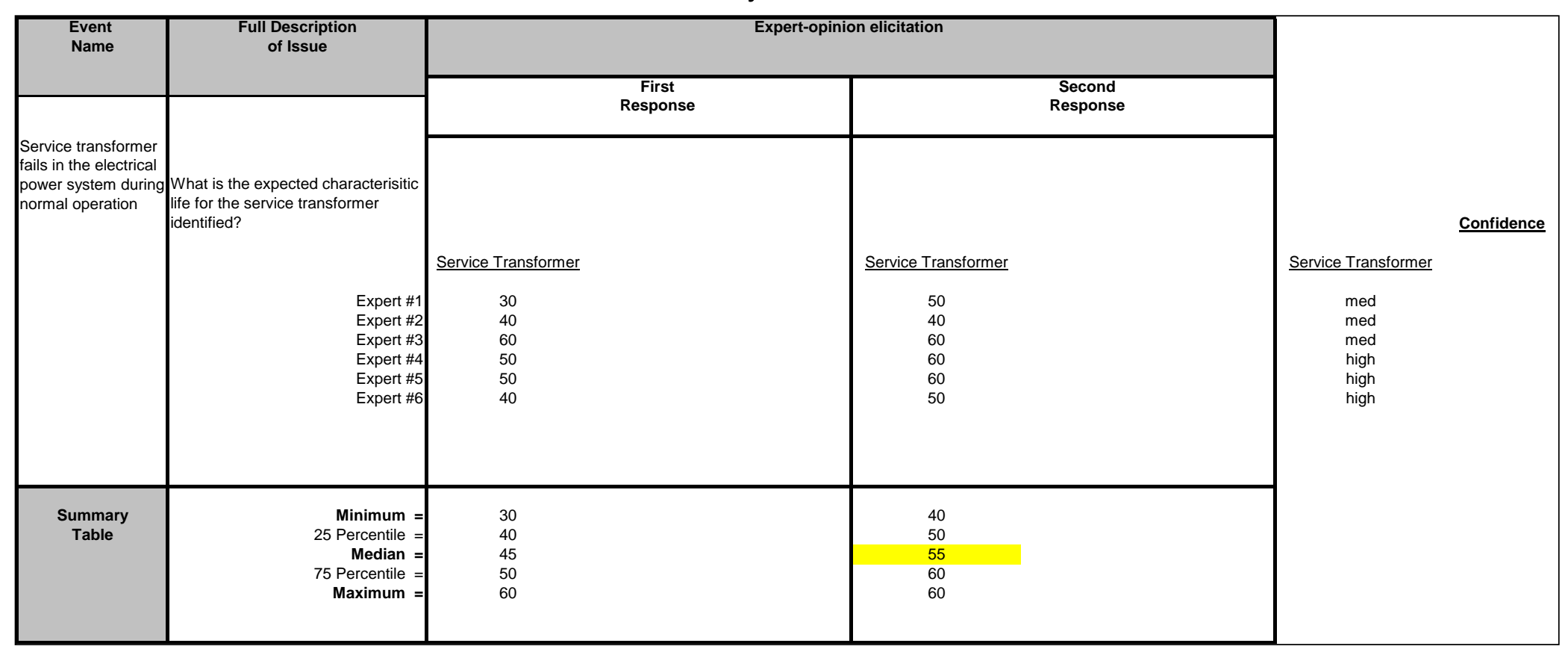


Table B3. Electrical system - transfer switch.

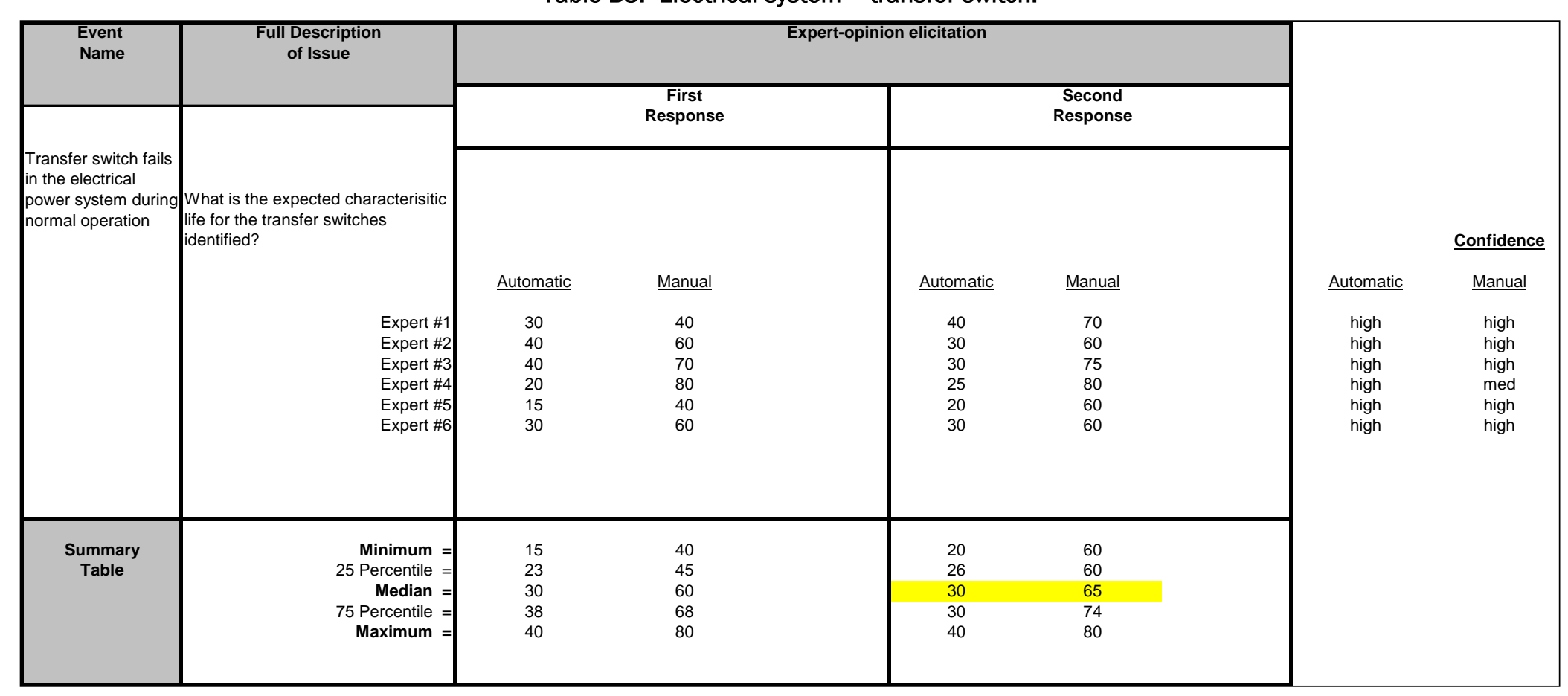


Table B4. Electrical system - switchgear.

\begin{tabular}{|c|c|c|c|c|c|}
\hline Event & Full Description & & elicitation & \multirow{5}{*}{$\begin{array}{c}\text { Switchgear } \\
\text { med } \\
\text { med } \\
\text { med } \\
\text { high } \\
\text { high } \\
\text { med }\end{array}$} & \multirow{5}{*}{ Confidence } \\
\hline \multirow{3}{*}{$\begin{array}{l}\text { Switchgear fails in } \\
\text { the electrical power } \\
\text { system during } \\
\text { normal operation }\end{array}$} & \multirow[b]{2}{*}{$\begin{array}{l}\text { What is the expected characterisitic } \\
\text { life for the switchgear identified? }\end{array}$} & $\begin{array}{c}\text { First } \\
\text { Response }\end{array}$ & $\begin{array}{l}\text { Second } \\
\text { Response }\end{array}$ & & \\
\hline & & & & & \\
\hline & $\begin{array}{l}\text { Expert \#1 } \\
\text { Expert \#2 } \\
\text { Expert \#3 } \\
\text { Expert \#4 } \\
\text { Expert \#5 } \\
\text { Expert \#6 }\end{array}$ & $\begin{array}{l}50 \\
50 \\
90 \\
65 \\
40 \\
60\end{array}$ & $\begin{array}{l}75 \\
70 \\
90 \\
85 \\
70 \\
80\end{array}$ & & \\
\hline $\begin{array}{l}\text { Summary } \\
\text { Table }\end{array}$ & $\begin{array}{r}\text { Minimum }= \\
25 \text { Percentile }= \\
\text { Median }= \\
75 \text { Percentile }= \\
\text { Maximum }=\end{array}$ & $\begin{array}{l}40 \\
50 \\
55 \\
64 \\
90\end{array}$ & $\begin{array}{l}70 \\
71 \\
78 \\
84 \\
90\end{array}$ & & \\
\hline
\end{tabular}


Table B5. Electrical system - circuit breakers.

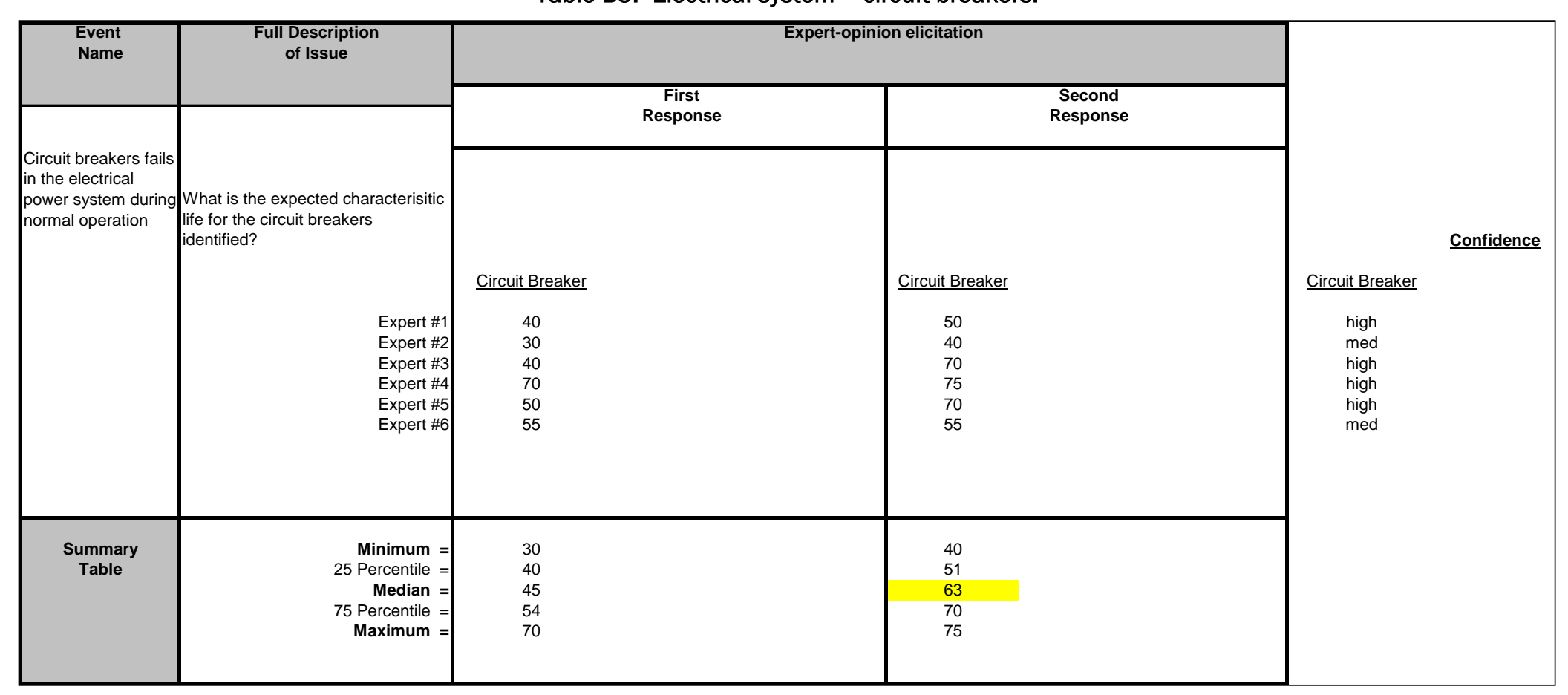


Table B6. Electrical system - power panelboard.

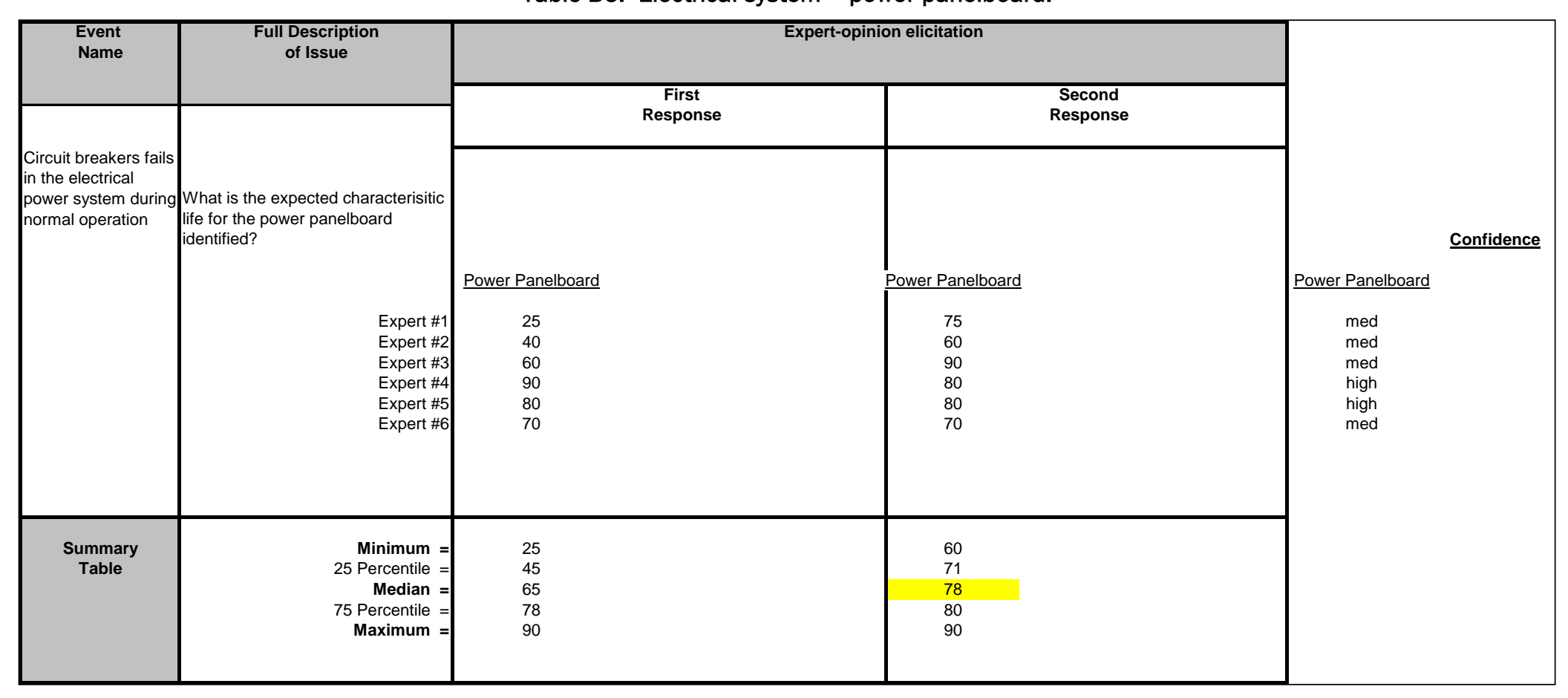


Table B7. Electrical system - cables.

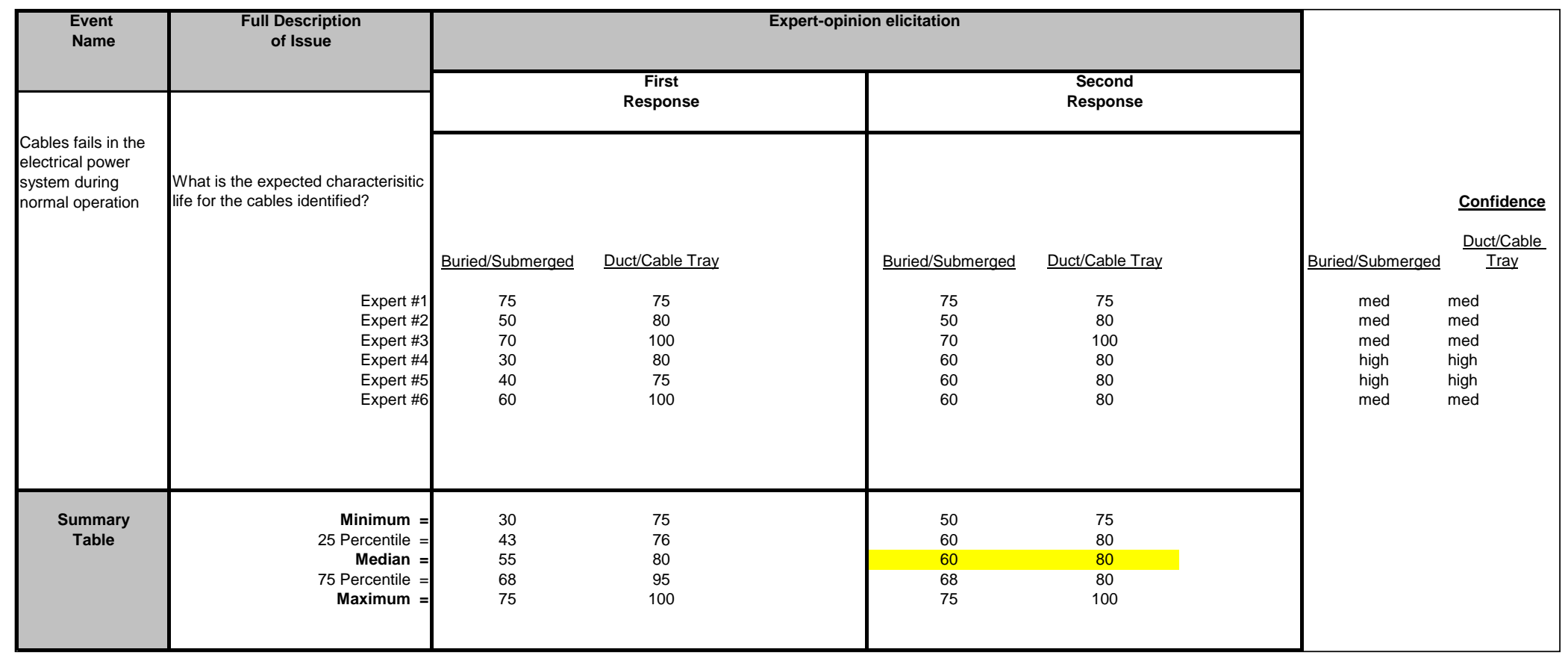


Table B7. (Cont'd).

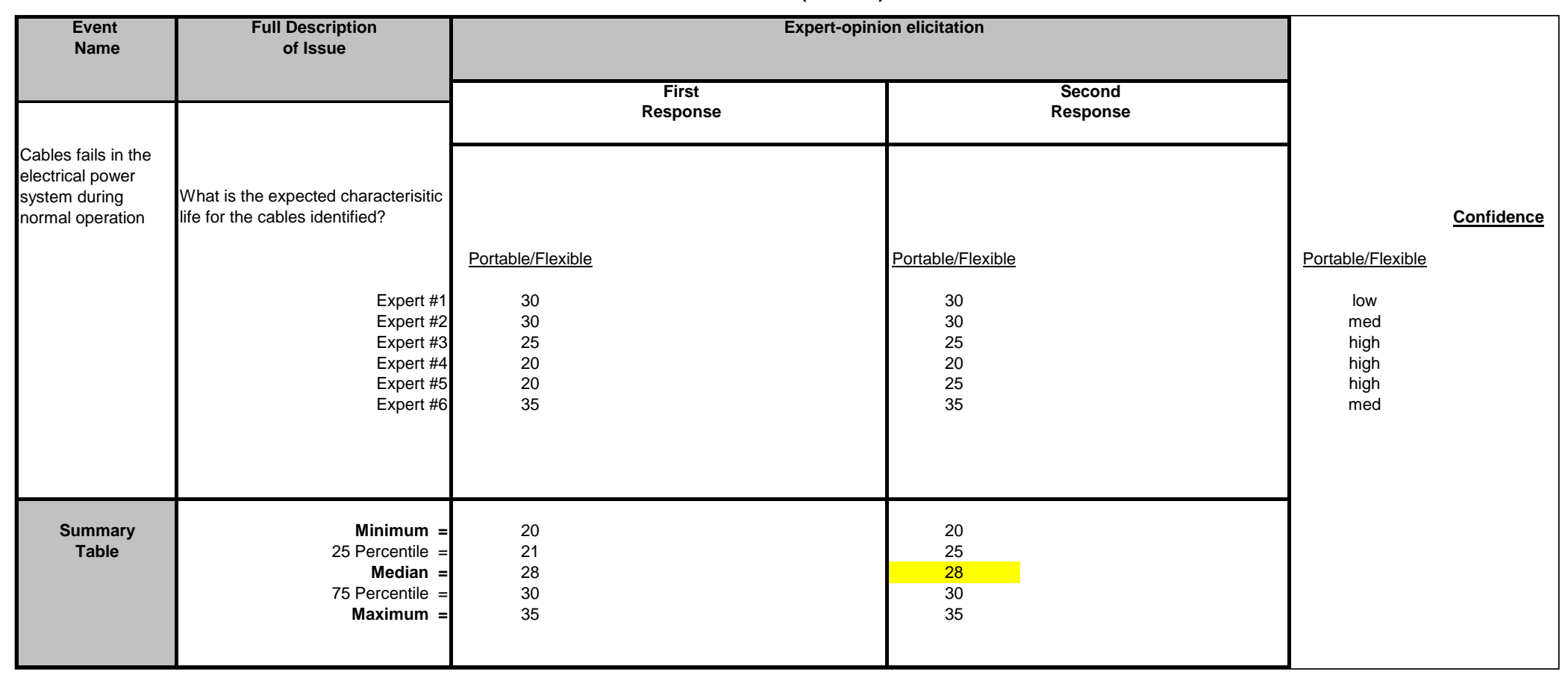


Table B8. Electrical system - bus duct.

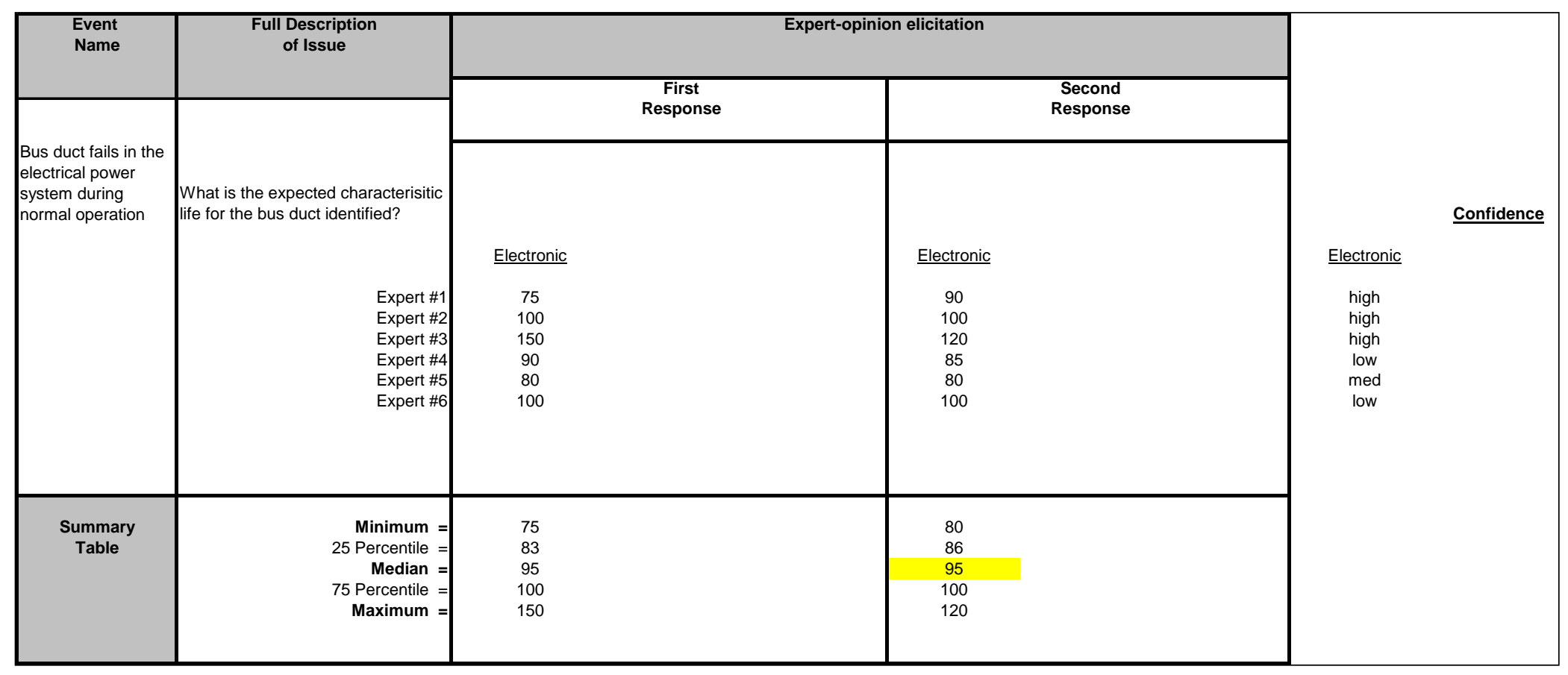


Table B9. Electrical system - switchboards.

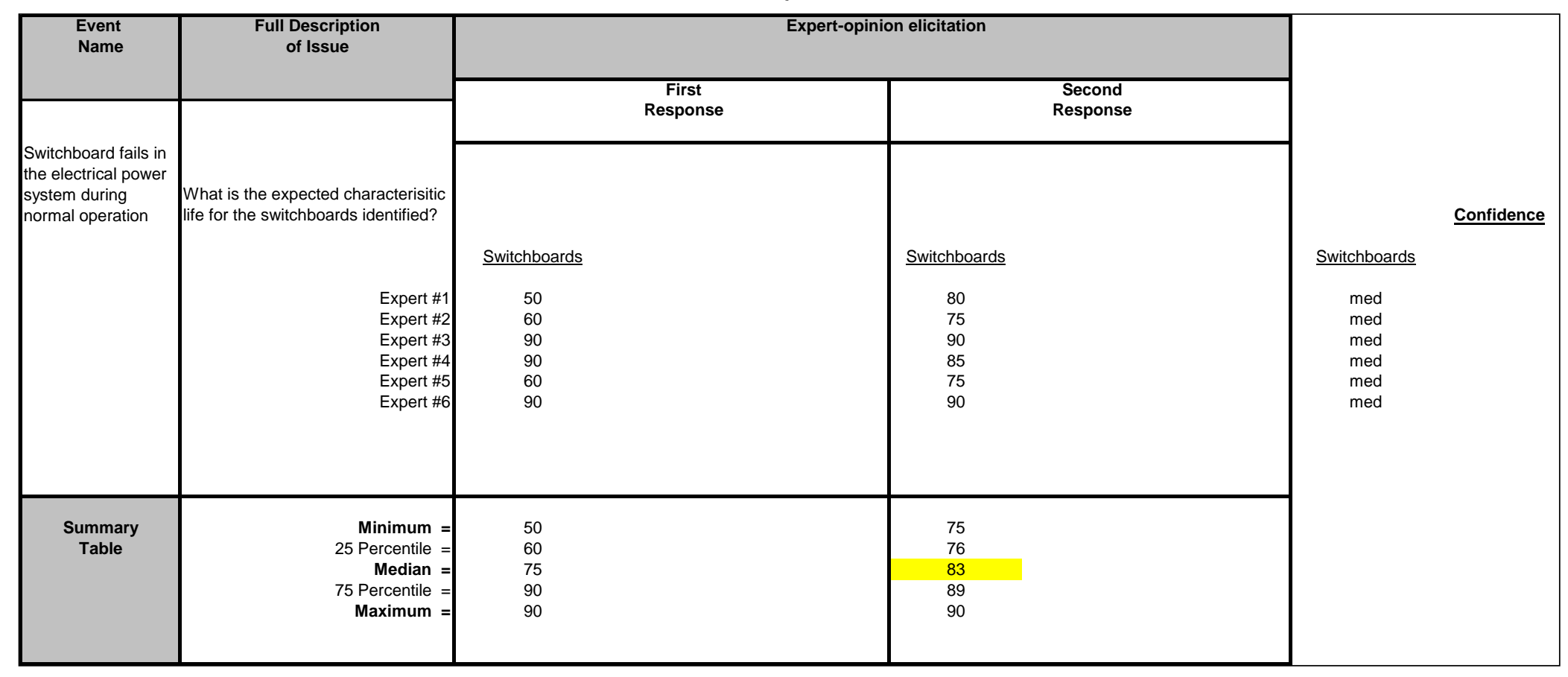


Table B10. Electrical system - motor control center.

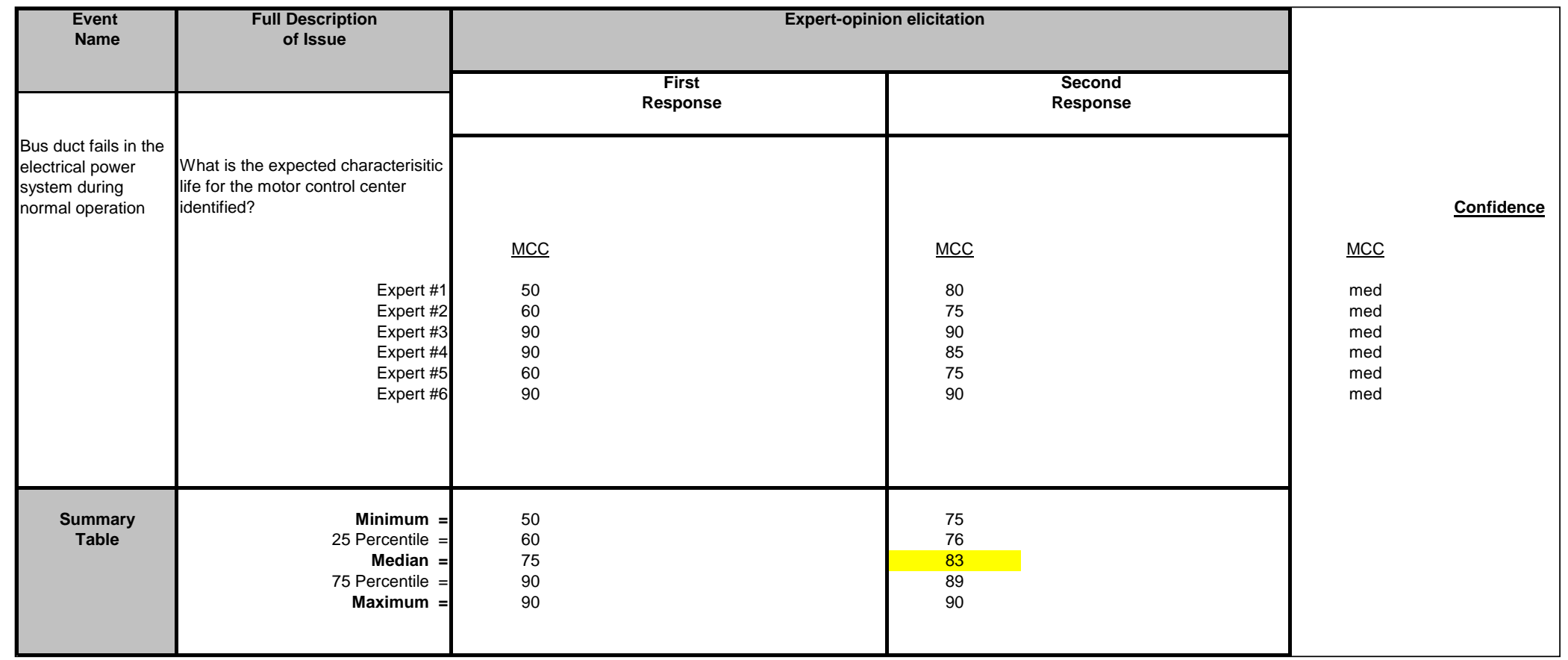


Table B11. Electrical system - motor starters.

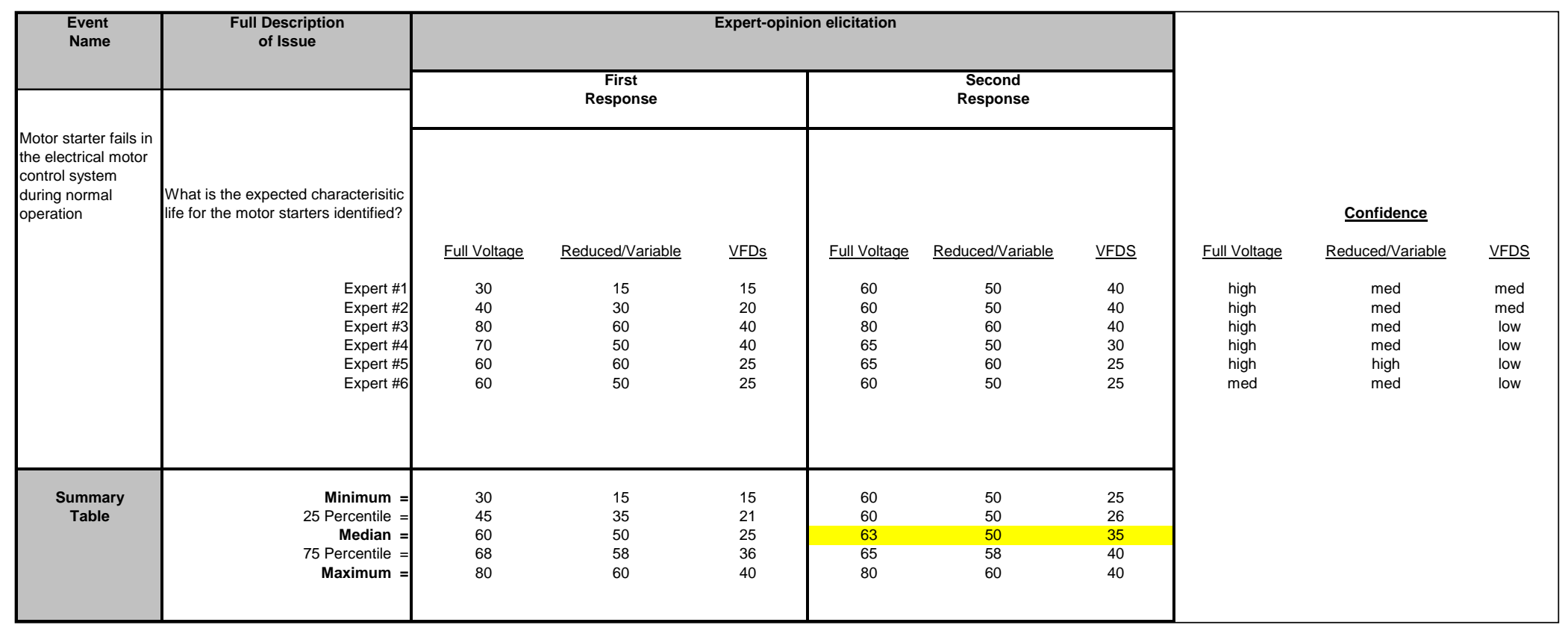


Table B12. Electrical system - PLC systems.

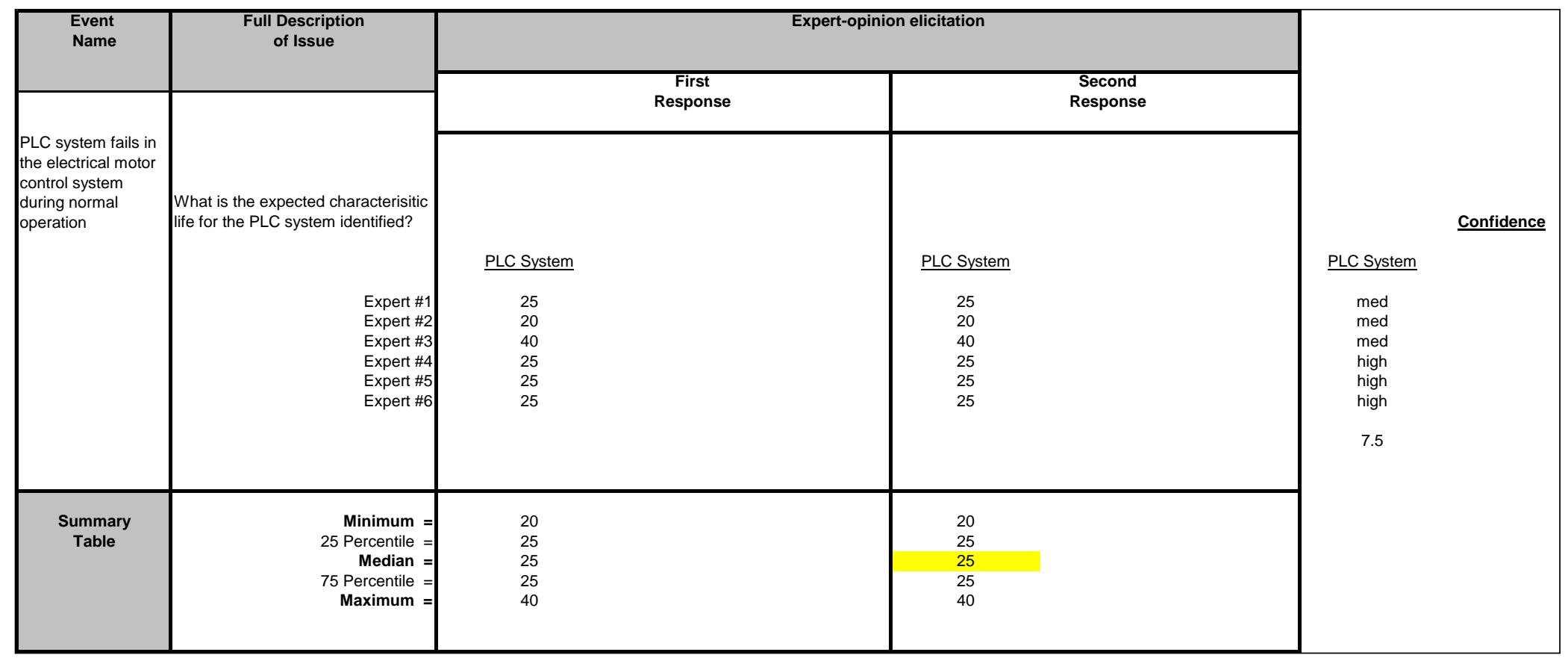


Table B13. Electrical system - sensors and switches.

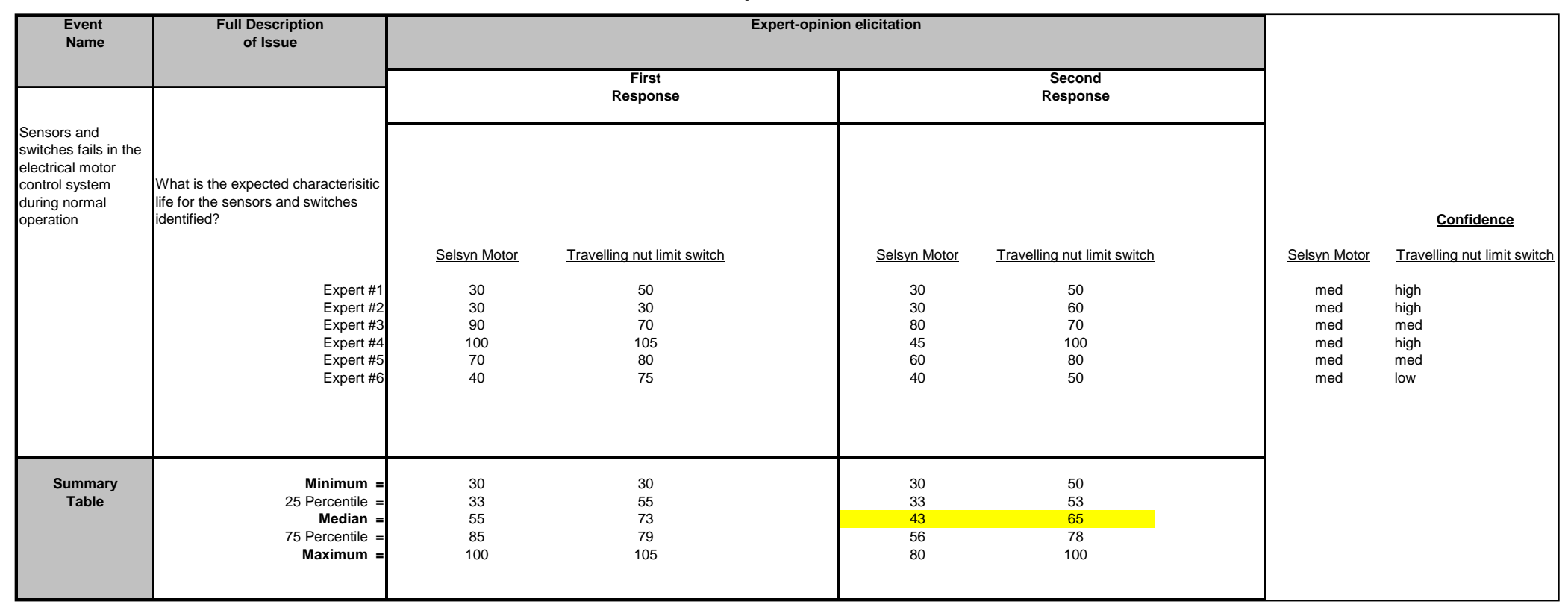


Table B14. Electrical system - electric motors.

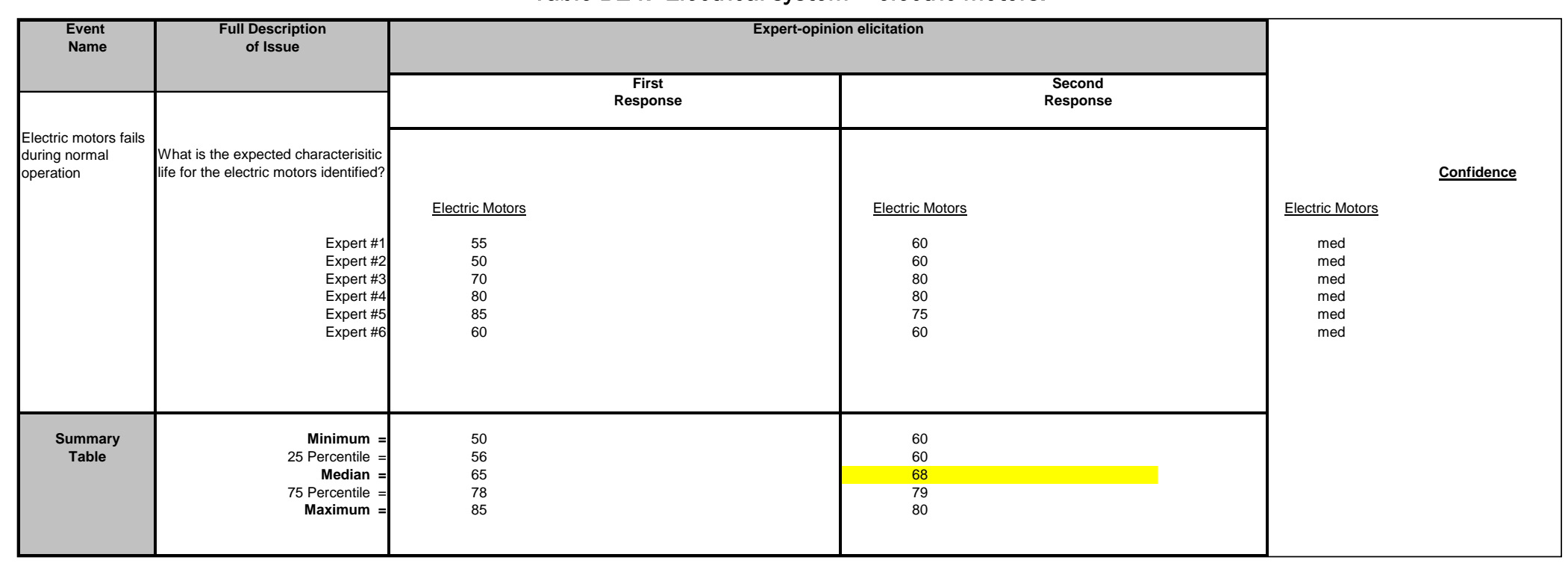


Table B15. Electrical system - standby generator set.

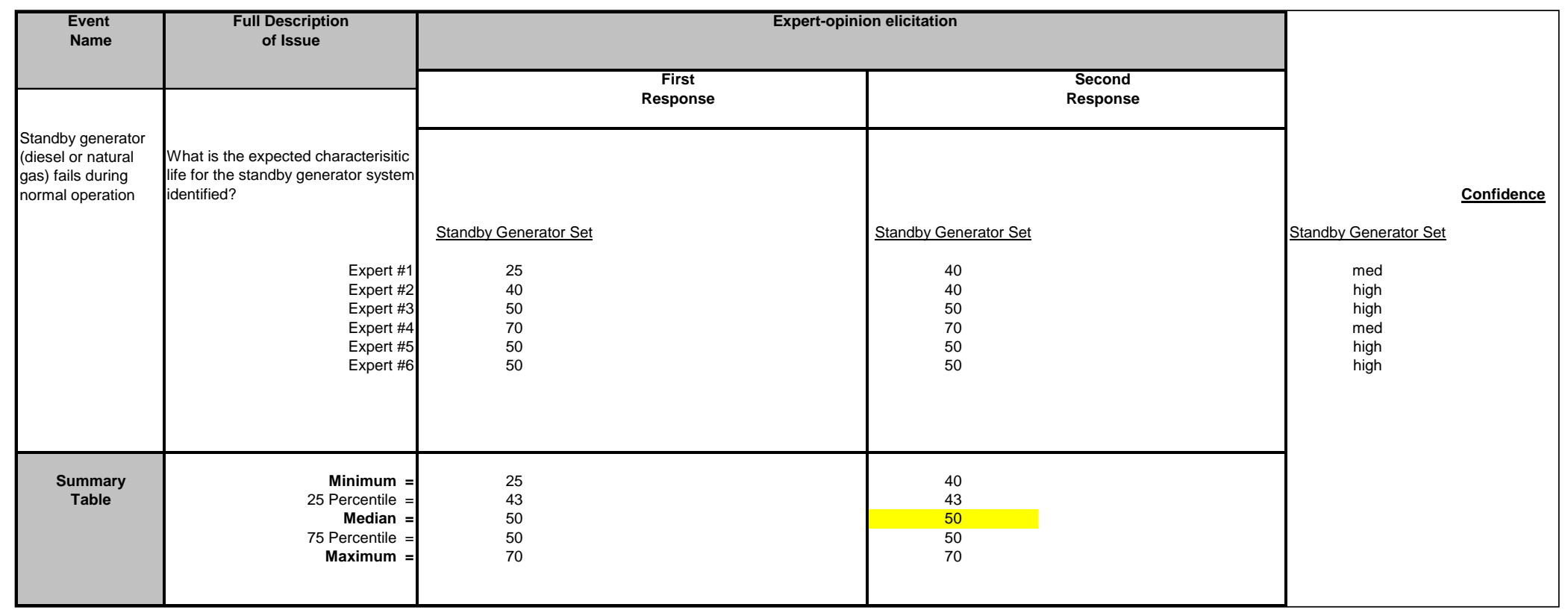


Table B16. Electrical system - DC rectifier.

\begin{tabular}{|c|c|c|c|c|c|}
\hline $\begin{array}{l}\text { Event } \\
\text { Name }\end{array}$ & $\begin{array}{l}\text { Full Description } \\
\text { of Issue }\end{array}$ & & icitation & \multirow{4}{*}{$\begin{array}{c}\text { DC Rectifier } \\
\text { high } \\
\text { high } \\
\text { high } \\
\text { low } \\
\text { high } \\
\text { med }\end{array}$} & \multirow{4}{*}{ Confidence } \\
\hline \multirow{2}{*}{\begin{tabular}{|l} 
Brake system fails \\
during normal \\
operation
\end{tabular}} & \multirow[b]{2}{*}{ 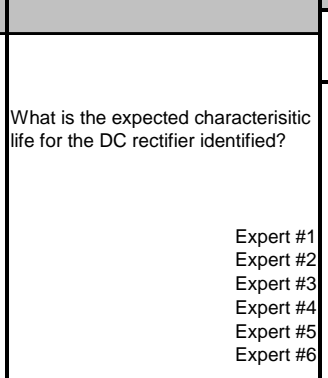 } & $\begin{array}{c}\text { First } \\
\text { Response }\end{array}$ & $\begin{array}{c}\text { Second } \\
\text { Response }\end{array}$ & & \\
\hline & & $\begin{array}{c}\text { DC Rectifier } \\
25 \\
40 \\
30 \\
10 \\
50 \\
45\end{array}$ & $\begin{array}{c}\text { DC Rectifier } \\
30 \\
40 \\
30 \\
25 \\
40 \\
45\end{array}$ & & \\
\hline $\begin{array}{c}\text { Summary } \\
\text { Table }\end{array}$ & $\begin{aligned} \text { Minimum } & = \\
25 \text { Percentile } & = \\
\text { Median } & = \\
75 \text { Perectile } & = \\
\text { Maximum } & =\end{aligned}$ & $\begin{array}{l}10 \\
26 \\
35 \\
44 \\
50\end{array}$ & $\begin{array}{l}25 \\
30 \\
35 \\
40 \\
45\end{array}$ & & \\
\hline
\end{tabular}




\section{Appendix C: Results from Flood Risk Management ME Expert-Opinion Elicitation}

An additional study was conducted using the same experts to elicit the characteristic lives of ME equipment at flood control projects. The values reflect the operation, maintenance, and environment to which they are exposed, and the consensus of the experts to a national standard that could be adjusted using k-factors as discussed in EC 1110-2-6062 (HQUSACE 2011).

Tables C1 and C2 list the final results, which provide the basis to compare the characteristic lives of the similar navigation ME components.

Table C1. Flood risk management ME expert-opinion results for mechanical components for navigation and dam projects (mechanical drive systems).

\begin{tabular}{|c|c|c|c|}
\hline Type & Component & $\begin{array}{c}\text { Navigation Components } \\
\text { CL (years) }\end{array}$ & $\begin{array}{l}\text { Flood Reduction } \\
\text { Components } \\
\text { CL (years) }\end{array}$ \\
\hline \multicolumn{4}{|l|}{ Bearings } \\
\hline & Rolling element & 40 & 60 \\
\hline & Sleeve (self lubricated) & 25 & 20 \\
\hline & Bronze sleeve & 40 & 60 \\
\hline \multicolumn{4}{|l|}{ Couplings } \\
\hline & Flexible & 35 & 40 \\
\hline & Rigid & 50 & 60 \\
\hline Shafts & & 80 & 100 \\
\hline Pins & & 35 & 70 \\
\hline \multicolumn{4}{|c|}{ Gear reducers } \\
\hline & Worm & 25 & 40 \\
\hline & Parallel & 40 & 60 \\
\hline & Right angle & 38 & 40 \\
\hline \multicolumn{4}{|c|}{ Open gearing } \\
\hline & Spur & 60 & 100 \\
\hline & Helical & 38 & 100 \\
\hline & Bevel & 40 & 50 \\
\hline & Rack & 60 & 80 \\
\hline Brake & Electromechanical & 45 & 60 \\
\hline \multirow[t]{2}{*}{ Clutch } & Slip & 30 & - \\
\hline & Jaw & - & 70 \\
\hline Wire ropes & & & \\
\hline
\end{tabular}




\begin{tabular}{|c|c|c|c|}
\hline Type & Component & $\begin{array}{l}\text { Navigation Components } \\
\text { CL (years) }\end{array}$ & $\begin{array}{c}\text { Flood Reduction } \\
\text { Components } \\
\text { CL (years) }\end{array}$ \\
\hline & Spiral plate & 5 & - \\
\hline & Single/multiple sheave(s) & 20 & - \\
\hline & Single Drum & 28 & - \\
\hline & Round & - & 50 \\
\hline & Flat & - & 20 \\
\hline Wire rope drums & & 75 & 100 \\
\hline Wire rope sheaves & & 33 & 50 \\
\hline \multirow[t]{2}{*}{ Chains } & Roller & 40 & 60 \\
\hline & Link & - & 40 \\
\hline Chain sprocket & & 60 & 75 \\
\hline \multicolumn{4}{|l|}{ Miter gates } \\
\hline & Sector arms & 73 & - \\
\hline & Strut arms - buffered & 35 & - \\
\hline & Strut arms - rigid & 50 & - \\
\hline & Support roller & 43 & - \\
\hline & Rack support beam & 60 & - \\
\hline \multicolumn{4}{|l|}{ Valves } \\
\hline & Bellcranks & 78 & - \\
\hline & Crosshead/guide & 73 & - \\
\hline & Strut & 43 & - \\
\hline & Butterfly & - & 50 \\
\hline & Ball & - & 50 \\
\hline & Slide & - & 50 \\
\hline & Knife & - & 50 \\
\hline & Jet & - & 50 \\
\hline
\end{tabular}


Table C2. Flood risk management ME expert-opinion results for mechanical components for navigation and dam projects.

\begin{tabular}{|c|c|c|c|}
\hline Type & Component & $\begin{array}{c}\text { Navigation Components } \\
\text { CL (years) }\end{array}$ & $\begin{array}{c}\text { Flood Reduction } \\
\text { Components } \\
\text { CL (years) }\end{array}$ \\
\hline Hydraulic cylinder & & 60 & 60 \\
\hline \multicolumn{4}{|l|}{ Control valves } \\
\hline & Check & 45 & 40 \\
\hline & Relief & 40 & 40 \\
\hline & Directional & & \\
\hline & Manual & 60 & 60 \\
\hline & Solenoid & 40 & 40 \\
\hline & Proportional/throttle & 40 & 40 \\
\hline \multicolumn{4}{|l|}{ Pumps } \\
\hline & Fixed & 50 & 60 \\
\hline & Variable & 30 & 35 \\
\hline \multicolumn{4}{|l|}{ Hydraulic Motors } \\
\hline & Fixed & 50 & - \\
\hline & Variable & 30 & - \\
\hline Piping & & 40 & 40 \\
\hline Hose & & - & 25 \\
\hline \multicolumn{4}{|c|}{ Misc Gate/Filling Emptying Valves } \\
\hline Wheel assembly (rollers) & & 40 & 50 \\
\hline Pintles/bushings & & 30 & - \\
\hline Gudgeon pin/bushings & & 43 & - \\
\hline Trunnion pin/bushings & & 38 & 60 \\
\hline Strut spindle pin & & 25 & - \\
\hline \multicolumn{4}{|c|}{ Other Systems } \\
\hline \multicolumn{4}{|l|}{ Tow haulage } \\
\hline & Hydraulic & 30 & - \\
\hline & Mechanical & 48 & - \\
\hline \multicolumn{4}{|l|}{ Emptying filling } \\
\hline & Butterfly & 50 & - \\
\hline & Vertical lift & 50 & - \\
\hline $\begin{array}{l}\text { Gate connection } \\
\text { (pins, cable, chain) }\end{array}$ & & - & 50 \\
\hline Grease/lube system & & - & 30 \\
\hline $\begin{array}{l}\text { Actuators } \\
\text { (screw type, limit torque) }\end{array}$ & & - & 50 \\
\hline
\end{tabular}




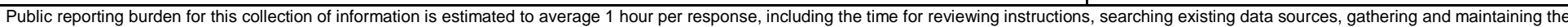

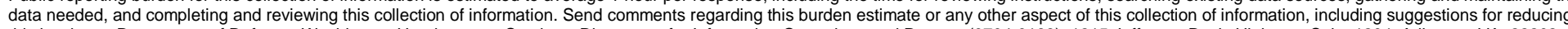

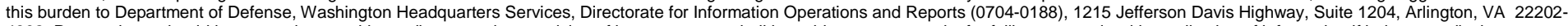

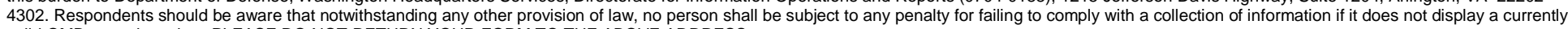
valid OMB control number. PLEASE DO NOT RETURN YOUR FORM TO THE ABOVE ADDRESS.

\begin{tabular}{l|l|l} 
1. REPORT DATE (DD-MM-YYYY) & 2. REPORT TYPE & 3. DATES COVERED (FrOm - To)
\end{tabular} 01-04-2013 Final

\section{TITLE AND SUBTITLE}

Improved Reliability Models for Mechanical and Electrical Components at Navigation Lock and Dam and Flood Risk Management Facilities

5a. CONTRACT NUMBER

5b. GRANT NUMBER

5c. PROGRAM ELEMENT

6. AUTHOR(S)

Robert C. Patev, David L. Buccini, J ames W. Bartek, and Stuart Foltz

5d. PROJECT NUMBER

5e. TASK NUMBER

5f. WORK UNIT NUMBER

7. PERFORMING ORGANIZATION NAME(S) AND ADDRESS(ES)

US Army Engineer Research and Development Center (ERDC)

Construction Engineering Research Laboratory (CERL)

PO Box 9005,

Champaign, IL 61826-9005

8. PERFORMING ORGANIZATION REPORT NUMBER

ERDC/ CERL TR-13-4

9. SPONSORING / MONITORING AGENCY NAME(S) AND ADDRESS(ES)

Headquarters, US Army Corps of Engineers (HQUSACE)

440 G St., NW

Washington, DC 20314-1000
10. SPONSOR/MONITOR'S ACRONYM(S)

HQUSACE

11. SPONSOR/MONITOR'S REPORT NUMBER(S)

\section{DISTRIBUTION I AVAILABILITY STATEMENT}

Approved for public release; distribution is unlimited.

\section{SUPPLEMENTARY NOTES}

\section{ABSTRACT}

This work developed the use of Expert-Opinion Elicitation (EOE) to help estimate the characteristic life (CL) of mechanical and electrical (ME) components at US Army Corps of Engineers (USACE) navigation projects. This effort developed improved reliability models for the ME components at the USACE navigation facilities. Current USACE ME reliability methods use generic component failure rate data from US Department of Defense (DoD) Military Standard (MIL-STD) 756B, in which failure rate data is processed for components that function in operating environments, failure modes, and maintenance practices different from those at USACE navigation and flood risk management projects. The reliability of the ME system from this data set yields very conservative results, very often overestimating the time-dependent reliability of the entire ME system. EOE will be used to define the CL for a list of critical ME components at USACE navigation and flood risk management projects. These elicited values for CL will form the basis for failure rates to be used with the existing methods for ME system reliability calculations. Additional work on fault trees for ME systems is being completed as part of dam safety and levee risk assessment procedures development.

\section{SUBJECT TERMS}

characteristic life, Delphi method, electrical failures, Expert-Opinion Elicitation, flood control dams, flood risk management

\begin{tabular}{|c|c|c|c|c|c|}
\hline \multicolumn{3}{|c|}{ 16. SECURITY CLASSIFICATION OF: } & \multirow{2}{*}{$\begin{array}{l}\text { 17. LIMITATION } \\
\text { OF ABSTRACT } \\
\text { SAR }\end{array}$} & \multirow{2}{*}{$\begin{array}{l}\text { 18. NUMBER } \\
\text { OF PAGES } \\
112\end{array}$} & \multirow{2}{*}{$\begin{array}{l}\text { 19a. NAME OF RESPONSIBLE PERSON } \\
\begin{array}{l}\text { 19b. TELEPHONE NUMBER } \\
\text { (include area code) }\end{array}\end{array}$} \\
\hline $\begin{array}{l}\text { a. REPORT } \\
\text { Unclassified }\end{array}$ & $\begin{array}{l}\text { b. ABSTRACT } \\
\text { Unclassified }\end{array}$ & $\begin{array}{l}\text { c. THIS PAGE } \\
\text { Unclassified }\end{array}$ & & & \\
\hline $7540-01-280-5500$ & & & & & $\begin{array}{l}\text { Standard Form } 298 \text { (Rev. 8-98) } \\
\text { Prescribed by ANSI Std. 239.1 }\end{array}$ \\
\hline
\end{tabular}

